JOÃO STEFANO LUNA CARDOSO

PROPOSIÇÃO DE UMA METODOLOGIA PARA A COMPARAÇÃO DE DESEMPENHO OPERACIONAL DE TERMINAIS PORTUÁRIOS DE GRANÉIS SÓLIDOS MINERAIS 
JOÃO STEFANO LUNA CARDOSO

\title{
PROPOSIÇÃO DE UMA METODOLOGIA PARA A COMPARAÇÃO DE DESEMPENHO OPERACIONAL DE TERMINAIS PORTUÁRIOS DE GRANÉIS SÓLIDOS MINERAIS
}

\author{
Dissertação apresentada à Escola \\ Politécnica da Universidade de São Paulo \\ para obtenção do título de Mestre em \\ Engenharia \\ Área de concentração: \\ Engenharia Naval e Oceânica \\ Orientador: Professor Doutor \\ Marcos Mendes de Oliveira Pinto
}


Este exemplar foi revisado e alterado em relação à versão original, sob responsabilidade única do autor e com a anuência de seu orientador.

São Paulo, 28 de março de 2011

Assinatura do autor

Assinatura do orientador

FICHA CATALOGRÁFICA

\section{Cardoso, João Stefano Luna}

Proposição de uma metodologia para a comparação de de sempenho operacional de terminais portuários de granéis sólidos minerais / J.S.L. Cardoso. - ed. rev. - São Paulo, 2011. $107 \mathrm{p}$.

Dissertação (Mestrado) - Escola Politécnica da Universidade de São Paulo. Departamento de Engenharia Naval e Oceânica.

1. Terminais marítimos (Desempenho; Eficiência) 2. Benchmarking I. Universidade de São Paulo. Escola Politécnica. Departamento de Engenharia Naval e Oceânica II. t. 


\section{AGRADECIMENTOS}

Agradeço a Deus e a todos que colaboraram para a realização desta dissertação de mestrado:

ao meu orientador e amigo, Prof. Dr. Marcos Pinto, que me mostrou os caminhos a serem seguidos, com muita paciência;

a meus pais e minhas irmãs, pelo incentivo e aporte;

a minha namorada Marina, pela contribuição e companheirismo;

a meus amigos do Centro de Estudos em Gestão Naval pela oportunidade e confiança no meu trabalho;

a meu primo Neimar, que me acolheu e proporcionou diversas oportunidades;

aos familiares e amigos, que acreditaram e apoiaram direta e indiretamente meu trabalho. 


\section{RESUMO}

As maiores dificuldades ao se avaliar o desempenho operacional portuário concentram-se na identificação e na expurgação das particularidades físicooperacionais que podem distorcer as comparações e mascarar algumas ineficiências. Por esta razão, a maior parte dos autores considera a produtividade em um nível macro de agregação de valores e atividades, o que dificulta a orientação de ações corretivas.

O propósito deste trabalho é desenvolver um método de avaliação do desempenho capaz de subsidiar a identificação das melhores práticas e a determinação de metas operacionais efetivamente pertinentes para cada sistema. Para isso, elaborou-se uma estrutura de indicadores de desempenho capaz de identificar e expurgar os efeitos das particularidades dos terminais.

O cerne da estrutura de indicadores sugerida é o atendimento aos navios por terminais especializados na exportação de minério de ferro, sob o ponto de vista do operador portuário. Seu desenvolvimento fundamenta-se em conceitos e instrumentos já consagrados de gestão por processos, gestão de organizações e gestão da qualidade.

O escopo do trabalho compreende a proposição do método de comparação e o estabelecimento de metas aplicado em um estudo de caso no contexto de um grande operador portuário.

Conclui-se que o método é simples e eficaz, na medida em que cumpre seu objetivo de aperfeiçoar o monitoramento e o controle do desempenho operacional, podendo ser um instrumento importante para o desenvolvimento dos operadores portuários e, porque não, do Brasil, que é carente em infraestrutura.

Palavras-chave: Terminais marítimos, Desempenho operacional, Eficiência, Benchmarking 


\begin{abstract}
The greatest difficulty in evaluating the operational performance of seaports lies in the identification and treatment of physical-operational particularities that can distort comparisons and mask inefficiencies. For this reason, the majority of authors consider port productivity at a highly aggregated level of values and activities, which hampers the orientation of corrective actions.

This study aims at developing a performance evaluation method capable of assisting with the identification of best practices and the determination of operational goals which are indeed relevant to each system.

The core of the proposed structure of indicators is the servicing of ships in specialized iron ore export terminals, from the port operator standpoint. The structure is elaborated on well-established concepts and instruments of process management, organizational management and quality management.

The scope of this study encompasses the proposition of comparison method and the definition of goals applied to a case study regarding a large port operator.

The study concludes that the method is simple and effective, as it fulfills its objective of enhancing the monitoring and the control of operational performance. The method could be an important tool for the development of port operators and, perhaps, of infrastructure-deficient Brazil.
\end{abstract}

Key-words: Seaport Terminals, Operational Performance, Efficiency, Benchmarking 


\section{LISTA DE ILUSTRAÇÕES}

FIGURA 1: DEFINIÇÃO DO OEE. FONTE: JEONG E PHILLIPS (2001).

FIGURA 2: OEE PARA UMA INDÚSTRIA DE CAPITAL INTENSIVO - NOVOS INDICADORES. FONTE: JEONG E

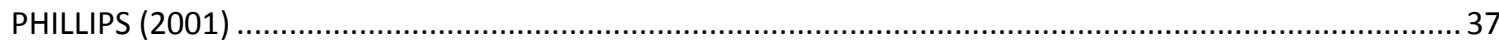

FIGURA 3: EXEMPLO DE CN DO TIPO TRAVELLING. FONTE: UNCTAD (1985) E THYSSENKRUPP............................ 39

FIGURA 4: EXEMPLO DE CN DO TIPO RADIAL. FONTE: UNCTAD (1985) E THYSSENKRUPP.................................. 40

FIGURA 5: EXEMPLO DE CN DO TIPO LINEAR . FONTE: UNCTAD (1985) E ELGIN NATIONAL INDUSTRIES ............. 41

FIGURA 6: EXEMPLO DE CN DO TIPO DUO-RADIAL. FONTE: UNCTAD (1985) E IHI TRANSPORT MACHINERY...... 42

FIGURA 7: EXEMPLO DE UMA RECUPERADORA RODA DE CAÇAMBA. FONTE: THYSSENKRUPP........................... 43

FIGURA 8: EXEMPLO DE EMPILHADEIRA. FONTE: UNCTAD (1985) E THYSSENKRUPP …….................................... 45

FIGURA 9: EXEMPLO DE UMA EMPILHADEIRA E RECUPERADORA. FONTE: THYSSENKRUPP .................................46

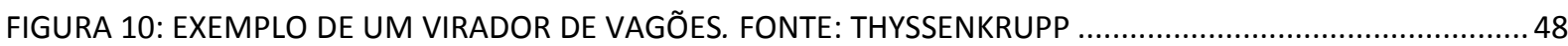

FIGURA 11: ETAPAS DA COMPARAÇÃO DE DESEMPENHO OPERACIONAL. FONTE: ELABORADO PELO AUTOR... 52

FIGURA 12: CÁLCULO DO BENCHMARK PARA O ÍNDICE DE PARADAS PRÉ E PÓS OPERACIONAIS. FONTE:

ELABORADO PELO AUTOR

FIGURA 13: ESTIMATIVA DE MOVIMENTAÇÃO ADICIONAL PARA O ÍNDICE DE PARADAS PRÉ E PÓS

OPERACIONAIS. FONTE: ELABORADO PELO AUTOR

FIGURA 14: EXEMPLO DA APLICAÇÃO DA ESTRUTURA DE INDICADORES PARA ESTIMAR OS GANHOS

POTENCIAIS. FONTE: ELABORADO PELO AUTOR

FIGURA 15: CONSOLIDAÇÃO DAS INFORMAÇÕES NA CRIAÇÃO DA BASE_A. FONTE: ELABORADO PELO AUTOR 69 FIGURA 16: CONSOLIDAÇÃO DAS INFORMAÇÕES NA CRIAÇÃO DA BASE_B. FONTE: ELABORADO PELO AUTOR 70 FIGURA 17: CONSOLIDAÇÃO DAS INFORMAÇÕES NA CRIAÇÃO DA BASE_C. FONTE: ELABORADO PELO AUTOR 70 FIGURA 18: OEE DOS BERÇOS DA AMOSTRA. FONTE: ELABORADO PELO AUTOR ............................................. 72 FIGURA 19: ÍNDICE DE OCUPAÇÃO. FONTE: ELABORADO PELO AUTOR ……………………………………......... 73 FIGURA 20: ÍNDICE DE OCIOSIDADE. FONTE: ELABORADO PELO AUTOR ………................................................. 74 FIGURA 21: ÍNDICE DE INDISPONIBILIDADE. FONTE: ELABORADO PELO AUTOR ………......................................... 75 FIGURA 22: ÍNDICE DE MANUTENÇÃO PREVENTIVA. FONTE: ELABORADO PELO AUTOR ……………................ 75 FIGURA 23: ÍNDICE DE UTILIZAÇÃO. FONTE: ELABORADO PELO AUTOR ……………….................................... 76 FIGURA 24: ÍNDICE DE ESPERA POR MARÉ, EM HORAS. FONTE: ELABORADO PELO AUTOR …............................... 77 FIGURA 25: ÍNDICE DE ESPERA POR MANOBRAS, EM HORAS. FONTE: ELABORADO PELO AUTOR ………........... 78 FIGURA 26: ÍNDICE DE PARADAS PRÉ E PÓS OPERACIONAIS, EM HORAS. FONTE: ELABORADO PELO AUTOR .... 79 FIGURA 27: ÍNDICE DE MANUTENÇÃO CORRETIVA DO CIRCUITO DE EMBARQUE. FONTE: ELABORADO PELO AUTOR

FIGURA 28: ÍNDICE DE MANUTENÇÃO CORRETIVA DAS ROTAS. FONTE: ELABORADO PELO AUTOR ..................... 80 FIGURA 29: ÍNDICE DE PARADAS OPERACIONAIS. FONTE: ELABORADO PELO AUTOR ……................................... 81 FIGURA 30: ÍNDICE DE BLOQUEIO DO CIRCUITO DE EMBARQUE. FONTE: ELABORADO PELO AUTOR .................. 82 
FIGURA 31: ÍNDICE DE BLOQUEIO DAS ROTAS. FONTE: ELABORADO PELO AUTOR

FIGURA 32: ÍNDICE DE PARADAS NÃO GERENCIÁVEIS. FONTE: ELABORADO PELO AUTOR................................... 83

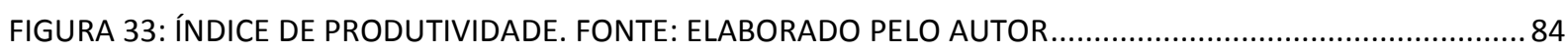

FIGURA 34: ÍNDICE DE VARIAÇÃO DA DENSIDADE. FONTE: ELABORADO PELO AUTOR …..................................... 85

FIGURA 35: ÍNDICE DE VARIAÇÃO DA TAXA DE MOVIMENTAÇÃO. FONTE: ELABORADO PELO AUTOR ………..... 86

FIGURA 36: ÍNDICE DE VARIAÇÃO DA TAXA NOMINAL. FONTE: ELABORADO PELO AUTOR................................. 87

FIGURA 37: EVOLUÇÃO DO ÍNDICE DE MANUTENÇÃO CORRETIVA DO CIRCUITO DE EMBARQUE. FONTE:

ELABORADO PELO AUTOR

FIGURA 38: GRUPOS DE TERMINAIS COM CARACTERÍSTICAS SEMELHANTES PARA CADA INDICADOR

COMPARÁVEL. FONTE: ELABORADO PELO AUTOR. 89

FIGURA 39: METAS OPERACIONAIS PARA CADA INDICADOR COMPARÁVEL. FONTE: ELABORADO PELO AUTOR90 FIGURA 40: GANHOS POTENCIAIS PARA O BERÇO 1. FONTE: ELABORADO PELO AUTOR ……............................92

FIGURA 41: GANHOS POTENCIAIS PARA O BERÇO 2. FONTE: ELABORADO PELO AUTOR ….................................. 92

FIGURA 42: GANHOS POTENCIAIS PARA O BERÇO 3. FONTE: ELABORADO PELO AUTOR ……........................... 93

FIGURA 43: GANHOS POTENCIAIS PARA O BERÇO 4. FONTE: ELABORADO PELO AUTOR ………….................... 94

FIGURA 44: GANHOS POTENCIAIS PARA O BERÇO 5. FONTE: ELABORADO PELO AUTOR …………….................95

FIGURA 45: GANHOS POTENCIAIS PARA O BERÇO 6. FONTE: ELABORADO PELO AUTOR .....................................95

FIGURA 46: GANHOS POTENCIAIS PARA O BERÇO 7. FONTE: ELABORADO PELO AUTOR ………...........................96

FIGURA 47: GANHOS POTENCIAIS PARA O BERÇO 8. FONTE: ELABORADO PELO AUTOR ………….................... 97

FIGURA 48: GANHOS POTENCIAIS PARA O BERÇO 9. FONTE: ELABORADO PELO AUTOR ….............................. 98

FIGURA 49: PERDAS OPERACIONAIS COM MAIORES PERSPECTIVAS DE MELHORA E OS TERMINAIS BENCHMARK.

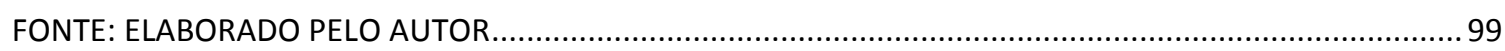

FIGURA 50: GANHO TEÓRICO POTENCIAL COM TODOS OS INDICADORES NOS NÍVEIS BENCHMARK. FONTE:

ELABORADO PELO AUTOR 99 


\section{LISTA DE QUADROS}

QUADRO 1: INDICADORES DE DESEMPENHO PORTUÁRIO. FONTE: UNCTAD (1976), WORLD BANK (2007) E ANTAQ (2003)

QUADRO 2: COMPARAÇÃO ENTRE FRONTEIRAS TECNOLÓGICAS E BENCHMARKING. FONTE: ELABORADO PELO AUTOR

QUADRO 3: PILARES DO TPM. FONTE: MORAES (2004). .32

QUADRO 4: PROCESSOS OPERACIONAIS CRÍTICOS NO ATENDIMENTO AOS NAVIOS. FONTE: ELABORADO PELO AUTOR 50

QUADRO 5: EFICIÊNCIAS OPERACIONAIS CONSIDERADAS NO ATENDIMENTO AOS NAVIOS. FONTE: ELABORADO PELO 53

QUADRO 6: DEFINIÇÃO DOS INDICADORES DE DESEMPENHO OPERACIONAIS. FONTE: ELABORADO PELO AUTOR 55

QUADRO 7: IDENTIFICAÇÃO DO GRUPO DE COMPARAÇÃO PARA OS INDICADORES. FONTE: ELABORADO PELO AUTOR. 60

QUADRO 8: PRINCIPAIS CARACTERÍSTICAS DOS BERÇOS ANALISADOS. FONTE: OPERADOR PORTUÁRIO (NÃO IDENTIFICADO) 


\section{LISTA DE TABELAS}

TABELA 1: SÍNTESE DOS RESULTADOS DOS INDICADORES DE DESEMPENHO. FONTE: ELABORADO PELO AUTOR 


\section{LISTA DE ABREVIATURAS E SIGLAS}

ANTAQ - Agência Nacional de Transportes Aquaviários

$B L_{C}$ - Soma dos tempos com bloqueios do circuito de embarque

$B L_{R}$ - Soma dos tempos com bloqueios das rotas

BSC - Balanced Scorecard

$\mathrm{CN}$ - Carregador de Navios

DEA - Data Envelopment Analysis

DISP - Índice de Disponibilidade

DWT - Capacidade média de carga das embarcações.

EP - Empilhadeira

ER - Empilhadeira/Recuperadora

FMI - Fundo Monetário Internacional

HC - Soma das horas calendário do período

HO - Soma das horas em operação efetiva

HOut - Soma das horas em operação útil (sem defeitos)

ID 1 - Índice de Ociosidade

ID 2 - Índice de Indisponibilidade

ID 3 - Índice de Manutenção Preventiva

ID 4 - Índice de Espera por Maré

ID 5 - Índice de Espera por Manobras

ID 6 - Índice de Paradas Pré e Pós Operacionais

ID 7 - Índice de Manutenção Corretiva do Circuito de Embarque

ID 8 - Índice de Manutenção Corretiva das Rotas

ID 9 - Índice de Paradas Operacionais

ID 10 - Índice de Bloqueio do Circuito de Embarque

ID 11 - Índice de Bloqueio das Rotas

ID 12 - Índice de Paradas Não Gerenciáveis

ID 13 - Índice de Variação da Densidade

ID 14 - Índice de Variação da Taxa de Movimentação

ID 15 - Índice de Variação da Taxa Nominal

IND - Soma dos tempos com indisponibilidades 
IP - Soma dos tempos com inatividade programada

JIPE - Japanese Institute of Plant Engineering

JIPM - Japanese Institute of Plant Maintenance

MA - Soma dos tempos com manobras de acostagem

MAR - Soma dos tempos com espera por maré

$\mathrm{MC}_{\mathrm{C}}$ - Soma dos tempos com manutenção corretiva do circuito de embarque

$M C_{R}$ - Soma dos tempos com manutenção corretiva das rotas

MP - Soma dos tempos com manutenção preventiva do circuito de embarque

OC - Soma dos tempos com ociosidade

OCUP - Índice de Ocupação

OEE - Overall Equipment Effectiveness

PERF - Índice de Performance Operacional

PIB - Produto Interno Bruto

PNG - Soma dos tempos com paradas não gerenciáveis

PNP - Soma dos tempos com paradas não programadas

PO - Soma dos tempos com paradas operacionais

PR - Soma dos tempos com atividades pré e pós-operacionais

PROD - Índice de Produtividade

QUAL - Índice de Qualidade

RP - Recuperadoras

TE - Taxa Efetiva

TEPP - Taxa Efetiva com Produto Padrão

TEU - Twenty-foot Equivalent Unit

TN - Taxa Nominal

$\mathrm{TN}_{\mathrm{R}}$ - Taxa Nominal das rotas

tph - Toneladas por hora

TPM - Total Productive Maintenance

TQC - Total Quality Control

UNCTAD - United Nations Conference on Trade and Development

UTIL - Índice de Utilização

V - Quantidade total Produzida

$V_{H D}$ - Quantidade potencial do sistema no período disponível para a operação

$V_{U T}$ - Quantidade útil produzida (sem defeitos)

VBA - Visual Basic for Aplications 
VV - Virador de Vagões

\#Navios - Número de Navios atendidos 


\section{SUMÁRIO}

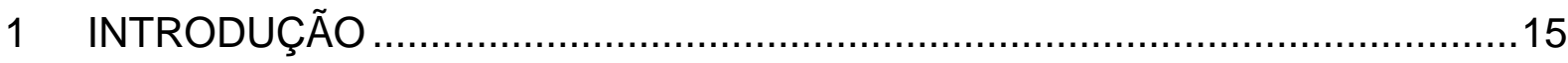

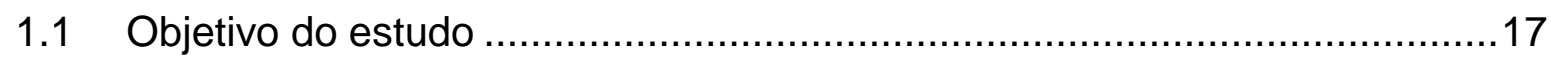

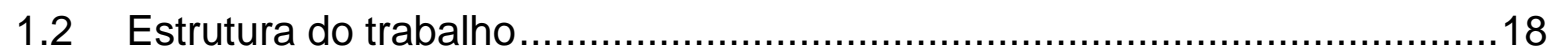

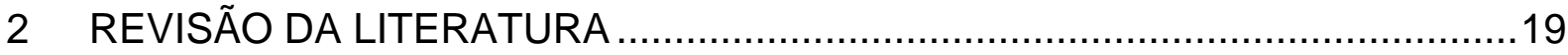

2.1 Análise do desempenho no setor portuário ..........................................20

2.1.1 Comparação da eficiência através de fronteiras tecnológicas ...............21

2.1.2 Benchmarking de indicadores de desempenho ...............................26

2.1.3 Comparação entre as abordagens ......................................... 30

2.2 O TPM e o Índice de Eficiência Global dos Equipamentos (OEE) ...............31

3 CARACTERIZAÇÃO DE TERMINAIS PORTUÁRIOS ESPECIALIZADOS EM EXPORTAÇÃO DE GRANÉIS SÓLIDOS MINERAIS ..................................... 38

3.1 O terminal portuário visto com um conjunto de processos ......................49

4 METODOLOGIA PARA A COMPARAÇÃO DE DESEMPENHO OPERACIONAL 51

4.1 Determinar os processos e as eficiências que serão mensurados .............52

4.2 Estabelecer os indicadores de desempenho....................................... 54

4.3 Eliminar da comparação os indicadores afetados por particularidades........58

4.4 Realizar o Benchmarking e determinar as metas operacionais ................61

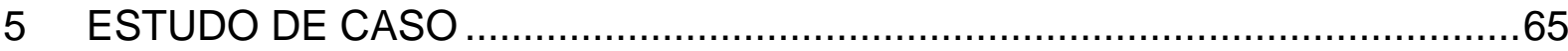

5.1 Principais considerações sobre os terminais analisados ........................66

5.2 Tratamento e consolidação dos dados operacionais ...............................68

5.3 Resultados dos indicadores de desempenho operacional .......................72

5.4 Definição de metas operacionais e estimativa de ganhos de produtividade 88

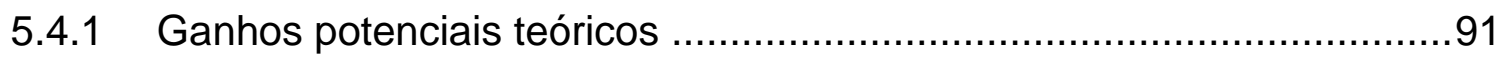

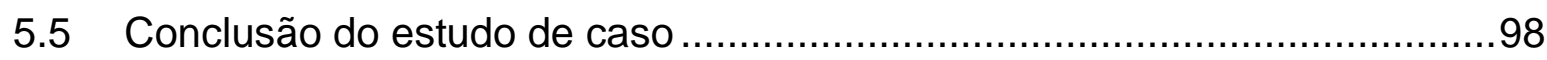




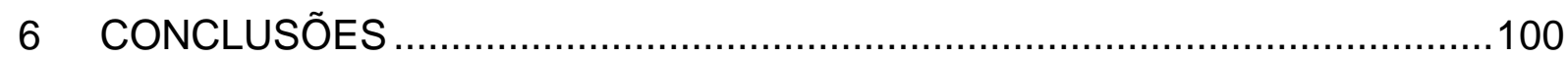

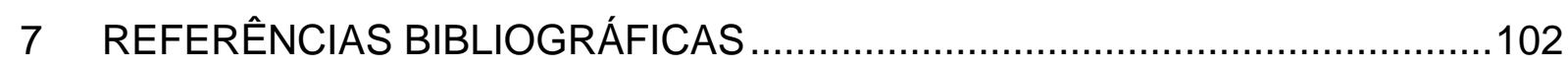




\section{INTRODUÇÃO}

"Eficiência é a questão principal da economia portuária contemporânea [...]".

(BARROS, 2006)

A frase que abre o trabalho remete à pressão que operadores e terminais portuários são submetidos para garantir serviços competitivos internacionalmente (TONGZON, 1989 apud WANKE et al., 2009), e assim apoiarem o crescimento econômico local.

O Brasil é uma das economias mais promissoras do mundo. As projeções recentes do Fundo Monetário Internacional (FMI) ${ }^{1}$ preveem um crescimento do PIB brasileiro de $7,1 \%$ para o ano de 2010 , significativamente superior à média mundial, de 4,6\%.

A exportação de commodities e insumos extrativos básicos representa cerca de $50 \%$ das exportações brasileiras (DEPLA, 2010). Como esses produtos costumam ser de baixo valor agregado e dependem de uma cadeia logística custosa, com portos possuindo papel de destaque, a utilização eficiente dos ativos portuários é, muitas vezes, determinante para a competitividade das empresas e do país. Assentindo com a frase de Barros (2006) que abre o trabalho.

Uma das abordagens mais utilizadas na avaliação do desempenho é a comparação entre sistemas. Entretanto, a comparação entre terminais portuários tende a ser complicada, já que as particularidades físicas, naturais e operacionais dos elementos dificultam uma comparação direta sem distorções. Por exemplo, um terminal pode ser mais produtivo que outro e ainda assim ser menos eficiente devido à influência da maré.

Embora seja relevante saber se um terminal é mais ou menos prejudicado por particularidades, quando se deseja melhorar a qualidade das operações portuárias deve-se priorizar a comparação entre os processos gerenciáveis, ou seja, que o terminal pode controlar.

Contudo, o enfoque voltado aos processos gerenciáveis não é comum, o que faz, na maioria das vezes, o debate sobre a infraestrutura portuária ser conduzido em

1 IMF. International Monetary Fund. "World Economic Outlook Update. An update of the key WEO projections." IMF. Washington - DC: FMI, July, 2010. 
termos genéricos (WANKE, FLEURY e HIJJAR, 2005), considerando a produtividade em um nível amplo de agregação de valores e atividades. Este enfoque tradicional conglomera tanto a ineficiência técnica quanto os fatores incontroláveis que aumentam o tempo do navio no porto (como espera pela maré alta, tráfego de embarcações no canal de acesso, intempéries e outros), que não deveriam ser contabilizados na comparação de terminais. Além disso, costuma-se considerar fatores que, apesar de controláveis (ou administráveis), dificilmente podem ser alterados pela gestão portuária por razões econômicas e estratégicas, como o tipo e o arranjo dos equipamentos, a ocupação do sistema, as cargas movimentadas, etc. Esses fatores, rotineiramente distorcem as comparações e são frequentemente utilizados como justificativas para desqualificar análises comparativas de desempenho.

De fato, existe uma falta de consenso na literatura que analisa a eficiência portuária $^{2}$, agravada pela baixa disponibilidade de dados operacionais ${ }^{3}$.

Os estudos que compararam a eficiência relativa de portos através de técnicas de fronteiras eficientes, como a Análise por Envoltória de Dados (TONGZON, 2001; HERRERA e PANG, 2005; CULLINANE et al., 2004) e a Fronteira Estocástica (ESTACHE et al., 2002; BARROS, 2005; CULLINANE et al.; 2003), são criticados por não terem clara vinculação da eficiência e da eficácia com os resultados dos processos operacionais, uma vez que não permitem identificar os aspectos críticos a serem monitorados e aprimorados durante a prestação dos serviços.

Já os estudos que utilizaram indicadores de produtividade (DE MONIE, 1987; PRODUCTIVITY COMMISSION, 1998; UNCTAD, 1976; WORLD BANK, 2007), reconheceram a importância de se avaliar a eficiência de cada processo da operação portuária e a necessidade de se considerar apenas os fatores que o operador pode gerir na comparação. Fourgeaud (2000) diz ainda que dependendo do caso, o gerenciamento do desempenho deve ser realizado para um conjunto

\footnotetext{
${ }^{2}$ Recomenda-se a leitura de González e Trujillo (2009) e Bichou (2006) para se aprofundar sobre o tema.

3 Usualmente, os dados disponíveis resumem-se nos registros requeridos pelas autoridades portuárias com relação ao tráfego de embarcações, parâmetros de tarifação, ocupação de cais e média de toneladas movimentadas.
} 
homogêneo de berços ou terminais. No entanto, o foco desses estudos é dotar a Autoridade Portuária de indicadores de alto nível, para serem aplicados em quase todos os portos, independente da especialização. Por isso, não apresentam uma solução que seja capaz de avaliar as principais perdas operacionais dos terminais. Muito menos indicam quais índices são comparáveis e em qual situação.

Sob essa ótica, esse trabalho visa contribuir avaliando, em um nível maior de detalhe, a eficiência em um nicho específico de terminais pouco explorado na literatura: aqueles especializados na exportação de granéis sólidos minerais.

\subsection{Objetivo do estudo}

O objetivo do trabalho é propor um sistema de avaliação de desempenho operacional que permita comparar terminais portuários com características físicooperacionais distintas.

O sistema proposto deverá ser capaz de identificar os processos a serem aprimorados, bem como as causas das ineficiências, e mensurar o impacto de ações corretivas com o propósito de elevar os padrões de atendimento dos serviços prestados.

O trabalho se fundamentará nos conceitos de gestão por processos e em instrumentos já consagrados de planejamento das organizações e gestão da qualidade.

O desempenho operacional dos processos será aferido, essencialmente, a partir dos tempos médios dos serviços (ou atividades) e dos rendimentos dos recursos empregados.

Como objetivo secundário do trabalho, se buscará um sistema de simples aplicação para evitar possíveis barreiras técnicas e sociais que inviabilizariam sua implantação. 


\subsection{Estrutura do trabalho}

A dissertação será estruturada em seis capítulos, conforme descritos a seguir:

- O capítulo 1 mostra a visão geral do assunto, sua relevância, o conhecimento previamente existente, o foco e o objetivo que se deseja atingir, a contribuição da pesquisa e a sua estruturação;

- O capítulo 2 expõe uma revisão bibliográfica que aborda aspectos da mensuração do desempenho e apresenta as principais técnicas utilizadas no setor portuário;

- O capítulo 3 relata as principais características físicas e operacionais de um terminal especializado na exportação de granéis minerais, com o intuito de se identificar fatores que devem ser considerados em uma comparação entre tipos distintos de tecnologia;

- O capítulo 4 descreve o método proposto para comparar o desempenho entre os terminais;

- No capítulo 5 um procedimento de aplicação desse método é desenvolvido;

- E por fim, no capítulo 6, comentam-se as principais conclusões do trabalho. 


\section{REVISÃO DA LITERATURA}

A mensuração do desempenho remonta das civilizações antigas, que já demonstravam em 6.000 a. C. a preocupação em realizar tarefas de modo eficiente e organizado. Com a revolução industrial, o foco passou a ser produzir em maior quantidade e com maior eficiência operacional e financeira. Ao longo dos anos, com o desenvolvimento da indústria e o aumento do número de empresas no mercado, o conceito de medição de desempenho se ampliou, incorporando a qualidade, a inovação e os desejos dos clientes, ganhando caráter estratégico para prover a competitividade e concretizar os objetivos da corporação.

A avaliação do desempenho pode ser definida como uma ferramenta gerencial que permite medir a eficiência de processos e a eficácia de ações tomadas por uma organização. Neste contexto, a eficácia mede a intensidade com que os objetivos foram atendidos, enquanto a eficiência mede o desperdício de recursos (BOURNE et al., 2003; HARRINGTON, 1993).

Por requerer a alocação de uma grande quantidade de recursos na maioria dos casos industriais (horas de processamento, pessoas, treinamento e qualificação, investimento em automação e controle, e inúmeros outros), a avaliação do desempenho pode ser bastante custosa. Por isso, Bandeira (1997) lembra que medir desempenho se justifica quando existe um objetivo explicito e alinhado com as prioridades da organização.

$\mathrm{Na}$ visão do autor, as principais justificativas para se mensurar o desempenho de uma entidade, são:

- $\quad$ Aumentar o lucro e a participação no mercado;

- Aprimorar a produtividade e da qualidade nas operações;

- Avaliar e comparar tecnologias de produção;

- Rastrear mudanças tecnológicas e no comportamento do mercado; e

- Aumentar a motivação e participação dos funcionários.

Por outro lado, as condicionantes do sucesso de um sistema de medição são: o permear da cultura de desempenho na organização; a orientação dos recursos humanos; o alinhamento entre os indicadores e os objetivos da organização; a 
simplicidade de sua operacionalização; e seu custeamento. Já a precisão do sistema depende da estruturação dos indicadores que devem permitir avaliar, em termos quantitativos ou qualitativos, a produtividade e a qualidade de um processo ou serviço, possibilitando o estabelecimento de metas de referência e a visualização de tendências e comparações (BOURNE et al., 2003; ARRUDA et al., 2008, RAMOS e MIYAKE, 2010).

Após esta visão geral, se mostrarão as principais técnicas aplicadas na comparação da eficiência portuária que se observou na literatura, e se discorrerá sobre o OEE (Overall Equipment Effectiveness), utilizado como indicador de desempenho em alguns terminais.

\subsection{Análise do desempenho no setor portuário}

Estudos sobre a eficiência e a produtividade dos portos são recentes. González e Trujillo (2009) sugerem que os primeiros trabalhos datam da década de $1980^{4}$.

A maior parte dos autores reconhece a dificuldade de se avaliar o desempenho portuário, atribuindo-a a complexidade das operações e aos inúmeros fatores incontroláveis que, na maioria dos casos, não permitem estabelecer valores de referência aplicáveis a qualquer sistema.

Alguns autores comentam que o modo ímpar com que as variações dos elementos naturais e operacionais impactam os sistemas torna difícil a adoção de indicadores padrões.

Em razão disso, poucos trabalhos na literatura conseguiram, de fato, contornar os fatores incontroláveis e realizar uma comparação equânime do desempenho operacional portuário.

Os estudos sobre o tema se desenvolveram em duas principais abordagens:

- Comparação da eficiência por fronteiras tecnológicas;

\footnotetext{
${ }^{4}$ Até a década de 1970, os pesquisadores estavam centrados em aspectos de tarifação, capacidade e políticas de investimento no setor portuário. A partir de então, iniciou-se linhas de pesquisas que pretendiam analisar as atividades econômicas portuárias. Essas pesquisas precederam os estudos de produtividade e eficiência no setor (GONZÁLEZ e TRUJILLO, 2009).
} 
- Benchmarking de indicadores de desempenho.

A seguir, essas abordagens serão descritas em mais detalhes.

\subsubsection{Comparação da eficiência através de fronteiras tecnológicas}

A ideia principal dessa abordagem é avaliar de forma genérica um grupo de portos, de forma a se obter os sistemas mais eficientes (fronteira eficiente) e a diferença relativa de produtividade entre os elementos.

A abordagem admite a existência de um conjunto de unidades de decisão que utiliza recursos para produzir. A eficiência técnica avalia a utilização dos recursos sem desperdício (ou seja, minimiza o uso de recursos ou maximiza a produção com os mesmos recursos disponíveis), enquanto a eficiência alocativa avalia o emprego dos recursos de menor custo - o que requer o conhecimento os custos de produção. Um produtor somente será economicamente eficiente se ele for tecnicamente e alocativamente eficiente (TUPY, 1996 e ZANINI, 2004).

Observam-se na literatura dois modelos principais concorrentes: fronteira estocástica e análise por envoltória de dados (DEA).

\section{Fronteira estocástica}

A fronteira estocástica é um modelo paramétrico que utiliza técnicas estatísticas para estimar a fronteira e computar sua eficiência relativa. O modelo considera que os desvios em relação à fronteira (de produção ou custo) podem ser causados pela ineficiência dos produtores ou por fenômenos aleatórios fora do seu controle ${ }^{5}$ (MENDONÇA et al., 2006; ZANINI, 2004; FRANCO e FORTUNA, 2003; SOUZA, 2003; CESPEDES, 2008). O modelo foi introduzido simultaneamente por Aigner, Lovell e Schimidt, e Meeusen e Van Den Broeck, em 1977, sendo especificado como:

\footnotetext{
${ }^{5}$ Cita-se como exemplo greves e condições ambientais sob a produção.
} 


$$
y_{i}=f\left(x_{i}, \beta\right) e^{v_{i}-u_{i}}
$$

Onde:

$y_{i}=$ nível de produção do i-ésimo produtor;

$f\left(x_{i}, \beta\right)=$ forma funcional adotada para representar a produção ou os custos;

$x_{i}=$ vetor de quantidade de insumos;

$\beta=$ vetor de parâmetros desconhecidos, cuja dimensão depende da forma funcional utilizada;

$v_{i}=$ variável aleatória que representa um erro simétrico (com distribuição favorável e desfavorável) fora do controle do produtor;

$u_{i}=$ variável que representa um componente de erro não negativo e captura o efeito da ineficiência dos produtores.

As funções funcionais adotadas com maior frequência são do tipo Cobb-Douglas e Translog, representadas pelas seguintes equações para a função produção (MENDONÇA et al.):

$$
\text { Cobb-Douglas: } \quad \operatorname{Lny}_{i}=\beta_{0}+\beta_{1} \operatorname{Ln} x_{1 i}+\cdots+\beta_{n} \operatorname{Ln} x_{n i}
$$

$$
\text { Translog: } \quad \operatorname{Lny}_{i}=\beta_{0}+\sum_{j=1}^{n} \beta_{j} \operatorname{Ln} x_{j i}+\frac{1}{2} \sum_{j=1}^{n} \sum_{k=1}^{n} \beta_{j k} \operatorname{Ln} x_{j i} \operatorname{Ln} x_{k i}
$$

Segundo Zanini (2004), a grande virtude da função Cobb-Douglas é a sua simplicidade, ao passo que a Translog permite ser expandida para acomodar múltiplos produtos.

Independente da forma funcional adotada, a eficiência técnica do i-ésimo produtor é definida pela razão entre a produção realizada e a máxima produção possível:

$$
T E=\frac{f\left(x_{i}, \beta\right) e^{v_{i}-u_{i}}}{f\left(x_{i}, \beta\right) e^{v_{i}}}=e^{-u_{i}}
$$

Os modelos de fronteira estocástica podem ser estimados por técnicas de máxima verossimilhança (função de probabilidade condicional dos dados observados) e de mínimos quadrados ordinários, sendo o primeiro estimador mais indicado porque 
tende a apresentar melhores resultados com o aumento do tamanho da amostra (SOUZA, 2003).

A principal vantagem da abordagem de fronteiras estocásticas é não ignorar o fato de que a produção pode ser afetada por fenômenos aleatórios fora do controle do produtor. A desvantagem é impor uma forma funcional restritiva aos dados, que pode confundir os efeitos de uma má especificação funcional com a ineficiência.

\section{Análise por Envoltória de Dados (DEA)}

A análise por envoltória de dados (DEA - Data Envelopment Analysis) foi proposta por Farrell em 1957, mas somente foi desenvolvida como modelo de programação matemática por Charnes, Cooper e Rodes em 1978 (COLIN, 2007).

O modelo adota como medida de eficiência a razão da soma ponderada das múltiplas saídas (produtos e serviços gerados) pelas múltiplas entradas (recursos utilizados para gerar os produtos ou serviços). É geralmente utilizado para avaliar a eficiência relativa de organizações em relação às outras, ou seja, compara a eficiência da aplicação de recursos assumindo que as unidades menos eficientes podem atingir a mesma relação das melhores da amostra (COLIN, 2007; BARROS. 2006; MENDONÇA et al., 2006).

A ideia do método é permitir que cada unidade defina sua estratégia de produção, atribuindo pesos para cada uma das entradas e saídas em análise, fazendo com que seu critério de ponderação seja o mais conveniente possível, desde que não ultrapasse o limite de $100 \%$ de eficiência quando aplicado em todas as unidades da amostra. Caso um dos pesos seja zero significa que a variável foi desconsiderada. Dessa forma, a técnica é classificada como não paramétrica, ou seja, não utiliza uma função de produção predefinida idêntica para todas as organizações em análise.

Os maiores rendimentos observados compõem a fronteira eficiente de solução. As demais unidades, não tão eficientes, estão posicionadas abaixo da fronteira, envolvidas pelo desempenho das unidades eficientes. O método define então unidades de referências para cada empresa menos eficiente, o que permite 
calcular os aumentos de produtos ou diminuição de insumos necessários para que o rendimento seja otimizado.

Conforme se observou na literatura (COLIN, 2007; BARROS. 2006; MENDONÇA et al., 2006), os dois modelos matemáticos mais utilizados na análise por envoltória de dados são o CCR (concebido por Charnes, Cooper e Rhodes em 1978) e o BCC (concebido por Banker, Charnes e Cooper em 1984).

O modelo CCR trabalha com retorno constante a escala de produção. Isso significa que alteração nos insumos provoca alteração igual na produção. Já o modelo BCC presume retornos variáveis, desconsiderando a proporcionalidade entre os insumos e os produtos, como indica a formulações a seguir (COLIN, 2007):

$$
\begin{gathered}
\text { Modelo CCR } \\
E F_{C C R}=\min \sum_{i=1}^{n} v_{i} x_{i j}
\end{gathered}
$$

$$
E F_{B C C}=\min \sum_{i=1}^{n} v_{i} x_{i j}-v^{*}
$$

sujeito a

$$
\begin{gathered}
\sum_{k=1}^{m} u_{k} y_{k j}=1 \\
\sum_{i=1}^{n} v_{i} x_{i j}-\sum_{k=1}^{m} u_{k} y_{k j} \leq 0 \\
j=1, \ldots, S \\
v_{i}, u_{k} \geq 0
\end{gathered}
$$

Sendo:

$s=$ instituições na amostra;

$n$ = quantidade de insumos;

$m$ = quantidade de produtos;

$x_{i j}=$ quantidade de insumo $\mathrm{i}$ da unidade $\mathrm{j}$;

$y_{k j}=$ quantidade de produto $\mathrm{k}$ da unidade $\mathrm{j}$;

$u_{k}=$ peso para cada produto $\mathrm{k}$;

$v_{i}=$ peso para cada insumo i;

$v^{*}=$ fator de escala.

\section{Modelo BCC}

$$
\begin{gathered}
\sum_{k=1}^{m} u_{k} y_{k j}=1 \\
\sum_{i=1}^{n} v_{i} x_{i j}-\sum_{k=1}^{m} u_{k} y_{k j}-v^{*} \leq 0 \\
j=1, \ldots, S \\
v_{i}, u_{k} \geq 0 \\
v^{*} \in \mathbb{R}
\end{gathered}
$$


A vantagem do modelo é a facilidade para lidar com múltiplas saídas e o fato de não necessitar de uma forma funcional explicita sobre os dados - como o método de fronteira estocástica. A desvantagem é que qualquer desvio em relação à fronteira é atribuída à ineficiência, podendo originar uma fronteira deformada se os dados estiverem contaminados por ruídos (ou erros de medição), não permitindo ser testada estatisticamente (COLIN, 2007; BARROS. 2006; MENDONÇA et al., 2006).

Segundo Colin (2007), a técnica em si serve mais para avaliar as eficiências do que para resolver o problema propriamente dito. $O$ autor recomenda após a determinação das eficiências, a realização de um processo de benchmarking para poder identificar as melhores práticas que originaram as diferenças.

\section{Fronteiras tecnológicas aplicadas no setor portuário}

Tanto a abordagem de fronteira estocástica, quanto a de análise por envoltória de dados, têm sido largamente utilizadas na comparação portuária por necessitar de poucos dados de entrada e por ranquear facilmente as eficiências globais.

O trabalho de González e Trujillo (2009) apresenta uma extensa revisão bibliográfica na qual compara diversos trabalhos que aplicam a abordagem de fronteira eficiente em portos. Segundo as autoras, nenhum modelo domina o outro: cada um tem vantagens e desvantagens e o uso dos modelos dependerá do caso em estudo.

Cita-se como exemplo da aplicação do DEA os trabalhos Tongzon (2001), Herrera e Pang (2005) e Cullinane et al. (2004), todos específicos em terminais de contêineres.

Já a aplicação de fronteira estocástica pode ser vista nos trabalhos Estache et al. (2002), Barros (2005) e Cullinane et al. (2003), sendo os primeiros aplicados em portos de múltiplas cargas e o último em terminais de contêineres. A forma funcional adotada por esses trabalhos foram: Cobb-Douglas, no estudo de Cullinane et al. (2003); Translog, no estudo de Barros (2005); e Cobb-Douglas e Translog no estudo de Estache et al. (2002).

O autor pesquisou o acervo das bibliotecas da Universidade de São Paulo, o banco de periódicos da CAPES, o site de busca Google (incluindo Google Acadêmico e 
Google Livros), e sites de pesquisa e publicação eletrônica de periódicos científicos, como Scielo, Elsevier, Emerald, ScienceDirect e ProQuest, mas não encontrou nenhum trabalho de fronteira eficiente que comparasse especificamente terminais de granéis sólidos.

\subsubsection{Benchmarking de indicadores de desempenho}

A ideia principal dessa abordagem é identificar como um processo está sendo realizado, quão produtivo ele pode ser e que ações devem ser tomadas para elevar sua eficiência, oferecendo às organizações a oportunidade de mudar e melhorar com base em exemplos bens sucedidos.

Benchmarking é um processo de avaliação da produção, serviços e atividades que tem como objetivo comparar práticas de agentes considerados excelentes (benchmark) para aumentar o desempenho da corporação (BARROS, 2006; BICHOU, 2007; APO, 2005).

O benchmarking permite uma comparação quantitativa capaz de identificar falhas e oportunidades em diversos níveis de detalhe e abrangência, a depender dos indicadores selecionados. Está abordagem permite que se use (ou crie) indicadores específicos para cada processo (ou evento), possibilitando expurgar os eventos afetados por fenômenos não gerenciáveis durante o estabelecimento de metas.

Os indicadores mais comuns na literatura portuária derivam dos trabalhos de De Monie (1987), UNCTAD (1976), World Bank (2007) e Fourgeaud (2000). No Brasil, a ANTAQ elaborou uma cartilha de orientação às autoridades portuárias ${ }^{6}$ que apresenta forte correlação com esses trabalhos. De forma geral, são recomendados diversos indicadores com foco operacional, financeiro e de qualidade dos serviços prestados, como mostra o Quadro 1.

\footnotetext{
${ }^{6}$ ANTAQ. "Indicadores de Desempenho Portuário - Sistema Permanente de Acompanhamento de Preços e Desempenho Operacional dos Serviços Portuários." Agencia Nacional de Transportes Aquaviários. Brasília, 2003.
} 


\begin{tabular}{|c|c|}
\hline \multicolumn{2}{|r|}{ Indicadores operacionais } \\
\hline Indicador & Descrição \\
\hline $\begin{array}{l}\text { Quantidades de } \\
\text { mercadorias movimentadas } \\
\text { em um período }\end{array}$ & $\begin{array}{l}\text { Quantidade total movimentada em toneladas, determinado } \\
\text { por grupo de carga e terminal (ou conjunto de berços), em } \\
\text { um período específico }\end{array}$ \\
\hline $\begin{array}{l}\text { Quantidades de contêineres } \\
\text { movimentados }\end{array}$ & $\begin{array}{l}\text { Quantidade de contêineres de } 20 \text { e } 40 \text { pés movimentada } \\
\text { por terminal (ou conjunto de berços) }\end{array}$ \\
\hline Atendimento ao tráfego & $\begin{array}{l}\text { Percentagem da movimentação de carga de cada terminal } \\
\text { (ou conjunto de berços) em relação à movimentação total } \\
\text { por grupo de carga }\end{array}$ \\
\hline $\begin{array}{l}\text { Tamanho médio de } \\
\text { consignação }\end{array}$ & $\begin{array}{l}\text { Quantidade média em toneladas (ou contêineres) } \\
\text { carregadas e descarregadas por navio, determinado por } \\
\text { tipo de embarcação, serviço e terminal (ou conjunto de } \\
\text { berços) }\end{array}$ \\
\hline $\begin{array}{l}\text { Índice médio de } \\
\text { conteinerização }\end{array}$ & $\begin{array}{l}\text { Percentagem da carga geral movimentada por contêineres } \\
\text { para um terminal (ou conjunto de berços) }\end{array}$ \\
\hline $\begin{array}{l}\text { Desbalanceamento ou } \\
\text { imbalance }\end{array}$ & $\begin{array}{l}\text { Percentagem de desbalanceamento entre importação e } \\
\text { exportação de contêineres cheios para um terminal (ou } \\
\text { conjunto de berços) }\end{array}$ \\
\hline $\begin{array}{l}\text { Relação contêiner } \\
\text { cheio/contêiner vazio }\end{array}$ & $\begin{array}{l}\text { Percentagem de desbalanceamento entre a movimentação } \\
\text { de contêineres cheios e vazios por terminal (ou conjunto de } \\
\text { berços) }\end{array}$ \\
\hline Taxa de chegada de navios & $\begin{array}{l}\text { Número médio de navios que chegam por dia, determinado } \\
\text { por tipo de embarcação e terminal (ou conjunto de berços) }\end{array}$ \\
\hline Tamanho médio de navios & $\begin{array}{l}\text { Capacidade média de transporte em toneladas ou TEUs } \\
\text { dos navios, por grupo de carga, tipo de embarcação e } \\
\text { terminal (ou conjunto de berços) }\end{array}$ \\
\hline $\begin{array}{l}\text { Índice médio de ocupação } \\
\text { de berços }\end{array}$ & $\begin{array}{l}\text { Relação entre o tempo em que o terminal ou conjunto de } \\
\text { berços esteve ocupado e o tempo total }\end{array}$ \\
\hline $\begin{array}{l}\text { Índice médio de ocupação } \\
\text { das instalações de } \\
\text { estocagem }\end{array}$ & $\begin{array}{l}\text { Relação entre as quantidades de cargas estocadas e a } \\
\text { capacidade nominal das instalações, por terminal (ou } \\
\text { conjunto de pátios e armazéns) }\end{array}$ \\
\hline
\end{tabular}

Quadro 1: Indicadores de desempenho portuário. Fonte: UNCTAD (1976), World Bank (2007) e ANTAQ (2003) 
Indicadores de qualidade dos serviços prestados

\begin{tabular}{l} 
Indicador \\
Tempo médio de \\
permanência do navio no \\
porto \\
\hline $\begin{array}{l}\text { Tempo médio de espera de } \\
\text { navios }\end{array}$
\end{tabular}

\section{Descrição}

Média do tempo de permanência dos navios, desde a chegada até a saída das embarcações da área do porto, por grupo de carga, tipo de embarcação e terminal (ou conjunto de berços)

Tempo médio em horas gasto com a espera de atracação dos navios, por grupo de carga e terminal (ou conjunto de berços)

Tempo médio de manobras e pré e pós-operacional

Tempo médio das manobras de atracação, desatracação, amarração, praticagem, visitas de autoridades, etc. por terminal (ou conjunto de berços)

Nível médio de serviço Relação entre o tempo de espera e o tempo atracado, por grupo de carga e terminal (ou conjunto de berços)

Índice médio de operação nas horas atracadas Média das relações entre o tempo de operação e o tempo total que o navios permaneceram atracados por terminal (ou conjunto de berços)

Quantidade movimentada por horas de permanência dos navios Média das toneladas (ou contêineres) movimentadas pelo tempo entre chegada e partida dos navios por terminal (ou conjunto de berços)

Prancha média de atendimento Média das toneladas (ou contêineres) movimentadas pelo tempo de permanência dos navios atracados por tipo de carga e terminal (ou conjunto de berços)

Quantidade movimentada por horas de equipes alocadas Média das toneladas (ou contêineres) movimentadas pelo tempo total das equipes alocadas em cada navio por tipo de carga e terminal (ou conjunto de berços)

Quantidade movimentada por horas de equipamentos alocados Média das toneladas (ou contêineres) movimentadas pelo tempo total dos equipamentos alocados em cada navio por tipo de carga e terminal (ou conjunto de berços)

Tempo médio das cargas nas dependências do porto

Tempo médio de espera para atendimento de veículos terrestres Tempo médio de estocagem, em dias e horas, por sentido de tráfego e terminal (ou conjunto de berços)

Tempo médio em horas de espera desde a chegada até a saída dos veículos de transporte, por terminal (ou conjunto de pátios e armazéns)

Produtividade média no atendimento de veículos terrestres

Quantidade média em toneladas (ou contêineres) carregadas e descarregadas por dia, determinado por terminal (ou conjunto de pátios e armazéns)

Tempo médio de espera de veículos para ovação ou desova de contêineres Tempo médio em horas de espera dos veículos transportando mercadorias desovadas ou destinadas à ovação de contêineres, por terminal (ou conjunto de pátios e armazéns)

Produtividade média nos serviços de ovação e desova de contêineres Quantidade de contêineres de 20 e 40 pés enchidas ou desovadas por dia, determinado por terminal (ou conjunto de pátios e armazéns)

Quadro 1: Indicadores de desempenho portuário. Fonte: UNCTAD (1976), World Bank (2007) e ANTAQ (2003) (cont.) 


\begin{tabular}{|c|c|}
\hline \multicolumn{2}{|r|}{ Indicadores financeiros } \\
\hline Indicador & Descrição \\
\hline $\begin{array}{l}\text { Preço médio de taxas } \\
\text { portuárias aos navios }\end{array}$ & $\begin{array}{l}\text { Preço médio, por tonelada (ou contêiner) movimentada, das } \\
\text { taxas portuárias pagas pelos armadores ou diretamente } \\
\text { pelo dono da mercadoria, pela movimentação das cargas }\end{array}$ \\
\hline $\begin{array}{l}\text { Preço médio de utilização } \\
\text { de terminal pelos navios }\end{array}$ & $\begin{array}{l}\text { Preço médio, por tonelada (ou contêiner) movimentada, dos } \\
\text { valores pagos pelo operador portuário ou dono de } \\
\text { mercadoria, aos arrendatários, pelo uso do terminal, } \\
\text { determinado por terminal (ou conjunto de berços) }\end{array}$ \\
\hline $\begin{array}{l}\text { Preço médio de mão de } \\
\text { obra }\end{array}$ & $\begin{array}{l}\text { Preço médio, por tonelada (ou contêiner) movimentada, dos } \\
\text { valores pagos com a mão de obra avulsa empregada nas } \\
\text { operações de carregamento/descarga, determinado por } \\
\text { terminal (ou conjunto de berços) }\end{array}$ \\
\hline $\begin{array}{l}\text { Preços médios de utilização } \\
\text { de equipamentos de } \\
\text { movimentação }\end{array}$ & $\begin{array}{l}\text { Preço médio, por tonelada (ou contêiner) movimentada, dos } \\
\text { valores pagos com o aluguel de equipamentos utilizados } \\
\text { nas operações de embarque/descarga, determinado por } \\
\text { terminal (ou conjunto de berços) }\end{array}$ \\
\hline $\begin{array}{l}\text { Outros custos de } \\
\text { movimentação }\end{array}$ & $\begin{array}{l}\text { Preço médio, por tonelada (ou contêiner) movimentada, dos } \\
\text { valores pagos com outros custos, determinado por terminal } \\
\text { (ou conjunto de berços). Por exemplo o custo da mão de } \\
\text { obra empregada nas operações complementares ao } \\
\text { carregamento/ descarga }\end{array}$ \\
\hline $\begin{array}{l}\text { Despesa média de entrada } \\
\text { e saída de navios }\end{array}$ & $\begin{array}{l}\text { Custo médio de escala do navio (call cost), para cada } \\
\text { terminal (ou conjunto de berços) }\end{array}$ \\
\hline $\begin{array}{l}\text { Preços médios de entrega } \\
\text { ou de recebimento }\end{array}$ & $\begin{array}{l}\text { Preço médio, por tonelada (ou contêiner) movimentada, } \\
\text { cobrados pelos operadores ou arrendatários pelos serviços } \\
\text { de recebimento/entrega de cargas, para cada terminal (ou } \\
\text { conjunto de berços) }\end{array}$ \\
\hline $\begin{array}{l}\text { Preços médios de ovação } \\
\text { ou desova }\end{array}$ & $\begin{array}{l}\text { Preço médio, por contêiner movimentado, cobrados por } \\
\text { operadores ou arrendatários pelos serviços de ovação e/ou } \\
\text { desova, determinado por terminal (ou conjunto de pátios e } \\
\text { armazéns) }\end{array}$ \\
\hline $\begin{array}{l}\text { Outros preços de serviços } \\
\text { aos donos de mercadorias }\end{array}$ & $\begin{array}{l}\text { Preço médio, por tonelada (ou contêiner) movimentada, dos } \\
\text { valores pagos com outros serviços complementares de } \\
\text { entrega e recebimento das cargas, determinado por } \\
\text { terminal (ou conjunto de pátios e armazéns) }\end{array}$ \\
\hline
\end{tabular}

Quadro 1: Indicadores de desempenho portuário. Fonte: UNCTAD (1976), World Bank (2007) e ANTAQ (2003) (cont.) 
A lista não é exaustiva e sua orientação é dotar a Autoridade Portuária de indicadores que permitam avaliar o nível do serviço prestado em quase todos os portos e terminais, independentemente da infraestrutura utilizada. Por isso, a maioria dos indicadores não é capaz de apontar as razões específicas das diferenças de desempenho e a origem das perdas operacionais.

Idealmente os indicadores deveriam isolar os fenômenos não gerenciáveis para submeter os sistemas às mesmas condições físicas e operacionais, permitindo a realização de comparações sem distorção.

Essa imparcialidade, no entanto, quase nunca é vista nos indicadores do Quadro 1, que são influenciados por diversos fatores e por diversas entidades do porto, dificultando as comparações. Por exemplo, o tempo médio de permanência dos navios depende da infraestrutura utilizada, da Autoridade Portuária, dos serviços de praticagem, do porte das embarcações, da condição climática, dentre outros.

A imparcialidade não é uma característica exclusiva dos indicadores do Quadro 1. $\mathrm{Na}$ literatura observada, nenhum trabalho apresentou uma estrutura de indicadores que solucionasse esse problema.

A aplicação do benchmarking parece ser comum em terminais de contêineres, podendo citar, por exemplo, o trabalho de Productivity Commission (1998), que analisa a evolução do serviço prestado em portos australianos. Contudo, não se encontrou nenhum trabalho de benchmarking com foco na operação de terminais de graneis sólidos ${ }^{7}$.

\subsubsection{Comparação entre as abordagens}

A comparação entre as abordagens de fronteira tecnológica e benchmarking é sintetizada no Quadro 2.

\footnotetext{
${ }^{7}$ O autor pesquisou o acervo das bibliotecas da Universidade de São Paulo, o banco de periódicos da CAPES, o site de busca Google (incluindo Google Acadêmico e Google Livros), e sites de pesquisa e publicação eletrônica de periódicos científicos, como Scielo, Elsevier, Emerald, ScienceDirect e ProQuest.
} 


\begin{tabular}{|c|c|c|}
\hline CRITÉRIO & FRONTEIRA TECNOLÓGICA & BENCHMARKING \\
\hline $\begin{array}{l}\text { DADOS DE } \\
\text { ENTRADA }\end{array}$ & $\begin{array}{l}\text { Necessita de poucos dados com } \\
\text { baixo grau de detalhamento }\end{array}$ & $\begin{array}{l}\text { Necessita de grande quantidade de } \\
\text { dados com alto grau de detalhamento }\end{array}$ \\
\hline $\begin{array}{l}\text { RESPOSTA DOS } \\
\text { MODELOS }\end{array}$ & $\begin{array}{l}\text { Relativa. Não fornece informações } \\
\text { detalhadas }\end{array}$ & $\begin{array}{l}\text { Relativa e absoluta. Fornece } \\
\text { informações detalhadas sobre os } \\
\text { processos }\end{array}$ \\
\hline $\begin{array}{c}\text { FATORES } \\
\text { INCONTROLÁVEIS } \\
\text { E PECULIARES }\end{array}$ & $\begin{array}{l}\text { É influenciado por fatores } \\
\text { incontroláveis e peculiares }\end{array}$ & $\begin{array}{l}\text { Permite isolar os processos } \\
\text { influenciados por fatores incontroláveis } \\
\text { e peculiares }\end{array}$ \\
\hline $\begin{array}{c}\text { METAS } \\
\text { OPERACIONAIS }\end{array}$ & $\begin{array}{l}\text { A meta operacional é global e visa à } \\
\text { eficiência da fronteira. Os fatores } \\
\text { incontroláveis e peculiares } \\
\text { prejudicam a precisão das metas }\end{array}$ & $\begin{array}{l}\text { A meta operacional é específica para } \\
\text { cada indicador, podendo isolar os } \\
\text { índices influenciados pelos fatores } \\
\text { incontroláveis e peculiares }\end{array}$ \\
\hline
\end{tabular}

Quadro 2: Comparação entre fronteiras tecnológicas e benchmarking. Fonte: Elaborado pelo autor

Em suma, apesar da abordagem de fronteira tecnológica ser amplamente utilizada na comparação de portos por requerer poucos dados de entrada, é uma técnica muito genérica e deficiente no que tange aos objetivos específicos e mais pragmáticos desse trabalho. A técnica não fornece, efetivamente, as ações necessárias para alcançar as melhorias, limitando-se, em diagnosticar a existência de ineficiências. Os fatores incontroláveis dos processos e as características físicooperacionais de todos os portos dificultam a adoção de uma forma funcional única. Por essas razões, a abordagem do benchmarking parece ser a mais indicada e será adotada neste trabalho.

\subsection{O TPM e o Índice de Eficiência Global dos Equipamentos (OEE)}

O TPM (Total Productive Maintenance) é um programa corporativo que busca a melhoria da eficiência dos sistemas produtivos por meio da prevenção de todos os tipos de perdas, atingindo assim o índice zero acidente, zero defeito e zero falhas durante todo o ciclo de vida dos equipamentos.

Criado em 1971 por Seiichi Nakajima e os demais membros do Instituto Japonês de Manutenção Industrial ${ }^{8}$, o TPM tem o objetivo de melhorar de forma contínua a qualidade das manutenções e ampliar a efetividade e a utilização dos equipamentos,

\footnotetext{
${ }^{8}$ Japan Institute for Plant Maintenance - JIPM.
} 
reduzindo os custos diretos e ampliando a produção sem gastar recursos financeiros.

O TPM incentiva o aumento da participação dos funcionários na prevenção de paradas operacionais, na identificação das perdas de produtividade dos processos e no controle da qualidade das operações.

A estrutura do TPM é sustentada por oito pilares, descritos no quadro a seguir:

\begin{tabular}{|c|c|}
\hline Pilar & Descrição \\
\hline $\begin{array}{l}\text { Melhoria } \\
\text { Específica }\end{array}$ & $\begin{array}{l}\text { Para atuar nas perdas crônicas relacionadas aos equipamentos } \\
\text { ou processo. }\end{array}$ \\
\hline $\begin{array}{l}\text { Manutenção } \\
\text { Autônoma }\end{array}$ & $\begin{array}{l}\text { Praticada pelos operários para a melhoria contínua das rotinas } \\
\text { de produção e manutenção. }\end{array}$ \\
\hline $\begin{array}{l}\text { Manutenção } \\
\text { Planejada }\end{array}$ & $\begin{array}{l}\text { Visando a melhoria contínua da disponibilidade e confiabilidade, } \\
\text { além da redução dos custos de manutenção. }\end{array}$ \\
\hline $\begin{array}{l}\text { Treinamento e } \\
\text { educação }\end{array}$ & $\begin{array}{l}\text { Treinamentos técnicos e comportamentais para liderança, } \\
\text { flexibilidade e autonomia das equipes. }\end{array}$ \\
\hline $\begin{array}{l}\text { Gestão } \\
\text { antecipada }\end{array}$ & $\begin{array}{l}\text { Prevenção da manutenção durante o projeto e construção dos } \\
\text { componentes para aumentar a confiabilidade e } \\
\text { manutenabilidade. }\end{array}$ \\
\hline $\begin{array}{l}\text { Manutenção da } \\
\text { qualidade }\end{array}$ & $\begin{array}{l}\text { Interação entre confiabilidade dos equipamentos com a } \\
\text { qualidade dos produtos e a capacidade de atendimento à } \\
\text { demanda. }\end{array}$ \\
\hline $\begin{array}{l}\text { Segurança, Saúde } \\
\text { e Meio Ambiente }\end{array}$ & $\begin{array}{l}\text { Melhoria contínua das condições de trabalho e da redução dos } \\
\text { riscos de acidentes operacionais e ambientais. }\end{array}$ \\
\hline $\begin{array}{l}\text { Melhoria dos } \\
\text { processos } \\
\text { administrativos }\end{array}$ & $\begin{array}{l}\text { Organização e eliminação de desperdícios nas rotinas } \\
\text { administrativas, que de alguma maneira acabam interferindo na } \\
\text { eficiência dos equipamentos ou processos. }\end{array}$ \\
\hline
\end{tabular}

Para aumentar a produtividade e planejar as atividades de manutenção, o TPM orienta a busca da eliminação de seis principais perdas:

1. Perda por quebra ou falha;

2. Perda por preparação e ajuste;

3. Perda por ociosidade e pequenas paradas;

4. Perda por velocidade reduzida;

5. Perda por defeitos no processo; e

6. Perda no início da produção. 
Na visão de Nakajima, essas perdas devem ser monitoradas constantemente por um indicador criado por ele próprio, o Índice de Eficiência Global dos Equipamentos, conhecido como OEE (Overall Equipment Effectiveness). O OEE é um índice de produtividade que avalia qual porcentagem da capacidade do equipamento ou sistema é efetivamente utilizada de maneira produtiva no período programado para a operação, podendo ser expresso pela multiplicação de três indicadores: o Índice de Disponibilidade (DISP), o Índice de Performance Operacional (PERF) e o Índice de Qualidade (QUAL), conforme mostra a equação 7.

$$
O E E=D I S P \cdot P E R F \cdot Q U A L=\frac{V_{U T}}{V_{H D}}
$$

Onde:

$V_{U T}$ : quantidade útil produzida (sem defeitos);

$V_{H D}$ : quantidade potencial do sistema no período disponível para a operação.

O Índice de Disponibilidade é um indicador que expressa à relação entre o tempo que um equipamento está disponível (em plenas condições de funcionamento) e o tempo total que uma operação poderia ocorrer se o equipamento estivesse sempre possibilitado. As perdas por quebra ou falha (Perda 1) e por preparação e ajuste (Perda 2) reduzem o Índice de Disponibilidade, uma vez que aumentam as paradas não programadas (PNP):

$$
D i s p=\frac{H C-I P-P N P}{H C-I P}
$$

Onde:

$H C$ : horas calendário do período analisado;

IP: inatividade programada;

PNP: paradas não programadas ${ }^{10}$.

\footnotetext{
${ }^{9}$ Como turno sem operação, finais de semana, feriados, etc.

${ }^{10}$ Como manutenção corretiva, trocas e ajustes de ferramentas, etc.
} 
Os períodos de inatividade programada como turno noturno, feriados, finais de semana, dentre outros, não são considerados no indicador, uma vez que são abatidos tanto no numerador quanto no denominador do índice. Esses períodos improdutivos não faziam parte das perdas apontadas por Nakajima, já que no momento de sua criação, poucas empresas possuíam regime operacional em horário integral.

O Índice de Performance expressa à relação entre o tempo líquido de operação e o tempo em que o equipamento estava disponível para operar. As perdas por ociosidade e pequenas paradas (Perda 3 ) e por velocidade reduzida ${ }^{11}$ (Perda 4) reduzem o indicador:

$$
\operatorname{Perf}=\frac{H O}{H C-I P-P N P}
$$

Onde:

HO: total de horas em operação;

$H C$ : horas calendário do período analisado;

IP: inatividade programada;

PNP: paradas não programadas.

O Índice de Qualidade expressa à relação entre a quantidade produzida que não precisou de retrabalho (ou não apresentou defeito) e a quantidade produzida total. $\mathrm{O}$ indicador pode ser calculado também pela relação entre o tempo de produção útil (sem defeitos) e o tempo líquido de operação. As perdas por defeitos no processo (Perda 5) e de refugo no início da produção (Perda 6) reduzem o Índice de Qualidade, como mostra a equação 10.

$$
\text { Qual }=\frac{V_{U T}}{V}=\frac{H O_{U T}}{H O}
$$

Onde:

$V_{U T:}$ quantidade útil produzida (sem defeitos);

\footnotetext{
${ }^{11}$ Devido à espera de algum recurso faltante, bloqueio causado por algum outro recurso à frente no fluxo de produção ou outras pequenas paradas não registradas.
} 
$V$ : quantidade total produzida;

HOUT: total de horas em operação útil (sem defeitos);

HO: total de horas em operação.

A Figura 1 consolida os indicadores e as principais perdas destacadas por Nakajima. Observa-se que todo o tempo programado para a operação está associado a algum indicador de desempenho, permitindo o monitoramento da eficiência global do equipamento ou sistema.

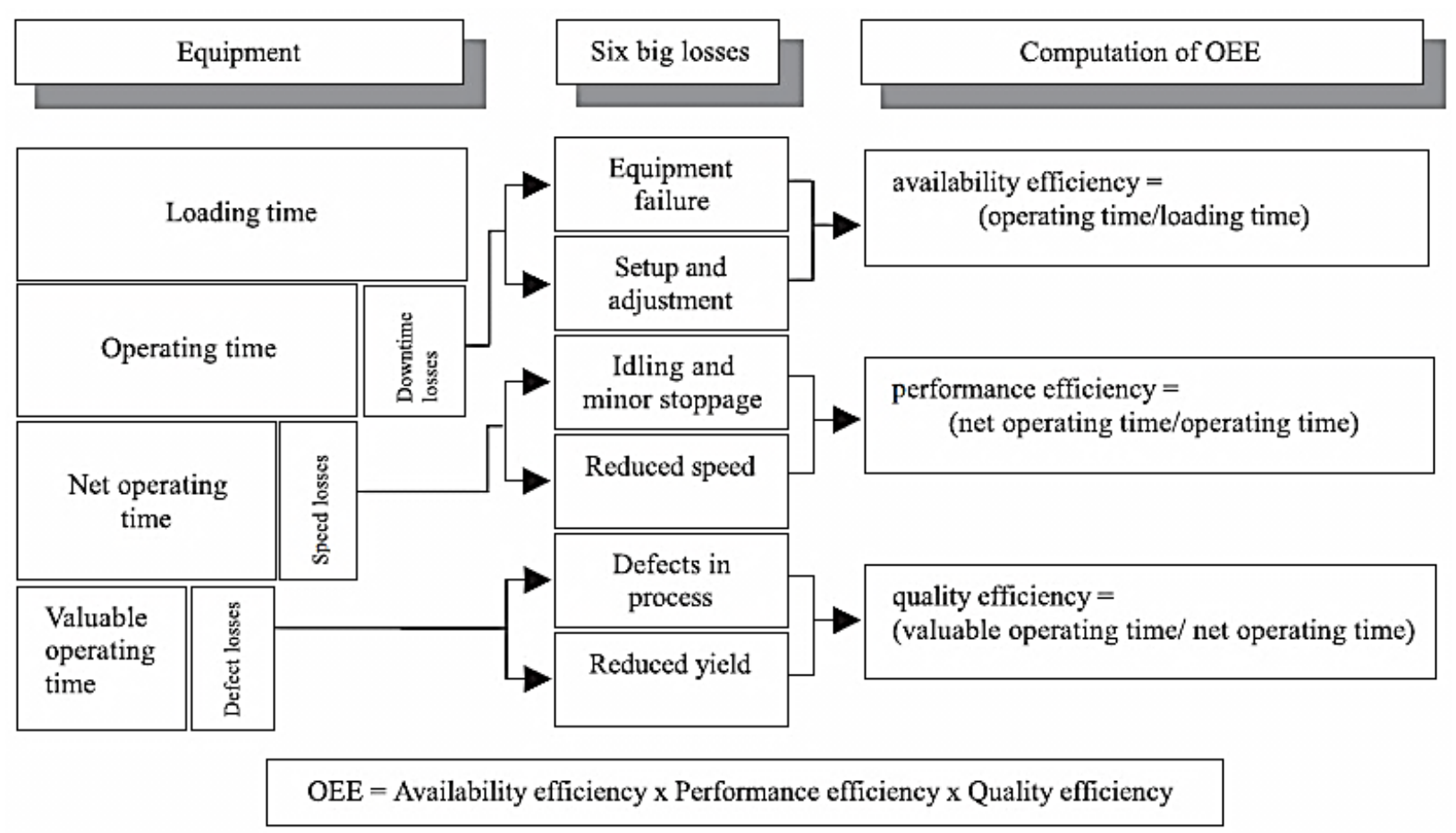

Figura 1: Definição do OEE. Fonte: Jeong e Phillips (2001)

Ljungberg (1998) e Jeong e Phillips (2001) criticam a definição de OEE de Nakajima por não considerar todos os tempos que reduzem a capacidade do equipamento ou sistema analisado. Segundo esses autores, O OEE seria mais eficaz se analisasse todas as horas do período, uma vez que muitas indústrias, principalmente as de capital intensivo, costumam ter regime operacional integral para utilizar o máximo da planta instalada. Dessa forma, os períodos de inatividade programada (incluindo a manutenção preventiva) passam a impactar diretamente o Índice de Disponibilidade, como evidencia a equação a seguir: 


$$
\text { Disp }=\frac{H C-I P-P N P}{H C}
$$

Onde:

$H C$ : horas calendário do período analisado;

IP: inatividade programada;

$P N P$ : paradas não programadas.

Essa alteração garante que nenhuma perda seja mascarada por não estar sendo considerada e propicia uma comparação mais fácil entre OEEs, bastando considerar um mesmo horizonte de tempo.

Ljungberg (1998) afirma ainda que as perdas que consomem grande parte da eficiência produtiva devem ser observadas com maior atenção e divididas em subgrupos. Jeong e Phillips (2001) complementam dizendo que os sistemas de classificação das perdas estão intimamente ligados ao tipo de indústria ou setor analisado e apresenta uma classificação diferenciada para atender a indústria de capital intensivo.

Essa nova classificação proposta por Jeong e Phillips (2001) considera 10 perdas reorganizadas em diferentes indicadores de desempenho que, assim como os indicadores originais de Nakajima, quando multiplicados formam o OEE. Esses indicadores são: o Índice de Operacionalidade, o Índice de Produtividade e o Índice de Qualidade, que podem ser vistos na Figura 2.

A reorganização proposta pelos autores permite identificar e controlar as perdas com origens diferentes, segregando-as em perdas devido às interrupções no equipamento, às reduções na taxa de produtividade e às irregularidades no padrão de qualidade. Os autores recomendam reorganizar a estrutura de indicadores sempre que se perceber que as métricas utilizadas não estão alinhadas com os objetivos da empresa. 


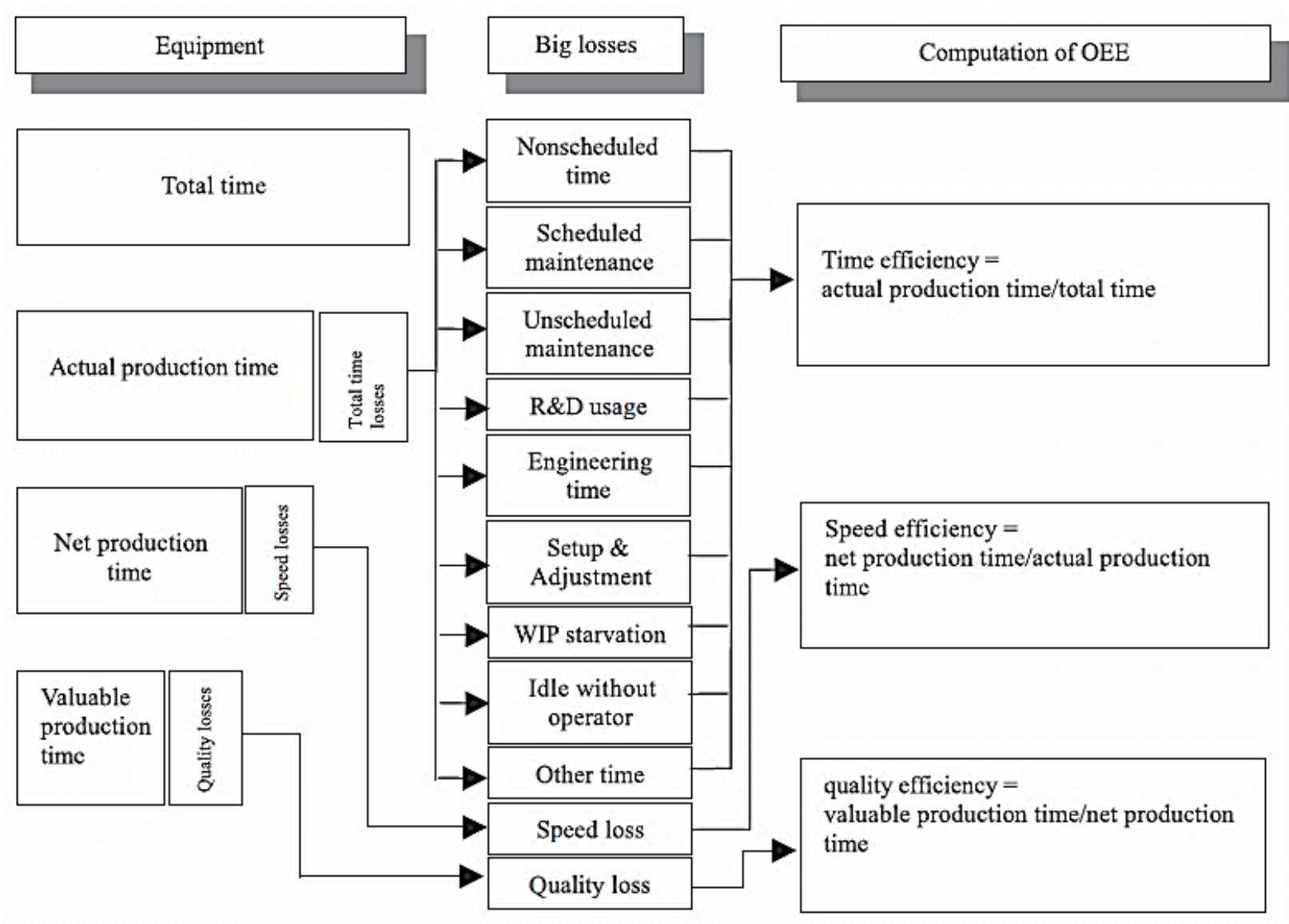

$\mathrm{OEE}=$ Time efficiency $\mathrm{x}$ Speed efficiency $\mathrm{x}$ Quality efficiency

Figura 2: OEE para uma indústria de capital intensivo - novos indicadores. Fonte: Jeong e Phillips (2001)

Embora não se tenha encontrado na literatura ${ }^{12}$ nenhum trabalho que aplicasse os conceitos do OEE na avaliação do desempenho portuário, verificou-se que um grande operador portuário de granéis sólidos do Brasil - cujo nome será omitido usufrui empiricamente da técnica para esse fim. Este operador, no entanto, não adaptou os indicadores e as perdas propostas por Nakajima às suas necessidades e objetivos, como recomenda Jeong e Phillips (2001). Tal adaptação será realizada na seção 4.2 deste trabalho.

\footnotetext{
${ }^{12} \mathrm{O}$ autor pesquisou o acervo das bibliotecas da Universidade de São Paulo, o banco de periódicos da CAPES, o site de busca Google (incluindo Google Acadêmico e Google Livros), e sites de pesquisa e publicação eletrônica de periódicos científicos, como Scielo, Elsevier, Emerald, ScienceDirect e ProQuest.
} 


\section{CARACTERIZAÇÃO DE TERMINAIS PORTUÁRIOS ESPECIALIZADOS EM EXPORTAÇÃO DE GRANÉIS SÓLIDOS MINERAIS}

De acordo com UNCTAD (1985), as características dos terminais portuários dependem fundamentalmente das condições locais, da finalidade da operação e da natureza do material.

Nesse contexto, o tipo de carga movimentada (granel sólido, granel líquido, carga geral solta, carga geral conteinerizada, etc.) e o sentido da operação (importação, exportação, transbordo, etc.) talvez sejam os aspectos mais relevantes na caracterização portuária, pois têm grande influência na escolha da infraestrutura utilizada e localização do terminal, além de influir no porte dos navios atendidos.

Para a compreensão completa do sistema proposto é conveniente que se conheça as principais características físicas e operacionais de um terminal portuário especializado na exportação de minério de ferro. Isso é feito nesse capítulo, o qual se comenta as principais diferenças entre os arranjos (e os tipos de equipamentos) e suas implicações na produtividade.

\section{Características da infraestrutura}

A infraestrutura marítima é dotada de instalações físicas que usualmente contemplam o canal de acesso, cais e píer dragados, quebra-mares, muros de contenção, além de equipamentos especializados para o transbordo de carga.

No caso específico da exportação de granéis sólidos, o principal equipamento de transbordo é o carregador de navios $(\mathrm{CN})$, que recebe o material de uma correia transportadora e o direciona nos porões das embarcações.

Os CNs operam sobre pórticos que correm em trilhos paralelamente ou radialmente a um eixo que tange o berço. Existem três tipos principais de CNs que se diferem quanto ao modo de se transladar até o porão do navio: o travelling, o radial e o linear. 
No CN do tipo travelling toda a estrutura do carregador se desloca paralelamente ao berço, possibilitando alcançar todos os porões cobertos pelos trilhos instalados na estrutura marítima, como ilustra a Figura 3. Esse tipo de CN requer um elevador de carga móvel (tripper) que permita transferir a carga das correias transportadoras para a lança do carregador, independentemente de sua localização no berço.

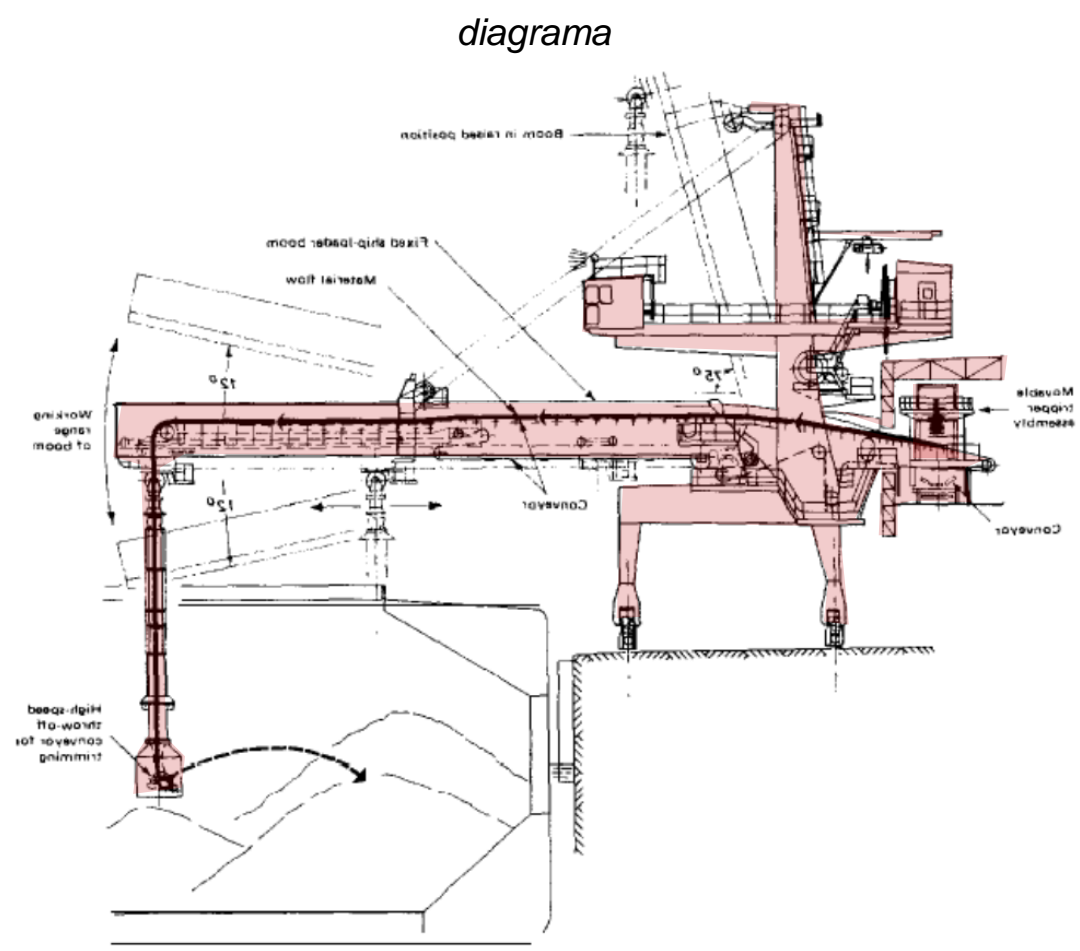

ilustração

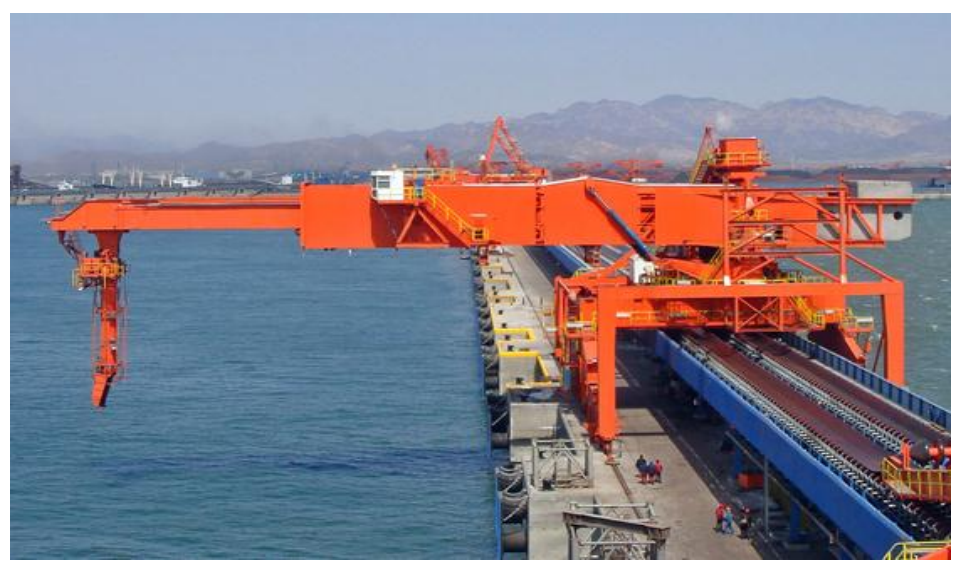

Figura 3: Exemplo de CN do tipo travelling. Fonte: UNCTAD (1985) e ThyssenKrupp 
A lança do CN travelling pode ser suspensa durante a movimentação do pórtico no berço para evitar colisões com a superestrutura da embarcação, possibilitando ao terminal operar mais de um navio em um mesmo píer com um único equipamento.

Já o CN do tipo radial possui sua base fixa e o deslocamento de sua lança deve-se ao movimento sob trilhos instalados em uma estrutura offshore curva (Figura 4). O movimento radial da lança atinge ângulos próximos de $90^{\circ}$ e seu comprimento restringe os porões que podem ser atendidos. Se a soma do comprimento dos porões do navio for maior que a distância coberta pelo carregador, o navio só poderá ser completamente carregado após a reatracação em outra posição que possibilite o término do carregamento.

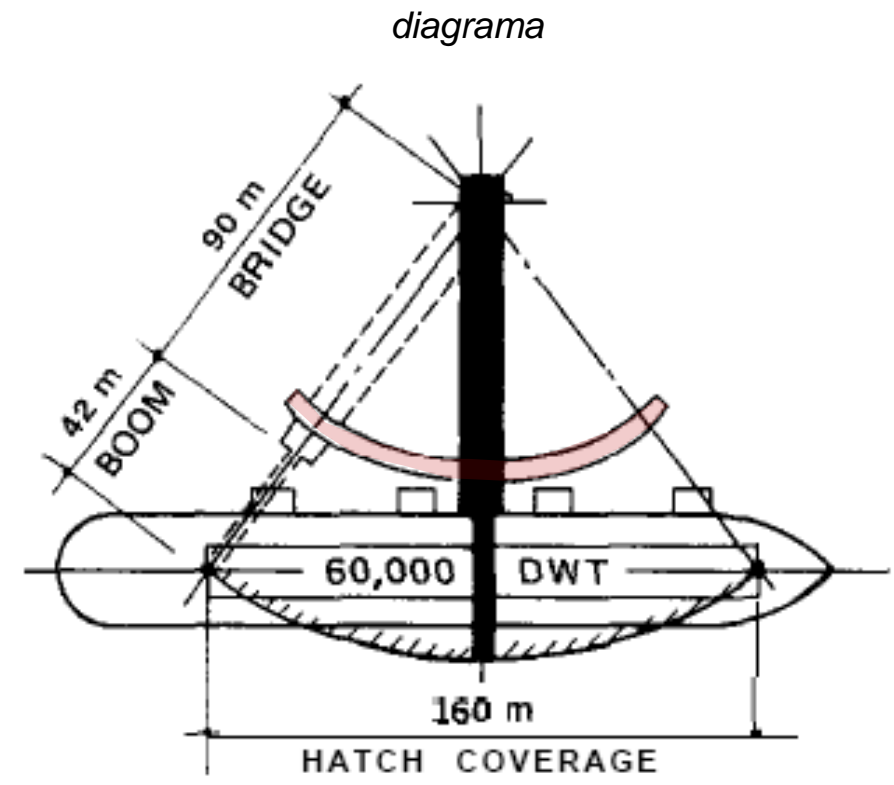

ilustração

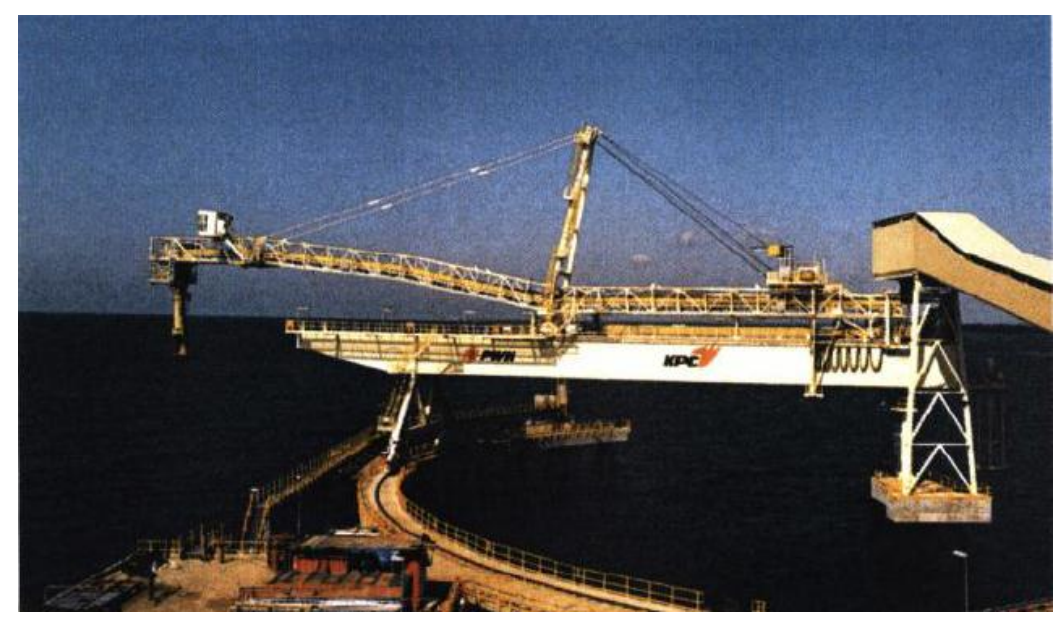

Figura 4: Exemplo de CN do tipo radial. Fonte: UNCTAD (1985) e ThyssenKrupp 
O CN do tipo linear possui um sistema semelhante ao radial, mas com a estrutura offshore paralela ao berço, como ilustra a Figura 5.

diagrama

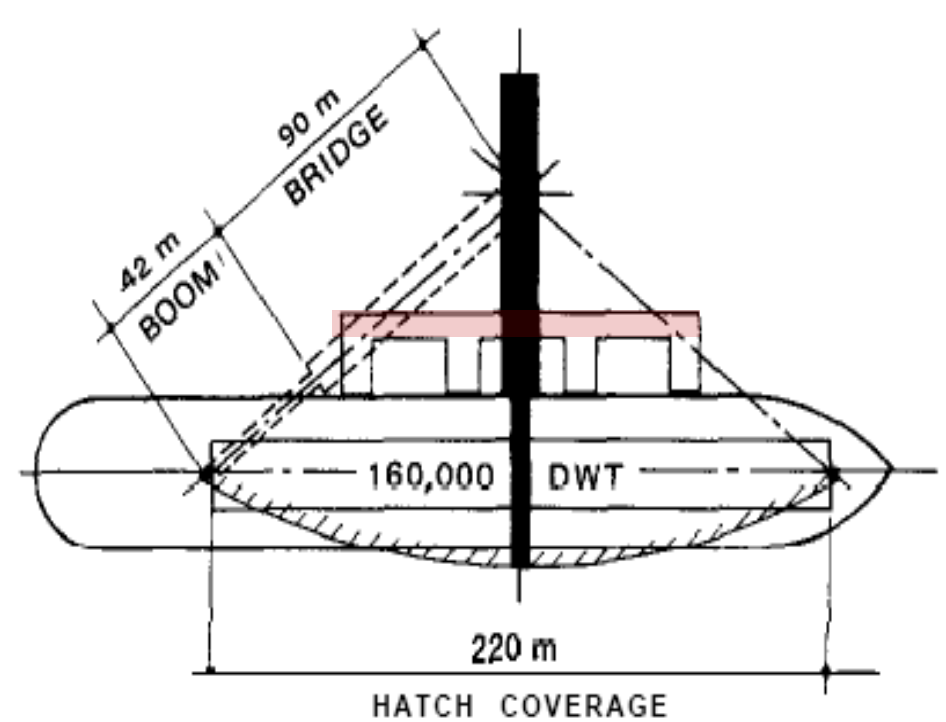

ilustração

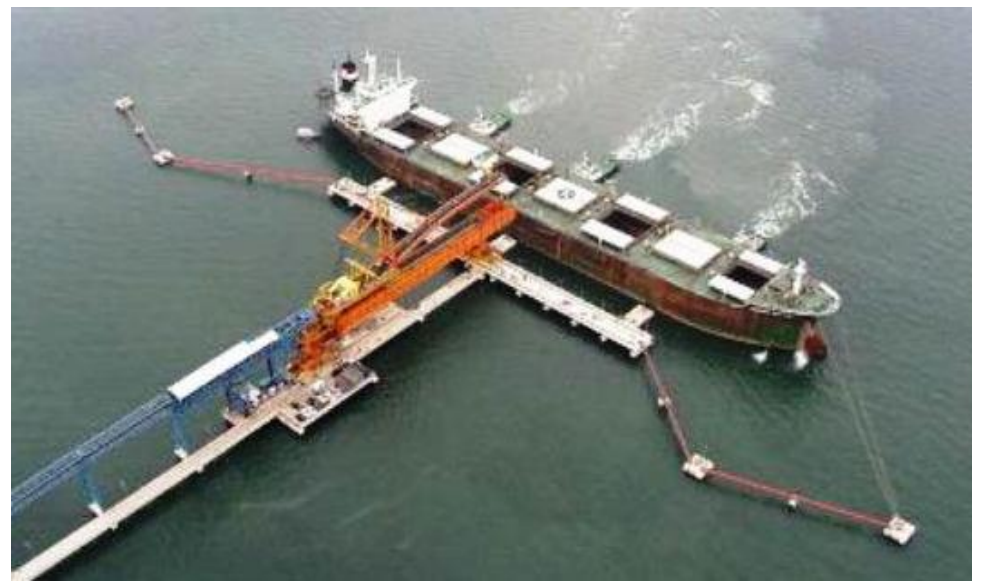

Figura 5: Exemplo de CN do tipo linear . Fonte: UNCTAD (1985) e Elgin National Industries

O tipo linear é o mais barato e o tipo travelling o mais caro, já que requer uma estrutura marítima extremamente resistente para garantir a movimentação de todo o equipamento no cais, além de necessitar de um sistema de transferência de carga móvel (tripper) que é mais caro que o fixo.

A desvantagem tanto do linear quanto do radial, quando comparado com o travelling, é a limitação do comprimento do navio que pode ser abastecido pelo CN, fator 
determinante no desempenho de terminais de minérios, que atendem navios de grande porte (normalmente acima de 100.000t de dwt).

Por isso, é comum os terminais instalarem CNs fixos com duas lanças de movimentação independentes, de forma a cobrir toda a extensão das embarcações. As lanças são abastecidas por uma única correia transportadora, que deve ser direcionada pelo operador. Essa configuração permite que se alterne o carregamento de porões sem interromper a operação, apenas redirecionando o fluxo de carga. O tipo mais usado desta configuração é o duo-radial, ilustrado na Figura 6.

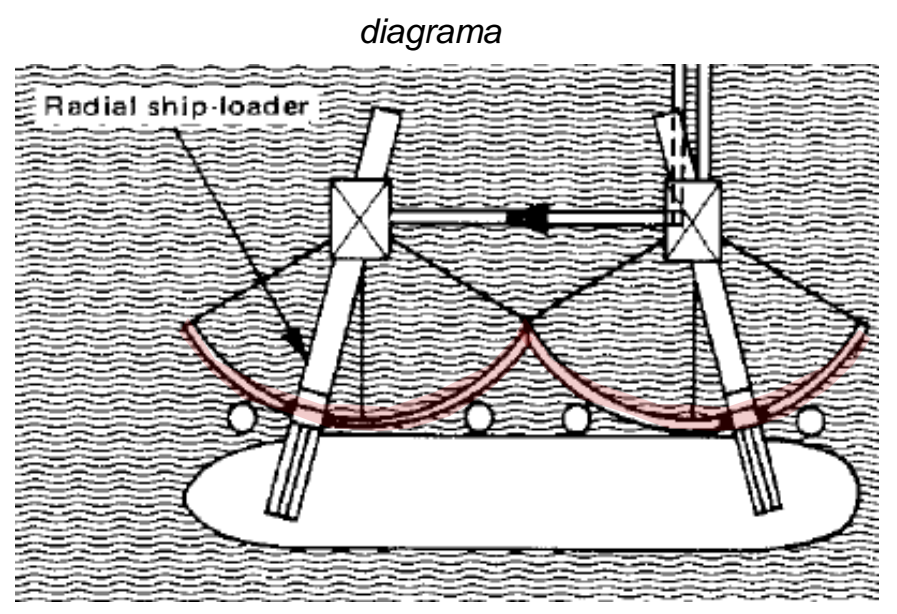

ilustração

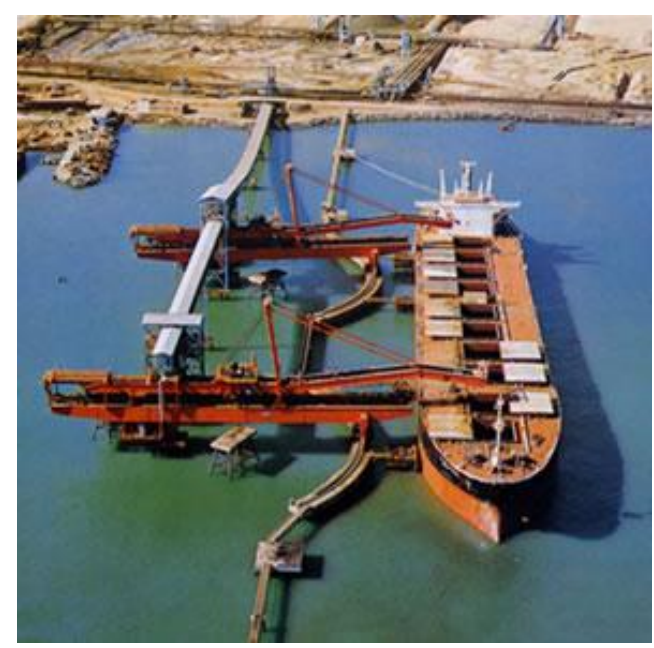

Figura 6: Exemplo de CN do tipo duo-radial. Fonte: UNCTAD (1985) e IHI Transport Machinery

Do ponto de vista financeiro, havendo demanda, é vantajoso possuir um terminal de alta capacidade ao invés de investir em dois ou mais terminais de capacidades modestas, devido aos altos custos da infraestrutura marítima e da dragagem. Por 
isso, não é raro encontrar terminais que possuam mais de um $\mathrm{CN}$ por berço. $\mathrm{A}$ utilização de dois equipamentos está associada a uma maior flexibilidade durante as manutenções e uma redução do tempo de parada operacional, pois diminui as distâncias a serem transladadas durante o plano de carga do navio. Contudo, o carregamento simultâneo depende, além da capacidade de abastecimento dos pátios, dos esforços estruturais gerados na embarcação.

Em grandes terminais exportadores, as correias transportadoras que alimentam os CNs são abastecidas por recuperadoras contínuas (RPs), tipicamente do tipo roda de caçamba, ilustrado na Figura 7. Esse equipamento recolhe o minério através de uma mesa giratória com garras que escavam as pilhas quando aproximadas.

diagrama

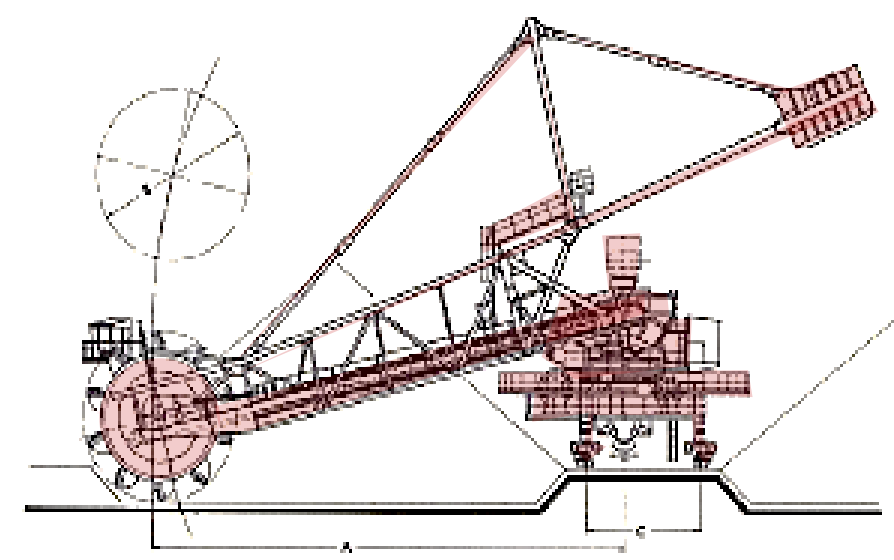

ilustração

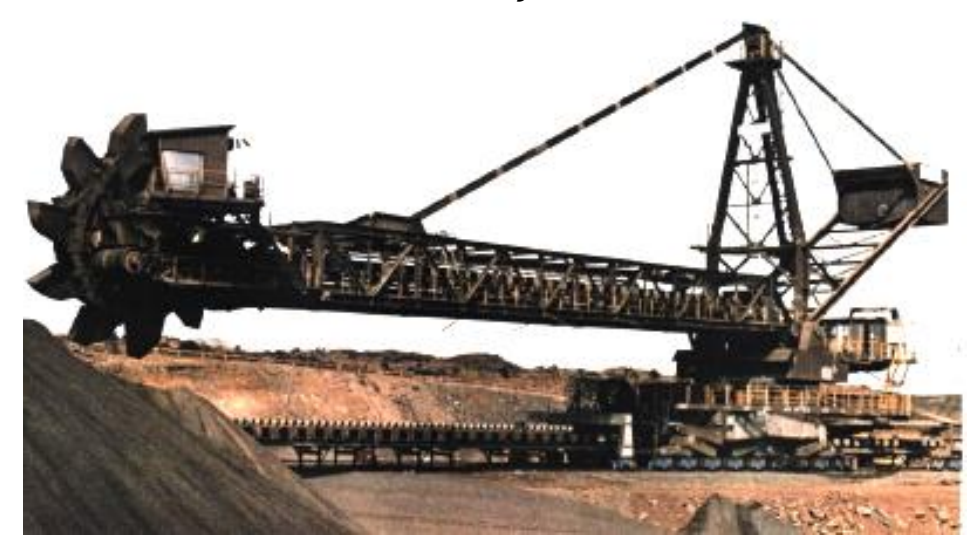

Figura 7: Exemplo de uma recuperadora roda de caçamba. Fonte: ThyssenKrupp 
A taxa de recuperação efetiva de uma RP varia bastante durante uma operação, já que depende do tamanho e posição da pilha. Normalmente, o início, as extremidades e o término das pilhas são os momentos mais críticos devido a três motivos principais: o ângulo de acomodação ${ }^{13}$ do minério não é o ideal para aproveitar o máximo de cada escavação; podem existir irregularidades no formato das pilhas que prejudiquem a retomada de produto; e a acessibilidade pode se tornar complicada nas proximidades com o solo. Neste último caso, é comum a utilização de retroescavadeiras para concentrar o resíduo mineral e possibilitar um recolhimento próximo do ideal.

$\mathrm{Na}$ armazenagem de minério de ferro utilizam-se pátios a céu aberto pavimentados com concreto asfáltico capazes de estocar uma ou mais pilhas de produtos.

Uma pilha de minério costuma ser bastante comprida, com seção transversal triangular ou trapezoidal ${ }^{14}$, a depender da disposição dos equipamentos. $O$ tamanho das pilhas de minério depende da área disponível, do layout dos pátios de armazenagem, das dimensões dos equipamentos, das características dos produtos, da quantidade de carga transportada e da programação do terminal.

De forma geral, cada terminal determina o tamanho ótimo de suas pilhas. Quanto maior o tamanho da pilha, mais eficiente é a operação de carga e descarga, pois mais tempo os equipamentos operam sem a necessidade de realizar manobras. Por outro lado, pilhas muito grandes limitam o número de máquinas disponíveis devido ao acesso aos pátios, podendo causar perda de flexibilidade em casos de manutenções.

Os pátios de minérios costumam ser espaçados com dimensão suficiente para acomodar até dois trilhos de equipamentos. A vantagem de alocar dois equipamentos em trilhos próximos é diminuir a necessidade de área com reforço estrutural. A desvantagem é que raramente esses equipamentos podem inverter sua posição no pátio, podendo gerar bloqueios e tornar parte do pátio inacessível momentaneamente.

13 O maior ângulo que o talude do monte de um determinado material solto faz com o plano horizontal sem ocorrer deslizamento à medida que mais material é adicionado. Para minérios, esse valor varia entre $30^{\circ}$ e $50^{\circ}$.

${ }^{14}$ No caso de abastecimento por ambos os lados da pilha. 
O abastecimento dos pátios é realizado por um sistema de descarga de veículos ligado a um regulador de fluxo, que está conectado a rede de correias transportadoras. O regulador de fluxo é projetado para entregar a carga de maneira contínua às empilhadeiras (EPs), que despejam o material nas pilhas de minério (Figura 8).

Tanto as EPs quanto as RPs percorrem os pátios por trilhos e possuem um sistema de elevação de carga móvel semelhante ao carregador de navios do tipo travelling.

\section{diagrama}

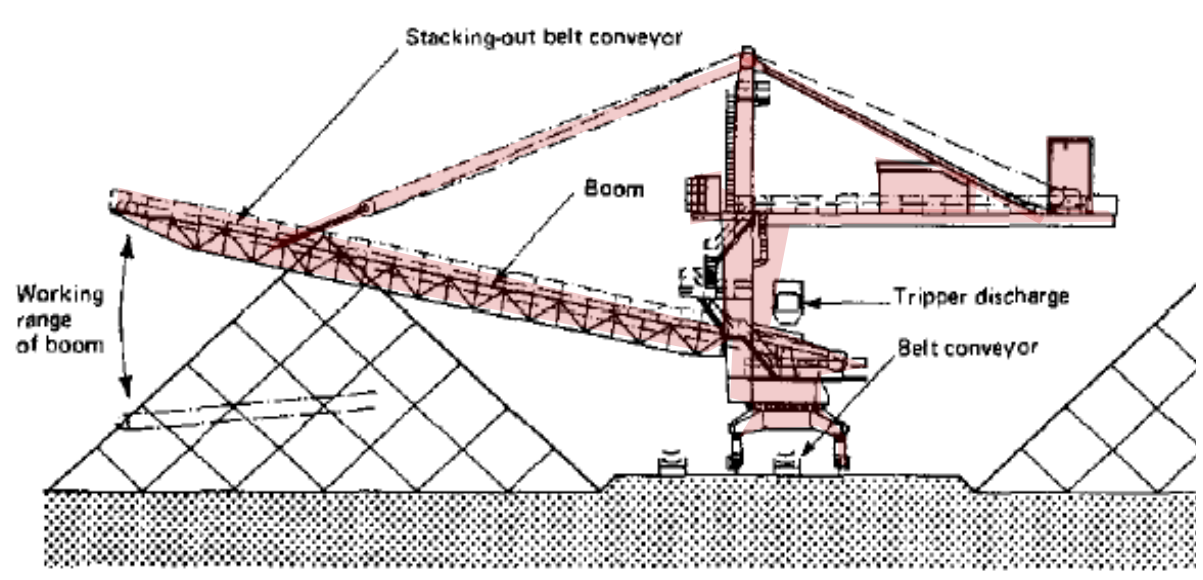

\section{ilustração}

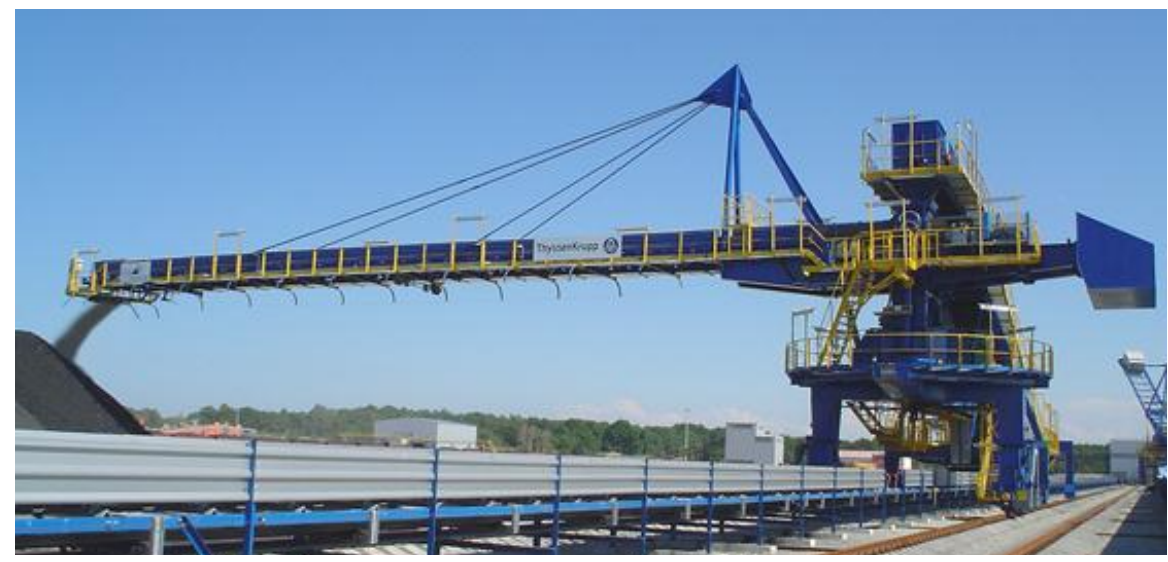

Figura 8: Exemplo de empilhadeira. Fonte: UNCTAD (1985) e ThyssenKrupp

A taxa de operação das EPs depende fundamentalmente da frequência de descarga dos veículos e da quantidade de carga no regulador de fluxo. O regulador de fluxo é um equipamento de princípio gravitacional semelhante a um funil, que assimila a 
variação da oferta dos veículos e entrega para as correias um fluxo de carga aproximadamente constante. Se a frequência de descarga for pequena a ponto de deixá-lo vazio, haverá instantes em que a EP ficará ociosa a espera de carga.

Quando as pilhas de minério estiverem próximas de ser completas, o operador deve deixar o regulador de fluxo esvaziar até parar o fornecimento de minério, permitindo que a EP se desloque até outra pilha. Por este motivo, o tamanho das pilhas são usualmente múltiplos da capacidade dos veículos descarregados.

Existe ainda um terceiro tipo de equipamento para pátios capaz de abastecer ou recolher minério das pilhas, denominado empilhadeira/recuperadora (ER), ilustrado na Figura 9. Esse equipamento alterna a direção do movimento da correia transportadora dependendo a operação a ser realizada.
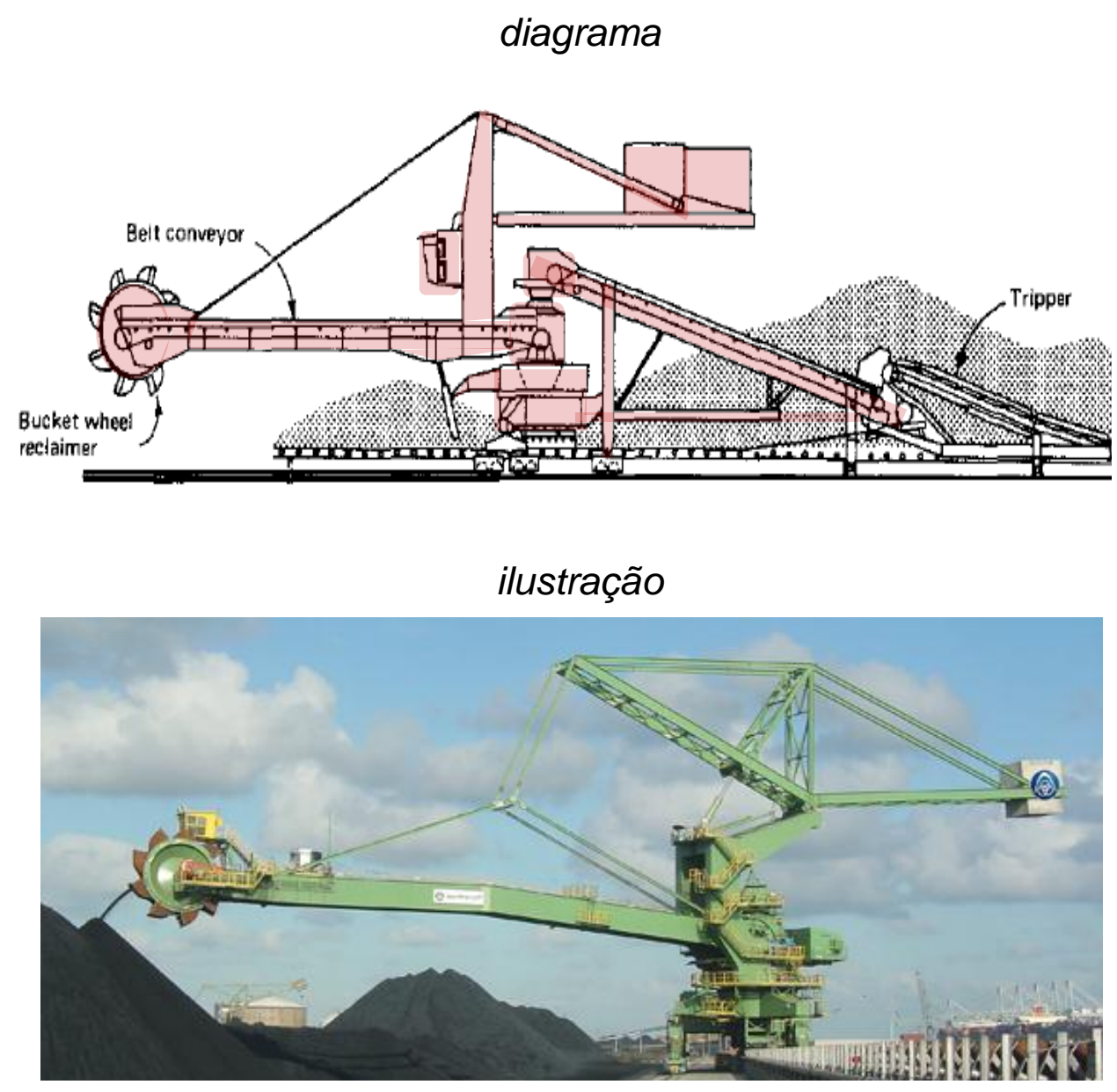

Figura 9: Exemplo de uma empilhadeira e recuperadora. Fonte: ThyssenKrupp 
A vantagem da ER é a flexibilidade que ela gera para o terminal, permitindo que um único equipamento movimente os produtos pelos pátios. Em terminais de grandes movimentações, é comum o investimento em mais de uma ER, para permitir que o embarque dos navios e o abastecimento dos pátios seja realizado de forma simultânea.

Uma aplicação alternativa das ERs é como equipamento sobressalente. Muitos terminais optam por ter redundância de equipamentos para garantir que os navios e os demais veículos de transporte não tenham que esperar as manutenções corretivas e preventivas das máquinas de pátio. O fato de a ER poder substituir tanto uma empilhadeira, quanto uma recuperadora, torna-a muito requisitada para essa finalidade.

Outro componente importante em um terminal portuário é a conexão com os modais terrestres.

Tipicamente, o minério de ferro chega até a zona portuária pelo modal ferroviário - o mais econômico para grandes distâncias e volumes.

Os três principais sistemas de descarga ferroviária para granéis sólidos são: abertura de comportas inferior dos vagões, rotação dos vagões e basculamento dos vagões.

O sistema de descarga mais produtivo para minérios é o de rotação de vagões, devido a sua velocidade e eficiência de recolhimento em cargas secas e úmidas. Nesse sistema, um lote ou composição ferroviária é posicionado em um virador de vagões (VV) capaz de acoplar um ou mais vagões e girá-lo fisicamente em um ângulo próximo de $180^{\circ}$, despejando a carga no regulador de fluxo conectado às correias transportadoras - sem a necessidade de desmembrar os vagões (Figura 10). 

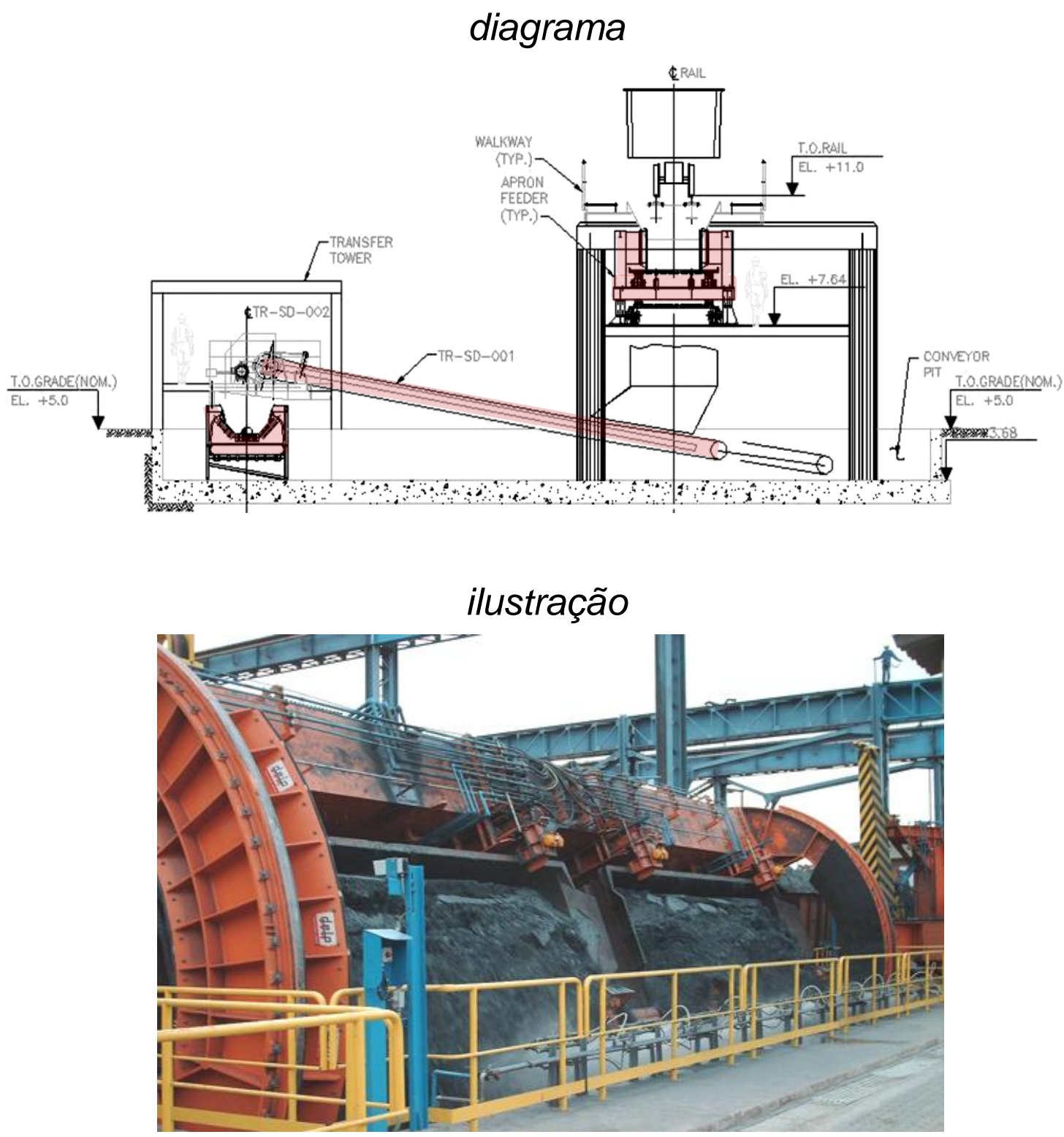

Figura 10: Exemplo de um virador de vagões. Fonte: ThyssenKrupp

Após a caracterização do sistema portuário, serão definidos os principais processos operacionais que ocorrem durante o atendimento aos navios, retomando-se a proposição fundamental do trabalho. 


\subsection{O terminal portuário visto com um conjunto de processos}

De modo geral, ocorre a seguinte sequencia de atividades e eventos durante o atendimento de uma embarcação:

- Um navio anuncia sua chegada a um porto e espera a disponibilidade do berço (se o mesmo estiver comprometido), a chegada do prático a bordo e a autorização do controlador de tráfego para navegar no canal de acesso;

- Próximo ao cais, rebocadores auxiliarão na operação de atracação do navio até que os amarradores finalizem a fixação;

- Logo após, ocorrem às vistorias das autoridades fiscais e dos agentes de segurança, que autorizam o início dos serviços de estiva e movimentação de carga no cais;

- Uma vez finalizada as operações de carga e descarga, as autoridades devem liberar novamente a embarcação para que se retomem os serviços dos amarradores, dos recobadores e do prático, a fim de que ocorra a desatracação da embarcação.

Naturalmente, essa sequencia de atividades não é exaustiva e nem completa.

Em uma organização complexa e grande como um porto, uma miríade de atividades é realizada, e cada uma está sujeita a atrasos e interrupções que se somam ao tempo total dos processos.

Para uma boa gestão de desempenho é fundamental identificar e controlar os processos críticos responsáveis pelo cumprimento dos objetivos da organização.

Ao dividir o tempo disponível de um berço em um conjunto de atividades com características operacionais semelhantes e executadas com um mesmo propósito, identificaram-se, do ponto de vista de um operador portuário, treze processos críticos, descritos no Quadro 4. Esses processos serão à base do sistema de mensuração do desempenho proposto nesse trabalho, como se verá na seção 4.1. 


\begin{tabular}{|c|c|c|}
\hline PROCESSO & SIGLA & DESCRIÇÃO \\
\hline Ociosidade & $\mathrm{OC}$ & $\begin{array}{l}\text { Soma do período em que não há nenhuma embarcação e } \\
\text { nenhuma atividade sendo realizada no terminal. Medido em } \\
\text { horas. }\end{array}$ \\
\hline Indisponibilidade & IND & $\begin{array}{l}\text { Soma do período em que alguma atividade ou evento impede a } \\
\text { atracação de navios. Exemplo: barra fechada, canal bloqueado, } \\
\text { espera por prático, etc. Medido em horas. }\end{array}$ \\
\hline $\begin{array}{l}\text { Manutenção } \\
\text { preventiva }\end{array}$ & MP & $\begin{array}{l}\text { Soma do período de paradas programadas para a conservação } \\
\text { do berço e dos equipamentos do circuito de embarque. Medido } \\
\text { em horas. }\end{array}$ \\
\hline Espera por maré & MAR & $\begin{array}{l}\text { Soma do período que impossibilita a realização de outro } \\
\text { processo devido às condições adversas de maré e correntes } \\
\text { marítimas. Medido em horas. }\end{array}$ \\
\hline $\begin{array}{l}\text { Manobras de } \\
\text { acostagem }\end{array}$ & MA & $\begin{array}{l}\text { Soma do período de atracação e desatracação dos navios. } \\
\text { Medido em horas. }\end{array}$ \\
\hline $\begin{array}{l}\text { Pré e pós } \\
\text { operacional }\end{array}$ & PR & $\begin{array}{l}\text { Soma do período que contempla as atividades entre o término } \\
\text { da atracação e o início do carregamento, e o término do } \\
\text { carregamento e o início da desatracação. Exemplos: amarração, } \\
\text { arqueação, vistoria de autoridades, etc. Medido em horas. }\end{array}$ \\
\hline $\begin{array}{c}\text { Manutenção corretiva } \\
\text { do circuito de } \\
\text { embarque }\end{array}$ & $\mathrm{MC}_{\mathrm{C}}$ & $\begin{array}{l}\text { Soma do período de interrupção por quebras e reparo no berço, } \\
\text { nos equipamentos ou nas correias que compõem o circuito de } \\
\text { embarque. Medido em horas. }\end{array}$ \\
\hline $\begin{array}{c}\text { Manutenção corretiva } \\
\text { das rotas }\end{array}$ & $M C_{R}$ & $\begin{array}{l}\text { Soma do período de interrupção por quebras e reparo nos } \\
\text { equipamentos ou nas correias que compóem a rota de } \\
\text { movimentação de cargas nos pátios. Medido em horas. }\end{array}$ \\
\hline Paradas operacionais & PO & $\begin{array}{l}\text { Soma do período de interrupção da operação devido às paradas } \\
\text { rotineiras decorrentes da operação, como troca de porão, } \\
\text { rechego da carga (ou trimming), troca de produto ou de pilha, } \\
\text { manobra de equipamentos, etc. Medido em horas. }\end{array}$ \\
\hline $\begin{array}{c}\text { Bloqueios do circuito } \\
\text { de embarque }\end{array}$ & $\mathrm{BL}_{\mathrm{C}}$ & $\begin{array}{l}\text { Soma do período de interrupção da operação no berço, nos } \\
\text { equipamentos ou nas correias que compõem do circuito de } \\
\text { embarque devido a bloqueios e falta de equipamentos no cais. } \\
\text { Medido em horas. }\end{array}$ \\
\hline Bloqueios das rotas & $\mathrm{BL}_{\mathrm{R}}$ & $\begin{array}{l}\text { Soma do período de interrupção da operação nos equipamentos } \\
\text { ou nas correias que compõem as rotas dos pátios devido a } \\
\text { bloqueios e paradas de responsabilidade do terminal, como } \\
\text { impedimento no deslocamento de máquinas, falta de } \\
\text { equipamentos disponíveis, falta de produtos nas pilhas, etc. } \\
\text { Medido em horas. }\end{array}$ \\
\hline $\begin{array}{l}\text { Paradas não } \\
\text { gerenciáveis }\end{array}$ & PNG & $\begin{array}{l}\text { Soma do período de interrupção da operação devido a paradas } \\
\text { que o terminal não é responsável ou não pode controlar, como } \\
\text { mau tempo, falta de energia, paradas a pedido do navio, etc. } \\
\text { Medido em horas. }\end{array}$ \\
\hline Operação & $\mathrm{HO}$ & $\begin{array}{l}\text { Soma do período de operação em que existe carga sendo } \\
\text { efetivamente movimentada. Medido em horas. }\end{array}$ \\
\hline
\end{tabular}

Quadro 4: Processos operacionais críticos no atendimento aos navios. Fonte: Elaborado pelo autor 


\section{METOdOLOGIA PARA A COMPARAÇÃO DE DESEMPENHO OPERACIONAL}

As maiores dificuldades ao se avaliar o desempenho de sistemas complexos concentram-se na identificação e na expurgação das particularidades físicooperacionais que podem distorcer as comparações e mascarar algumas ineficiências.

No caso específico de complexos portuários e de seus subsistemas, as principais particularidades que potencializam distorções estão, sobretudo, associadas a: idade e tipo dos equipamentos; origens de interrupções operacionais; tempos de manobra; condições climáticas (chuva, vento e maré) e de navegabilidade do canal de acesso; frotas de navios e de trens operadas; tipo de carga movimentada; arranjo do sistema e a gestão da alocação dos ativos (por exemplo, a ocupação dos berços).

Ainda que os eventos possam ser comparados, as particularidades dos sistemas inibem o estabelecimento de metas realmente atingíveis a priori. Por isso, o sistema de benchmarking desenhado buscou estabelecer indicadores capazes de identificar as diferenças entre os elementos para eliminá-las da comparação, concebendo um instrumento de gestão útil, de alto nível e com acuracidade suficiente para o propósito em questão.

O desenvolvimento desse trabalho parte da existência de uma base de dados detalhada, que indique precisamente o período de cada atividade e sua produção (movimentação de cargas). Usualmente os terminais portuários já coletam essas informações para uma aferição interna, mas raramente as divulgam e as compartilham, deixando de usufruir dos benefícios da comparação.

Nesse capítulo, é apresentada uma proposta de quais particularidades devem ser expurgadas da base comparativa para que as comparações não se distorçam, permitindo acompanhar a evolução do desempenho e determinar metas operacionais efetivamente pertinentes para cada sistema.

A metodologia adota é composta por quatro etapas descritas na Figura 11 e detalhadas nos itens a seguir. 
1)

) Determinar os processos e as eficiências que serão mensurados

2)

3)

4) Realizar o benchmarking e determinar as metas operacionais

Figura 11: Etapas da comparação de desempenho operacional. Fonte: Elaborado pelo autor

\subsection{Determinar os processos e as eficiências que serão mensurados}

O Quadro 4 apresentou os processos críticos sugeridos pelo autor, cujo controle foi classificado como fundamental para reduzir o tempo de permanência das embarcações e otimizar a utilização dos ativos portuários.

Conforme se observou na definição do OEE (página 31), a perda de produtividade nos processos incide, principalmente, em decorrência de dois fenômenos distintos:

- Ocorrência de atividades ou eventos indesejáveis que podem ser eliminados ou minimizados;

- Execução de atividades ou eventos com eficiência abaixo do padrão esperado.

Neste trabalho, o gerenciamento dos processos críticos se dará pela aferição da duração média dos processos, o que visa identificar os terminais que conseguem minimizar os efeitos das atividades e eventos indesejados.

Com exceção do processo crítico "Operação", todos os demais processos são compostos de atividades e eventos indesejáveis ou que se desejam minimizar. $\mathrm{O}$ processo "Operação", por sua vez, é afetado por fatores que diminuem sua eficiência como: a movimentação de produtos de menor densidade, que ocupam o equipamento em volume sem atingir sua capacidade em massa; a indisponibilidade 
de máquinas de pátio que subutilizam a capacidade máxima do berço; e a própria oscilação da operação de movimentação decorrente dos formatos das pilhas de minério, da precisão dos operadores, do equipamento utilizado, etc.

Serão utilizadas quatro taxas (ou índices de rendimento) para mensurar as eficiências do processo "Operação". A primeira taxa representa a taxa efetiva realizada e considera todas as perdas que ocorreram durante o processo operacional. A segunda taxa desconsidera as perdas associadas à movimentação de produtos de menor densidade que o minério do tipo Sinter Feed (produto padrão adotado). A terceira taxa desconsidera, adicionalmente, as perdas associadas à indisponibilidade de equipamentos, representando as taxas nominais médias das rotas alocadas em cada instante. Por fim, a quarta taxa representa a taxa nominal do sistema de embarque à plena capacidade.

As razões entre essas taxas permitirão mensurar as eficiências da movimentação, o impacto e o motivo das perdas (Quadro 5).

Deste modo, tanto a ocorrência de eventos indesejáveis quanto a baixa eficiência operacional poderão ser observadas e controladas.

\begin{tabular}{|c|c|l|}
\hline NOME & SIGLA & \multicolumn{1}{|c|}{ DESCRIÇÃO } \\
\hline Taxa efetiva & TE & $\begin{array}{l}\text { Taxa efetiva média de operação, calculada pela razão da quantidade } \\
\text { total movimentada sob as horas de operação. Medido em toneladas } \\
\text { por horas. }\end{array}$ \\
\hline $\begin{array}{c}\text { Taxa efetiva } \\
\text { com produto } \\
\text { padrão }\end{array}$ & $\mathrm{TE}_{\mathrm{PP}}$ & $\begin{array}{l}\text { Média da taxa efetiva normalizada pela densidade dos produtos } \\
\text { ponderada pela utilização. O Sinter Feed é considerado o produto } \\
\text { padrão, com eficiência de 100\%. Medido em toneladas por horas. }\end{array}$ \\
\hline $\begin{array}{c}\text { Taxa nominal } \\
\text { das rotas }\end{array}$ & $\mathrm{TN}_{\mathrm{R}}$ & $\begin{array}{l}\text { Média da taxa nominal das rotas ponderada pela utilização em cada } \\
\text { instante de operação. Medido em toneladas por horas. }\end{array}$ \\
\hline $\begin{array}{c}\text { Taxa nominal do } \\
\text { sistema de } \\
\text { embarque }\end{array}$ & $\mathrm{TN}$ & $\begin{array}{l}\text { Média da taxa nominal dos equipamentos que servem o berço } \\
\text { ponderada pela utilização. Medido em toneladas por horas. }\end{array}$ \\
\hline
\end{tabular}

Quadro 5: Eficiências operacionais consideradas no atendimento aos navios. Fonte: Elaborado pelo 


\subsection{Estabelecer os indicadores de desempenho}

O intuito desta etapa é obter um conjunto de indicadores de desempenho que permita, além de orientar o foco de ações de aperfeiçoamento e melhorias operacionais, eliminar da comparação possíveis diferenças entre os terminais ${ }^{15}$.

$\mathrm{O}$ esforço em segregar as atividades funcionais em processos com objetivos e características operacionais semelhantes resultou no estabelecimento de quinze indicadores (Quadro 6), dos quais três são adimensionais e relativizam a proporção de um processo indesejado sobre as horas calendário (ou seja, as horas totais do período); três possuem a dimensão "horas" e mensuram o tempo médio gasto com um processo indesejado por navio; seis são adimensionais e relativizam a proporção de um processo indesejado sobre as horas de operação efetiva; e três são adimensionais e relativizam as taxas de rendimento do transbordo para mensurar a eficiência da operação.

O desenvolvimento de tais indicadores baseou-se em duas importantes hipóteses:

- Os indicadores são independentes entre si;

- Os efeitos de segunda ordem são pouco representativos e podem ser desconsiderados.

Assim, o tempo acumulado de um processo, como por exemplo, o processo "Pré e pós-operacional", dependerá fundamentalmente de seu parâmetro de relativização no caso do exemplo escolhido o número de navios atendidos - podendo desconsiderar as pequenas variações decorrentes de outros fatores como o clima, do tamanho da embarcação, do número e a experiência dos operadores, etc.

Eventualmente, após a avaliação dos resultados dos indicadores aqui propostos, os operadores portuários poderão investigar os fatores e os efeitos de segunda ordem para orientar uma ação específica de aperfeiçoamento operacional. Este nível de detalhamento, no entanto, não será abordado neste trabalho.

\footnotetext{
${ }^{15}$ Ou seja, quando se percebe que um processo é impactado pelas diferenças entre os terminais, os indicadores de desempenho deste processo deixam de ser comparados entre todos os elementos, criando-se grupos de comparação com características semelhantes.
} 


\begin{tabular}{|c|c|c|c|c|c|}
\hline ITEM & NOME DO INDICADOR & $\begin{array}{l}\text { PARÂMETRO DE } \\
\text { RELATIVIZAÇÃO }\end{array}$ & FÓRMULA & UNIDADE & DESCRIÇÃO \\
\hline ID 1 & Índice de Ociosidade & $\begin{array}{l}\text { Horas } \\
\text { calendário }\end{array}$ & $\frac{O C}{H C}$ & - & $\begin{array}{l}\text { Tempo médio de ociosidade }(\mathrm{O} \\
\text { nas horas calendário }(\mathrm{HC}) \text {. }\end{array}$ \\
\hline ID 2 & $\begin{array}{c}\text { Índice de } \\
\text { Indisponibilidade }\end{array}$ & $\begin{array}{l}\text { Horas } \\
\text { calendário }\end{array}$ & $\frac{I N D}{H C}$ & - & $\begin{array}{l}\text { Tempo médio de indisponibilidade } \\
\text { (IND) nas horas calendário. }\end{array}$ \\
\hline ID 3 & $\begin{array}{l}\text { Índice de } \\
\text { Manutenção } \\
\text { Preventiva }\end{array}$ & $\begin{array}{l}\text { Horas } \\
\text { calendário }\end{array}$ & $\frac{M P}{H C}$ & - & $\begin{array}{l}\text { Tempo médio de manutençãa } \\
\text { preventiva do circuito de embarque } \\
\text { (MP) nas horas calendário. }\end{array}$ \\
\hline ID 4 & $\begin{array}{c}\text { Índice de Espera por } \\
\text { Maré }\end{array}$ & $\begin{array}{l}\text { Número } \\
\text { de navios }\end{array}$ & $\frac{\text { MAR }}{\# \text { Navio }}$ & Horas & $\begin{array}{l}\text { Tempo médio que cada navio } \\
\text { interrompido devido à espera po } \\
\text { maré (MAR). }\end{array}$ \\
\hline ID 5 & $\begin{array}{c}\text { Índice de Espera por } \\
\text { Manobras }\end{array}$ & $\begin{array}{l}\text { Número } \\
\text { de navios }\end{array}$ & $\frac{M A}{\# \text { Navio }}$ & Horas & 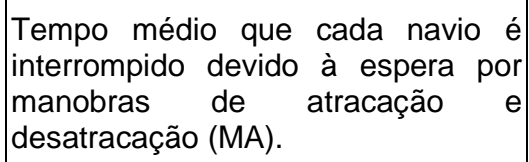 \\
\hline ID 6 & $\begin{array}{l}\text { Índice de Paradas } \\
\text { Pré e Pós } \\
\text { Operacionais }\end{array}$ & $\begin{array}{l}\text { Número } \\
\text { de navios }\end{array}$ & $\frac{P R}{\# \text { Navio }}$ & Horas & $\begin{array}{l}\text { Tempo médio que cada navio é } \\
\text { interrompido devido a paradas pré e } \\
\text { pós-operacionais (PR). }\end{array}$ \\
\hline ID 7 & $\begin{array}{c}\text { Índice de } \\
\text { Manutenção } \\
\text { Corretiva do Circuito } \\
\text { de Embarque } \\
\end{array}$ & $\begin{array}{c}\text { Horas de } \\
\text { operação efetiva }\end{array}$ & $\frac{M C_{c}}{H O}$ & - & $\begin{array}{l}\text { Tempo médio de quebras no circuito } \\
\left.\text { de embarque (MC }{ }_{C}\right) \text { por hora de } \\
\text { operação (HO). }\end{array}$ \\
\hline ID 8 & $\begin{array}{c}\text { Índice de } \\
\text { Manutenção } \\
\text { Corretiva das Rotas }\end{array}$ & $\begin{array}{c}\text { Horas de } \\
\text { operação efetiva }\end{array}$ & $\frac{M C_{r}}{H O}$ & - & $\begin{array}{l}\text { Tempo médio de quebras no } \\
\text { equipamentos das rotas }\left(M C_{R}\right) \text { pc } \\
\text { hora de operação. }\end{array}$ \\
\hline ID 9 & $\begin{array}{l}\text { Índice de Paradas } \\
\text { Operacionais }\end{array}$ & $\begin{array}{c}\text { Horas de } \\
\text { operação efetiva }\end{array}$ & $\frac{P O}{H O}$ & - & 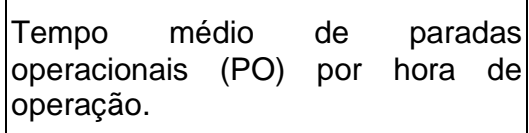 \\
\hline ID 10 & $\begin{array}{l}\text { Índice de Bloqueio do } \\
\text { Circuito de Embarque }\end{array}$ & $\begin{array}{c}\text { Horas de } \\
\text { operação efetiva }\end{array}$ & $\frac{B L_{c}}{H O}$ & - & $\begin{array}{l}\text { Tempo médio de bloqueio do berço } \\
\text { ou do circuito de embarque }\left(\mathrm{BL}_{\mathrm{C}}\right) \\
\text { por hora de operação. }\end{array}$ \\
\hline ID 11 & $\begin{array}{l}\text { Índice de Bloqueio } \\
\text { das Rotas }\end{array}$ & $\begin{array}{c}\text { Horas de } \\
\text { operação efetiva }\end{array}$ & $\frac{B L_{r}}{H O}$ & - & $\begin{array}{l}\text { Tempo médio de bloqueio nas rotas } \\
\left(B L_{R}\right) \text { por hora de operação. }\end{array}$ \\
\hline ID 12 & $\begin{array}{l}\text { Índice de Paradas } \\
\text { Não Gerenciáveis }\end{array}$ & $\begin{array}{c}\text { Horas de } \\
\text { operação efetiva }\end{array}$ & $\frac{P N G}{H O}$ & - & $\begin{array}{l}\text { Tempo médio de paradas não } \\
\text { gerenciáveis (PNG) por hora de } \\
\text { operação. }\end{array}$ \\
\hline ID 13 & $\left|\begin{array}{c}\text { Índice de Variação da } \\
\text { Densidade }\end{array}\right|$ & $\begin{array}{l}\text { Taxa efetiva com } \\
\text { produto padrão }\end{array}$ & $\frac{T E}{T E_{P P}}$ & - & $\begin{array}{l}\text { Eficiência média entre a taxa efetiva } \\
\text { realizada (TE) e a taxa efetiva com } \\
\text { produto padrão (TEPP), no caso o } \\
\text { Sinter Feed. }\end{array}$ \\
\hline ID 14 & $\begin{array}{c}\text { Índice de Variação da } \\
\text { Taxa de } \\
\text { Movimentação }\end{array}$ & $\begin{array}{l}\text { Taxa nominal } \\
\text { das rotas }\end{array}$ & $\frac{T E_{p p}}{T N_{R}}$ & - & $\begin{array}{l}\text { Eficiência média entre a taxa efetiva } \\
\text { com o produto padrão e a taxa } \\
\text { nominal das rotas }\left(\mathrm{TN}_{\mathrm{R}}\right) \text {. }\end{array}$ \\
\hline ID 15 & $\begin{array}{c}\text { Índice de Variação da } \\
\text { Taxa Nominal }\end{array}$ & $\begin{array}{l}\text { Taxa nominal } \\
\text { do sistema }\end{array}$ & $\frac{T N_{R}}{T N}$ & - & $\begin{array}{l}\text { Eficiência média entre a taxa } \\
\text { nominal das rotas e a taxa nominal } \\
\text { do sistema de embarque (TN). }\end{array}$ \\
\hline
\end{tabular}

Quadro 6: Definição dos indicadores de desempenho operacionais. Fonte: Elaborado pelo autor 
Existiu a preocupação de aumentar o grau de agregação dos processos (e consequentemente dos indicadores) para permitir que os operadores portuários continuem realizando suas análises habituais - baseadas no OEE.

Assim, inspirado no trabalho de Jeong e Phillips (2001), definiram-se três novos indicadores chave de desempenho que multiplicados compõem o OEE: o Índice de Ocupação (OCUP), o Índice de Utilização (UTIL) e o Índice de Produtividade (PROD).

$$
\text { OEE }=\text { Ocup } x \text { Util } x \text { Prod }
$$

O Índice de Ocupação avalia a proporção do tempo que o sistema esteve ocupado com algum processo operacional sobre as horas calendário do período, cujo controle é fundamental para restringir as filas e o tempo de estadia dos navios no porto ${ }^{16}$. A ociosidade, as perdas por indisponibilidades e a manutenção preventiva reduzem o índice, conforme mostra a equação a seguir:

$$
\begin{gathered}
\text { Ocup }=\frac{H C-O C-I N D-M P}{H C} \\
\text { Ocup }=1-\frac{O C}{H C}-\frac{I N D}{H C}-\frac{M P}{H C} \\
\text { Ocup }=1-I D 1-I D 2-I D 3
\end{gathered}
$$

O Índice de Utilização mede a proporção do tempo de operação efetiva sobre o tempo que o sistema esteve ocupado com a operação. As interrupções e os

\footnotetext{
${ }^{16}$ Para maiores informações recomenda-se a leitura de "Measuring and Evaluating Port Performance and Productivity", elaborado por De Monie em 1987.
} 
processos indesejáveis que ocorrem durante a operação reduzem o indicador, conforme se observa nas equações a seguir:

$$
\begin{gathered}
U t i l=\frac{H O}{H C-O C-I N D-M P}(14) \\
U t i l=\frac{H O}{H O+M C_{c}+M C_{r}+P O+B L_{c}+B L_{r}+P N G+M A R+M A+P R} \\
U t i l=\frac{1}{1+\left(\frac{M C_{C}}{H O}+\frac{M C_{r}}{H O}+\frac{P O}{H O}+\frac{B L_{C}}{H O}+\frac{B L_{r}}{H O}+\frac{P N G}{H O}\right)+\left(\frac{M A R}{\# N a v i o}+\frac{M A}{\# N a v i o}+\frac{P R}{\# N a v i o}\right) \cdot\left(\frac{T E}{T E_{P P}} \cdot \frac{T E_{P P} P}{T N_{R}} \cdot \frac{T N_{R}}{T N}\right) \cdot \frac{\mathrm{TN}}{D W T}} \\
U t i l=\frac{1}{1+\left(I D 7+I D \text { 8+ID 9+ID 10+ID 11+ID 12)+(ID 4 +ID 5+ID 6).(ID 13+ID 14+ID 15) } \cdot \frac{\mathrm{TN}}{D W T}\right.}
\end{gathered}
$$

Onde:

DWT: Capacidade média de carga das embarcações

O Índice de Utilização é função da taxa nominal do sistema de embarque (TN) e da capacidade média dos navios atendidos (DWT), que são parâmetros peculiares a cada terminal. $O$ impacto da alteração desses parâmetros no desempenho portuário pode ser mensurado pelo indicador, o que é uma das vantagens da estrutura proposta.

Por fim, o Índice de Produtividade mede as perdas que ocorrem durante a operação de carregamento, correspondendo à razão entre a taxa efetiva de operação e a taxa nominal dos equipamentos que servem o berço, como se pode ver na equação a seguir:

$$
\text { Prod }=\frac{T E}{T E_{P P}} \cdot \frac{T E_{P P}}{T N_{R}} \cdot \frac{T N_{R}}{T N}
$$




$$
\text { Prod }=I D 13 \cdot I D 14 \cdot I D 15
$$

O OEE, então, pode ser representado pelos indicadores de desempenho definidos da seguinte forma:

$$
\begin{aligned}
O E E= & (1-I D 1-I D 2-I D 3) \cdot \\
& \left(\frac{1}{1+(I D 6+I D 7+I D 8+I D 9+I D 10+I D 11)+(I D 3+I D 4+I D 5) \cdot(I D 13 \cdot I D 14 \cdot I D 15) \cdot \frac{\mathrm{TN}}{D W T}}\right) \\
& (I D 13 \cdot I D 14 \cdot I D 15)
\end{aligned}
$$

A formulação possibilita aferir a relação de cada indicador com o desempenho global do sistema e com a quantidade de carga movimentada, bastando para isso multiplicar o resultado do OEE pelas horas calendário do período e pela capacidade nominal do sistema de embarque, como mostra a equação seguinte.

$$
\text { Quantidade Movimentada }=O E E \cdot H C \cdot T N
$$

Essa estrutura associada ao processo de benchmarking fornece uma previsão de ganho de produtividade potencial com o atingimento das metas operacionais, além de indicar quais ações devem ser priorizadas para que se obtenham os maiores ganhos.

\subsection{Eliminar da comparação os indicadores afetados por particularidades}

Nem todos os indicadores propostos podem ser comparados entre todos os terminais quando se deseja estabelecer metas operacionais. Existem grupos de sistemas que gozam de propriedades diferentes e por isso devem ser considerados 
separadamente dos demais quando se avalia um determinado indicador, formando assim diversos grupos de comparação. Alguns indicadores, inclusive, não devem ser comparados entre nenhum outro terminal (como o indicador que mede a interferência da maré, ID 4, por exemplo). Entretanto, o conjunto de indicadores concebido permite isolar esses indicadores não comparáveis, o que é um grande benefício.

No limite, sempre existirá alguma característica peculiar a cada sistema que interferirá marginalmente no desempenho operacional. No entanto, para que o sistema seja útil na prática, deve se empenhar somente na segregação das características mais importantes, de modo que se viabilize a comparação entre o maior número de berços possível de maneira adequada.

Neste trabalho, julgou-se pertinente expurgar da comparação os indicadores que dependem diretamente de fatores climáticos e de condições naturais do local, como a espera por variação da maré (ID 4), o tempo de navegação no canal e acostagem (ID 5) e as paradas devido a intempéries (ID 2 e ID 12). Além destes, foram expurgados os indicadores que dependem de agentes externos e que são de cunho estratégico para a empresa, como a ociosidade (ID 1), a política de manutenção preventiva (ID 3), a densidade dos produtos movimentados (ID 13) e as paradas externas (ID 12).

O Quadro 7 apresenta uma lista com os principais atributos que deverão ser levados em consideração na comparação de cada indicador. O Quadro sugere também os indicadores potencialmente comparáveis entre todos os terminais e os que necessariamente deverão ser expurgados. 


\begin{tabular}{|c|c|c|c|c|c|c|c|c|}
\hline & \multirow{3}{*}{ 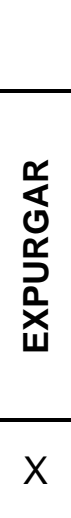 } & \multirow[b]{2}{*}{ 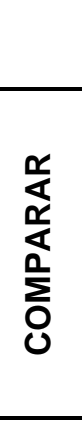 } & \multicolumn{5}{|c|}{$\begin{array}{c}\text { COMPARAR DESDE QUE POSSUAM } \\
\text { SEMELHANÇA ENTRE }\end{array}$} \\
\hline & & & & 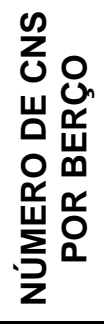 & 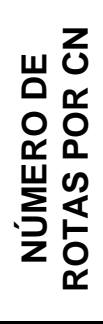 & 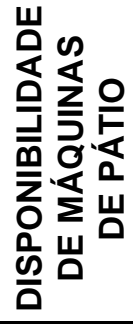 & 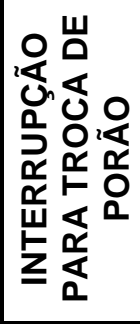 & 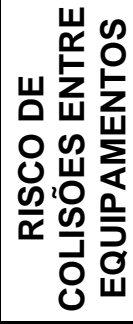 \\
\hline OEE & $\begin{array}{l}\text { Índice de Eficiência } \\
\text { Global do Equipamento }\end{array}$ & & & & & & & \\
\hline OCUP & Índice de Ocupação & $x$ & & & & & & \\
\hline UTIL & Índice de Utilização & $X$ & & & & & & \\
\hline PROD & Índice de Produtividade & $X$ & & & & & & \\
\hline ID 1 & Índice de Ociosidade & $X$ & & & & & & \\
\hline ID 2 & $\begin{array}{c}\text { Índice de } \\
\text { Indisponibilidade }\end{array}$ & $X$ & & & & & & \\
\hline ID 3 & $\begin{array}{l}\text { Índice de Manut. } \\
\text { Preventiva }\end{array}$ & $X$ & & & & & & \\
\hline ID 4 & $\begin{array}{l}\text { Índice de Espera } \\
\text { por Maré }\end{array}$ & $X$ & & & & & & \\
\hline ID 5 & $\begin{array}{l}\text { Índice de Espera } \\
\text { por Manobras }\end{array}$ & $X$ & & & & & & \\
\hline ID 6 & $\begin{array}{c}\text { Índice de Paradas Pré e } \\
\text { Pós Operacionais }\end{array}$ & & $X$ & & & & & \\
\hline ID 7 & $\begin{array}{l}\text { Índice de Manut. Corret. } \\
\text { Circuito de Embarque }\end{array}$ & & & $\mathrm{X}$ & & & & \\
\hline ID 8 & $\begin{array}{l}\text { Índice de Manut. } \\
\text { Corretiva das Rotas }\end{array}$ & & & $\mathrm{X}$ & $\mathrm{X}$ & $\mathrm{X}$ & & \\
\hline ID 9 & $\begin{array}{l}\text { Índice de Paradas } \\
\text { Operacionais }\end{array}$ & & & $x$ & & & $\mathrm{X}$ & \\
\hline ID 10 & $\begin{array}{l}\text { Índice de Bloqueio do } \\
\text { Circuito de Embarque }\end{array}$ & & & $\mathrm{X}$ & & & & $x$ \\
\hline ID 11 & $\begin{array}{l}\text { Índice de Bloqueio } \\
\text { das Rotas }\end{array}$ & & & $\mathrm{X}$ & $\mathrm{X}$ & $\mathrm{X}$ & & \\
\hline ID 12 & $\begin{array}{l}\text { Índice de Paradas } \\
\text { Não Gerenciáveis }\end{array}$ & $X$ & & & & & & \\
\hline ID 13 & $\begin{array}{l}\text { Índice de Variação } \\
\text { da Densidade }\end{array}$ & $X$ & & & & & & \\
\hline ID 14 & $\begin{array}{l}\text { Índice de Variação da } \\
\text { Taxa de Movimentação }\end{array}$ & & $X$ & & & & & \\
\hline ID 15 & $\begin{array}{l}\text { Índice de Variação da } \\
\text { Taxa Nominal }\end{array}$ & & & $\mathrm{X}$ & $X$ & $\mathrm{X}$ & & \\
\hline
\end{tabular}

Quadro 7: Identificação do grupo de comparação para os indicadores. Fonte: Elaborado pelo autor 


\subsection{Realizar o Benchmarking e determinar as metas operacionais}

O objetivo dessa etapa é comparar o desempenho de cada indicador entre os membros de cada grupo de comparação.

No caso de amostras pequenas, o que deve ocorrer com frequência em se tratando de terminais portuários, sugere-se um processo de benchmarking que analise diversos períodos de cada sistema - por exemplo, uma análise mensal para um período de um ano. Deste modo, os registros serão comparados entre um mesmo berço e entre berços de diferentes terminais.

As metas (ou valores benchmark) de cada grupo de comparação serão definidas como a média dos $25 \%$ dos registros mensais mais eficientes (média do quartil superior). Assim, não existirá um terminal benchmark e sim um índice benchmark, que poderá ser observado em diversos terminais.

É importante notar que o valor da meta poderia ser definido de inúmeras outras maneiras. Da forma como foi estabelecido representa um valor referência de alto desempenho que pode ser atingido e até ultrapassado. Alguns de seus benefícios são:

- Existirá uma meta a ser perseguida por todos os terminais - uma vez que mesmo os elementos mais eficientes costumam apresentar oscilações de produtividade que podem ser eliminadas;

- Não desestimula os operadores porque é um valor potencialmente atingível inclusive já foi alcançado e ultrapassado no período analisado;

- Busca a redução das oscilações;

- Busca o melhoramento contínuo.

A Figura 12 exemplifica o cálculo do índice benchmark para o indicador ID 6, que mede as atividades pré e pós-operacionais. No exemplo, os resultados do período são ordenados para se determinar a média do quarto quartil da amostra. 
Média mensal do indicador

[h/embarcação]
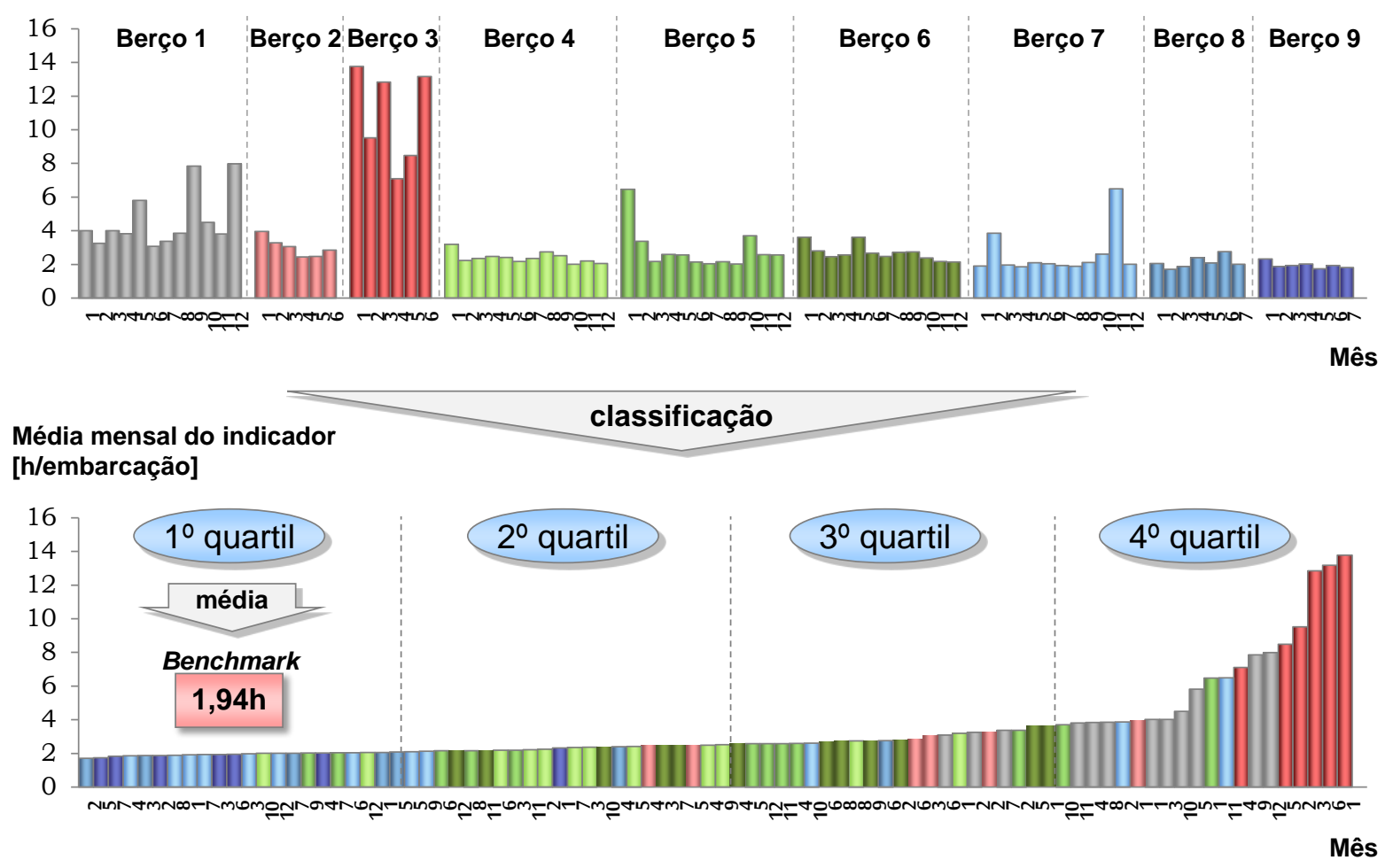

Figura 12: Cálculo do benchmark para o Índice de Paradas Pré e Pós Operacionais. Fonte: Elaborado pelo autor

Após a determinação das metas, os gestores dos berços devem concentrar seus esforços em ações que permitam alcançar tais valores. O estabelecimento das ações é particular de cada sistema e deve resultar de observações em visitas técnicas e estudos de procedimento padrão. Eventualmente, pode-se verificar a existência de fatores externos (não considerados neste trabalho) que impossibilite o alcance da meta por parte dos berços. Neste caso, devem-se reavaliar os grupos de comparação e estabelecer novas metas para os elementos.

O método proposto permite estimar o aumento de movimentação (ou ganho potencial) admissível se o índice benchmark puder ser alcançado por cada indicador $^{17}$.

A Figura 13 ilustra um exemplo em que se determina o aumento do volume de um berço arbitrário, se o mesmo atingir a meta estipulada no exemplo anterior (ID $6=$ $1,94 \mathrm{~h}$, Figura 12). Nesse caso, a redução de $27 \%$ do indicador (de $2,65 \mathrm{~h}$ para $1,94 \mathrm{~h}$ )

\footnotetext{
${ }^{17}$ Uma vez que é conhecida a relação de cada indicador com o OEE (página 56).
} 
implicaria em uma diminuição do tempo médio de atendimento de cerca de 40 minutos por navio, o que aumentaria o volume movimentado em 1,7Mt em um ano, mantendo a mesma ocupação.
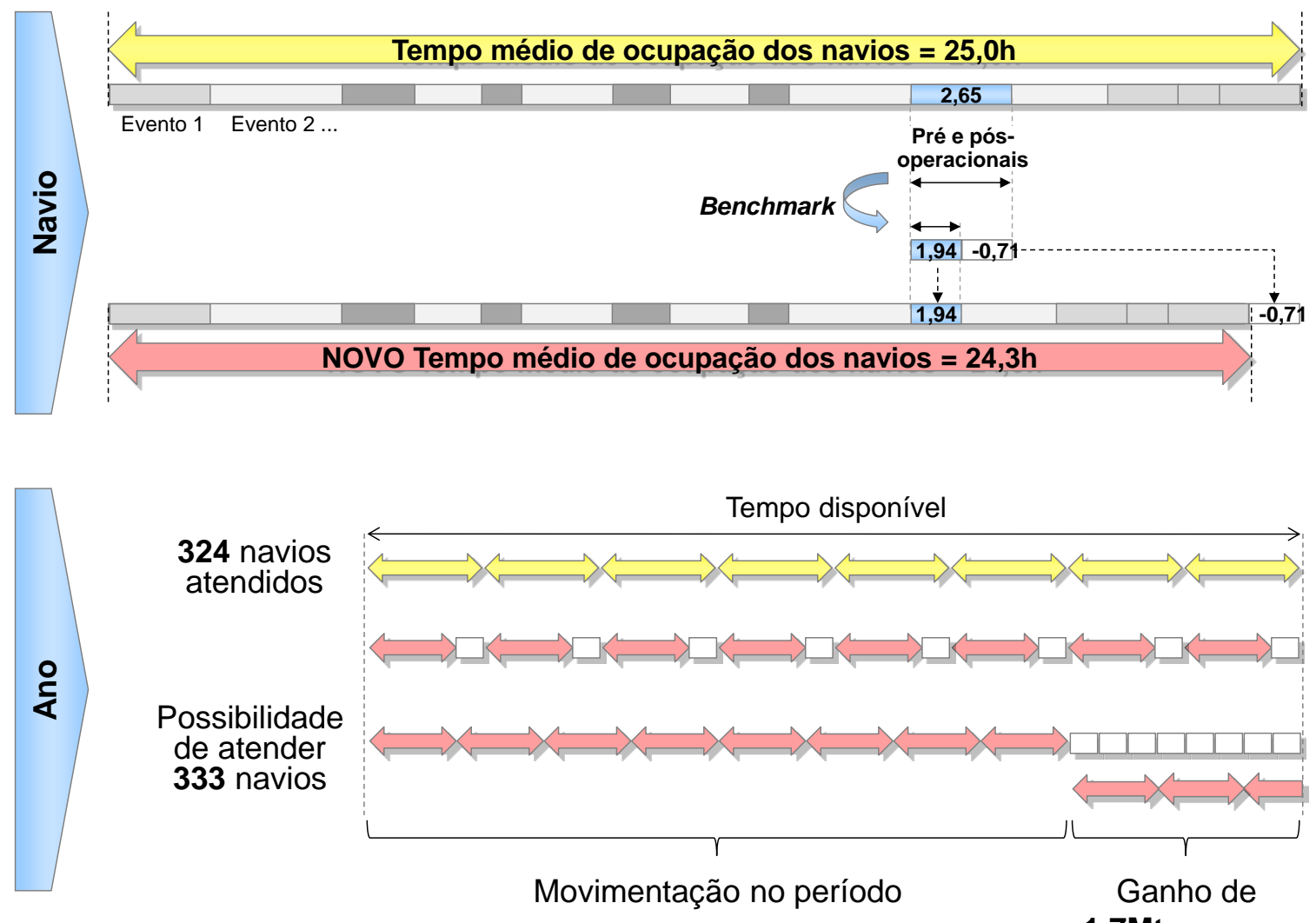

Figura 13: Estimativa de movimentação adicional para o Índice de Paradas Pré e Pós Operacionais. Fonte: Elaborado pelo autor

Ao replicar esse procedimento para todos os indicadores comparáveis, determina-se o potencial teórico de cada berço. A Figura 14 ilustra um exemplo dessa análise, indicando um aumento potencial de 10,4Mt na movimentação para o mesmo berço arbitrário do exemplo anterior. 


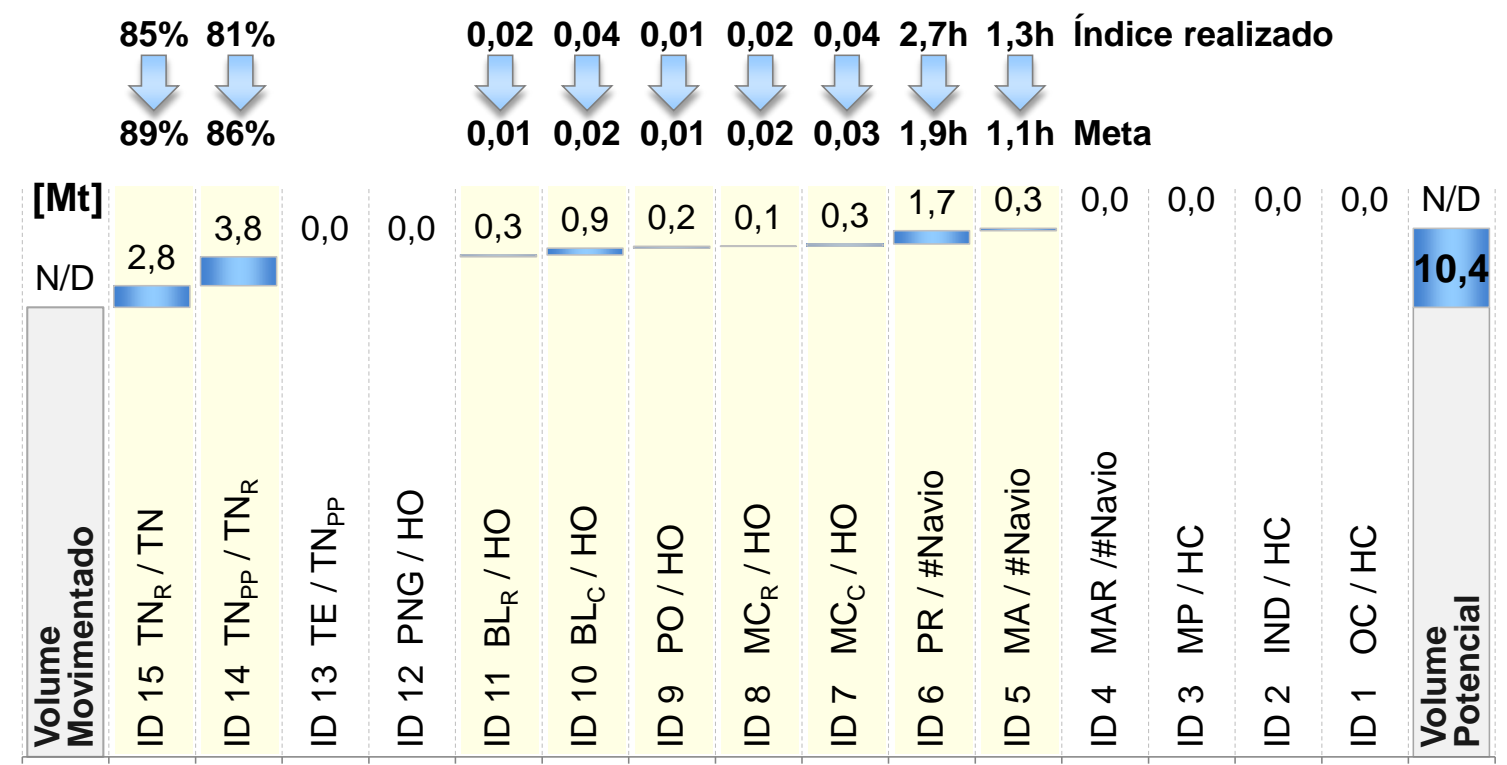

Figura 14: Exemplo da aplicação da estrutura de indicadores para estimar os ganhos potenciais. Fonte: Elaborado pelo autor

Dessa forma, a estrutura proposta permite que o gestor portuário amplie sua capacidade de análise com a possibilidade de:

- Identificar as principais fontes de perdas operacionais;

- Comparar o desempenho com terminais semelhantes;

- Determinar as metas operacionais de cada berço; e

- Estimar os ganhos potências para os terminais.

Uma aplicação prática dessas análises será apresentada no capítulo a seguir, no qual se comparará o desempenho de nove berços de um grande operador de granéis sólidos do Brasil. 


\section{ESTUDO DE CASO}

Com o intuito de ilustrar a metodologia proposta e sua utilidade como ferramenta de gestão, desenvolveu-se um estudo de caso $^{18}$ aplicando-a a quatro terminais de exportação de minérios de um único operador brasileiro. Ao todo serão analisados nove berços de diferentes capacidades e equipamentos.

A disponibilidade de acesso aos dados operacionais foi o fator preponderante na escolha da amostra estudada. Os dados do operador foram coletados mediante o levantamento de apontamentos operacionais consolidados em um banco de dados, fornecidos pelos gerentes dos terminais.

Este estudo vale-se de uma abordagem exploratória-qualitativa na tentativa de ampliar a compreensão dos fenômenos estudados e confrontar o referencial teórico pesquisado com o meio em que os terminais estão inseridos.

Como característica de pesquisas qualitativas, não se espera obter generalizações estatísticas acerca do universo pesquisado. Contudo, conforme explica Yin apud Miglioli (2006), as proposições teóricas que baseiam o estudo podem ser generalizadas.

Dessa forma, o estudo de caso será apresentado em quatro seções:

- Na primeira seção são descritas as principais características dos berços analisados;

- Na segunda seção é descrito o método de tratamento e consolidação dos dados coletados;

- Na terceira seção são apresentados os resultados dos indicadores propostos e são tecidos comentários sobre as principais diferenças observadas e a influência das características dos terminais no desempenho global;

\footnotetext{
${ }^{18}$ Entre os métodos qualitativos, o estudo de caso mostra-se potencialmente valioso na exploração das ligações causais em intervenções ou situações da vida real que são complexas demais para tratamento através de estratégias experimentais (MIGLIOLI, 2006).
} 
- Na quarta seção são determinadas as metas operacionais para cada indicador comparável (por grupo de comparação) e os ganhos de produtividades teóricos que se poderia alcançar em cada terminal.

\subsection{Principais considerações sobre os terminais analisados}

O operador portuário não autorizou a publicação da descrição detalhada dos sistemas. Assim, o Quadro 8 sintetiza somente as propriedades mais relevantes de cada berço, de forma a possibilitar a realização da comparação do desempenho.

\begin{tabular}{|c|c|c|}
\hline BERÇO & $\begin{array}{l}\text { NÚMERO E } \\
\text { TIPO DO CN }\end{array}$ & $\begin{array}{c}\text { PRINCIPAIS } \\
\text { CARACTERÍSTICAS }\end{array}$ \\
\hline $\begin{array}{c}\text { Berço 1 } \\
\text { (Terminal 1) }\end{array}$ & $\begin{array}{l}1 \mathrm{CN} \text { do tipo } \\
\text { travelling de } \\
\text { capacidade } \\
\text { nominal de } 10.000 \\
\text { toneladas } \\
\text { por hora (tph); } \\
\text { Alimentado por } \\
\text { duas rotas dos } \\
\text { pátios; }\end{array}$ & $\begin{array}{l}\text { Comprimento do berço: } 310 \mathrm{~m} \text {; } \\
\text { Calado: } 17,5 \mathrm{~m} \text {; } \\
\text { Viradores de vagões: } 1 \text { de } 7.000 \text { tph } \\
\text { Máquinas de pátio: } 2 \text { ERs de 4.500tph na } \\
\text { recuperação e 7.000tph no empilhamento; } \\
\text { Outros: Faltam equipamentos de pátio, o que força } \\
\text { o sistema a realizar o embarque direto da descarga } \\
\text { ferroviária (sem passar pelos pátios) para } \\
\text { aproveitar a máxima capacidade do CN e do VV } \\
\text { nas operações simultâneas; } \\
\text { Canal de acesso longo que não pode ser trafegado } \\
\text { em duas mãos. }\end{array}$ \\
\hline \begin{tabular}{|c|} 
navio \\
Berço 2 \\
Berço 3 \\
navio \\
\end{tabular} & $\begin{array}{l}\text { 1 CN do tipo } \\
\text { travelling de } \\
\text { capacidade } \\
\text { nominal de } 13.800 \\
\text { tph, compartilhado } \\
\text { com o Berço 3; } \\
\text { Alimentado por } \\
\text { duas rotas; }\end{array}$ & $\begin{array}{l}\text { Comprimento do berço: } 390 \mathrm{~m} \text {; } \\
\text { Calado: } 19 \mathrm{~m} \text {; } \\
\text { Viradores de vagões: } 1 \text { de } 8.800 \text { tph e } 1 \text { de } \\
\text { 8.000tph; } \\
\text { Máquinas de pátio: } 3 \text { ERs de } 8.800 \text { tph para } \\
\text { empilhamento e } 8.400 \text { tph para recuperação; } \\
\text { Outros: O fato do Berço } 2 \text { e } 3 \text { possuir somente um } \\
\text { CN faz com que, na maior parte do tempo, um } \\
\text { berço fique bloqueado esperando o término do } \\
\text { carregamento de seu vizinho; } \\
\text { Faltam equipamentos de pátio, o que força o } \\
\text { sistema a realizar o embarque direto para } \\
\text { aproveitar a máxima capacidade do CN e dos VVs } \\
\text { nas operações simultâneas. }\end{array}$ \\
\hline \begin{tabular}{|c|}
\multicolumn{1}{c}{ navio } \\
Berço 2 \\
Z Berço 3 \\
navio \\
\end{tabular} & $\begin{array}{l}\text { Mesmo CN do } \\
\text { Berço 2, que deve } \\
\text { ser compartilhado; } \\
\text { Alimentado por } \\
\text { duas rotas; }\end{array}$ & $\begin{array}{l}\text { Comprimento do berço: } 390 \mathrm{~m} \text {; } \\
\text { Calado: } 24 \mathrm{~m} \text {; } \\
\text { As demais características são semelhantes ao } \\
\text { Berço } 2 \text {. }\end{array}$ \\
\hline
\end{tabular}




\begin{tabular}{|c|c|}
\hline $\begin{array}{c}\text { Berço } 4 \\
\text { (Terminal 3) }\end{array}$ & $\begin{array}{l}1 \mathrm{CN} \text { do tipo } \\
\text { travelling de } \\
\text { capacidade } \\
\text { nominal de } 8.000 \\
\text { tph; }\end{array}$ \\
\hline O Berço 4 & Alimentado por \\
\hline Z Berço 5 & $\begin{array}{l}\text { Eventualmente } \\
\text { compartilhado com } \\
\text { o berço Berço } 5\end{array}$ \\
\hline
\end{tabular}

Comprimento do berço: $320 \mathrm{~m}$;

Calado: $17 \mathrm{~m}$;

Viradores de vagões: 4 de 6.000tph;

Máquinas de pátio: 5 RPs (2 de 6.000tph e 3 de 8.000tph), 4 EPs (3 de 6.000tph e 1 de 16.000tph) e 3 ERs (de 8.000tph para empilhamento e recuperação), além de 4 RPs e 7 EPs nos pátios das sete pelotizadoras.

Outros: Embora ocorra raramente, ambos os CNs do Berço 4 e 5 podem ser utilizados em apenas um navio.

\begin{tabular}{|c|c|c|}
\hline $\begin{array}{c}\text { Berço 5 } \\
\text { (Terminal 3) } \\
\text { z navio } \\
\text { Berço } 4\end{array}$ & $\begin{array}{l}1 \mathrm{CN} \text { do tipo } \\
\text { travelling de } \\
\text { capacidade } \\
\text { nominal de } 6.000 \\
\text { tph; }\end{array}$ & $\begin{array}{l}\text { Comprimento do berço: } 285 \mathrm{~m} \text {; } \\
\text { Calado: } 13 \mathrm{~m} \text {; } \\
\text { As demais características são semelhantes ao }\end{array}$ \\
\hline Z Berço 5 & $\begin{array}{l}\text { Alimentado por } \\
\text { uma rota; }\end{array}$ & Berço 4. \\
\hline
\end{tabular}
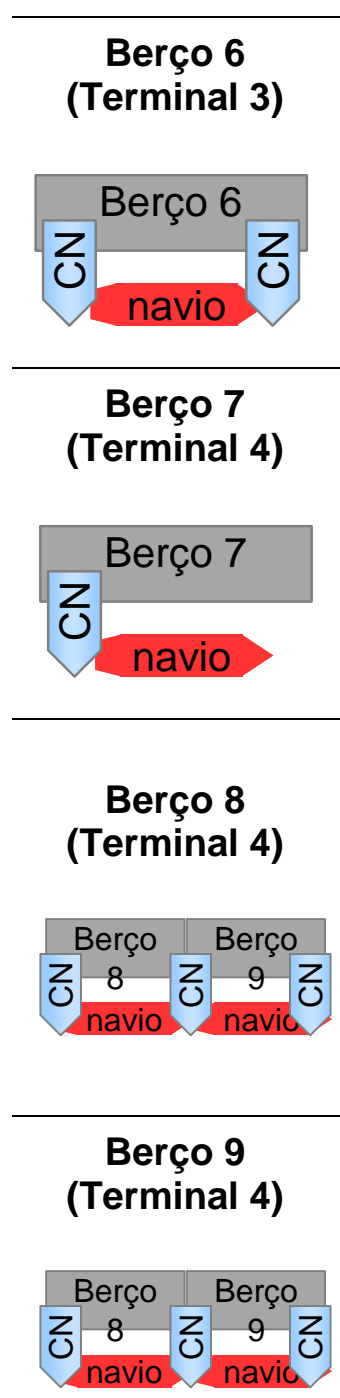

1 CN do tipo duo-

radial de capacidade nominal de 16.000 tph;

Alimentado por duas rotas;

$1 \mathrm{CN}$ do tipo travelling de capacidade nominal de 16.000 tph;

Alimentado por duas rotas;

3 CNs do tipo travelling de capacidade nominal de 8.000 tph, compartilhados com o Berço 9;

Alimentados por uma rota cada;
Comprimento do berço: $350 \mathrm{~m}$;

Calado: 20m;

As demais características são semelhantes ao Berço 4.

Mesmos 3 CNs do

Berço 8, que

devem ser

compartilhados; $\quad$ As características são semelhantes ao Berço 8.

Comprimento do berço: 330m;

Calado: 23m;

Viradores de vagões: 3 de 8.000tph;

Máquinas de pátio: 3 RPs (de 8.000 tph), 3 EPs (1 de 8.000 tph e 2 de 16.000 tph) e 4 ERs (de 8.000 tph), além de 1 RP e 2 EPs para as usinas pelotizadoras e de peneiramento.

\section{Comprimento do berço: 490m (2 berços);}

Calado: 21m;

Outros: $O$ fato dos Berços 8 e 9 possuírem três CNs faz com que, na maior parte do tempo, cada berço opere com um único carregador e tenha auxílio do $\mathrm{CN}$ sobresselente nas trocas de porão e em partes do carregamento;

As demais características são semelhantes ao Berço 6.

Alimentado por

uma rota; 


\subsection{Tratamento e consolidação dos dados operacionais}

O operador portuário não dispunha de uma base de dados nos padrões requeridos para o estudo de caso. $O$ tratamento dos dados consumiu enorme esforço e só foi possível com o auxílio de uma rotina computacional desenvolvida exclusivamente para esse fim. A seguir serão descritos o tratamento dos dados e a lógica da rotina computacional.

Para cada berço analisado, foram fornecidas quatro bases de dados oriundas de seu sistema de apontamento:

1. Planilhas Movimento - base que contém os instantes em que cada rota esteve comprometida com a operação e seu volume movimentado.

2. Planilhas Paradas Movimento - base que contém os instantes das paradas de todos os equipamentos e seu motivo.

3. Planilhas Evento Embarque - base que contém todos os eventos relativos a um navio, mas com nível de detalhe limitado. Indica os momentos de manobras, de paradas operacionais, operação, dentre outros, mas não informa o motivo das paradas, os equipamentos utilizados, os volumes operados, etc.

4. Planilha Vacância Píer - base que contém os intervalos de tempos ociosos e os eventos que ocorreram entre as manobras de desatracação de um navio e atracação do navio seguinte.

Estas bases de dados não se comunicam entre si e abrangem períodos operacionais distintos. Por isso, se desenvolveu uma rotina computacional em VBA (Visual Basic for Aplications) para consolidar as informações das diversas fontes através da composição temporal entre os eventos apontados.

A lógica da rotina computacional consiste em cruzar os instantes de todos os movimentos e paradas realizadas durante a operação (base de dados 1 e 2) formando uma nova base com as informações consolidadas, identificada como $B A S E \_$. Adotou-se como premissa que as taxas efetivas de movimentação variam pouco durante a operação de uma rota, e que o valor médio obtido no período pode 
ser considerado constante em cada instante de operação efetiva, mesmo nos casos em que uma operação é segregada por uma interrupção. Nas operações que utilizam mais de uma rota simultaneamente, a taxa efetiva do período é resultante da soma da taxa média de cada rota, como ilustra Figura 15.

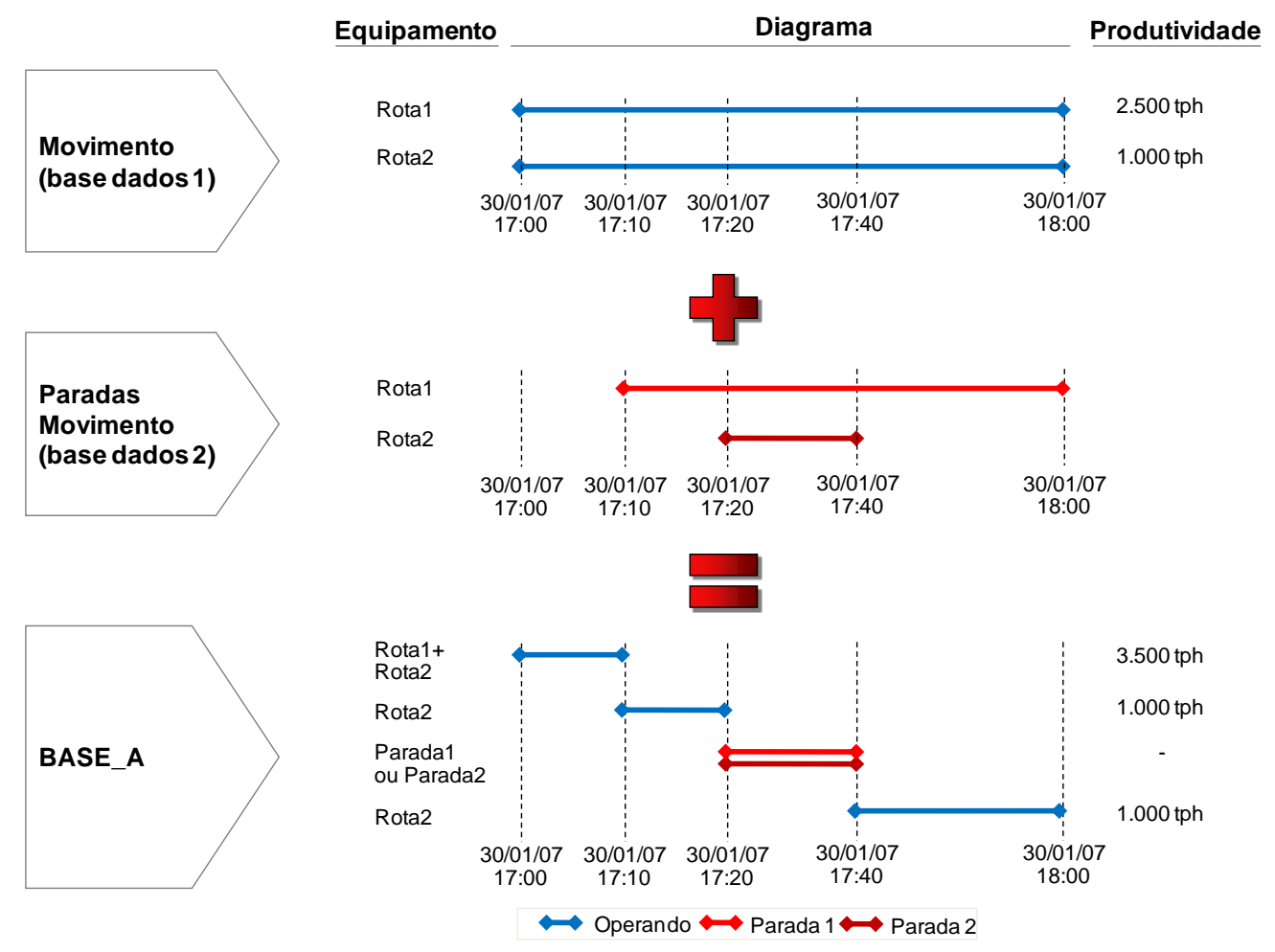

Figura 15: Consolidação das informações na criação da BASE_A. Fonte: Elaborado pelo autor

Em uma segunda etapa, a rotina faz algo análogo entre a Planilha Evento Embarque (base de dados 3) e a Planilha Vacância Píer (base de dados 4), formando a $B A S E \_B$, como ilustra a Figura 16.

Por fim, a $B A S E \_C$ é formada com a consolidação das bases $A$ e $B$, resultando em uma tabela de dados detalhada e com apontamentos nas 24 horas dos dias. 

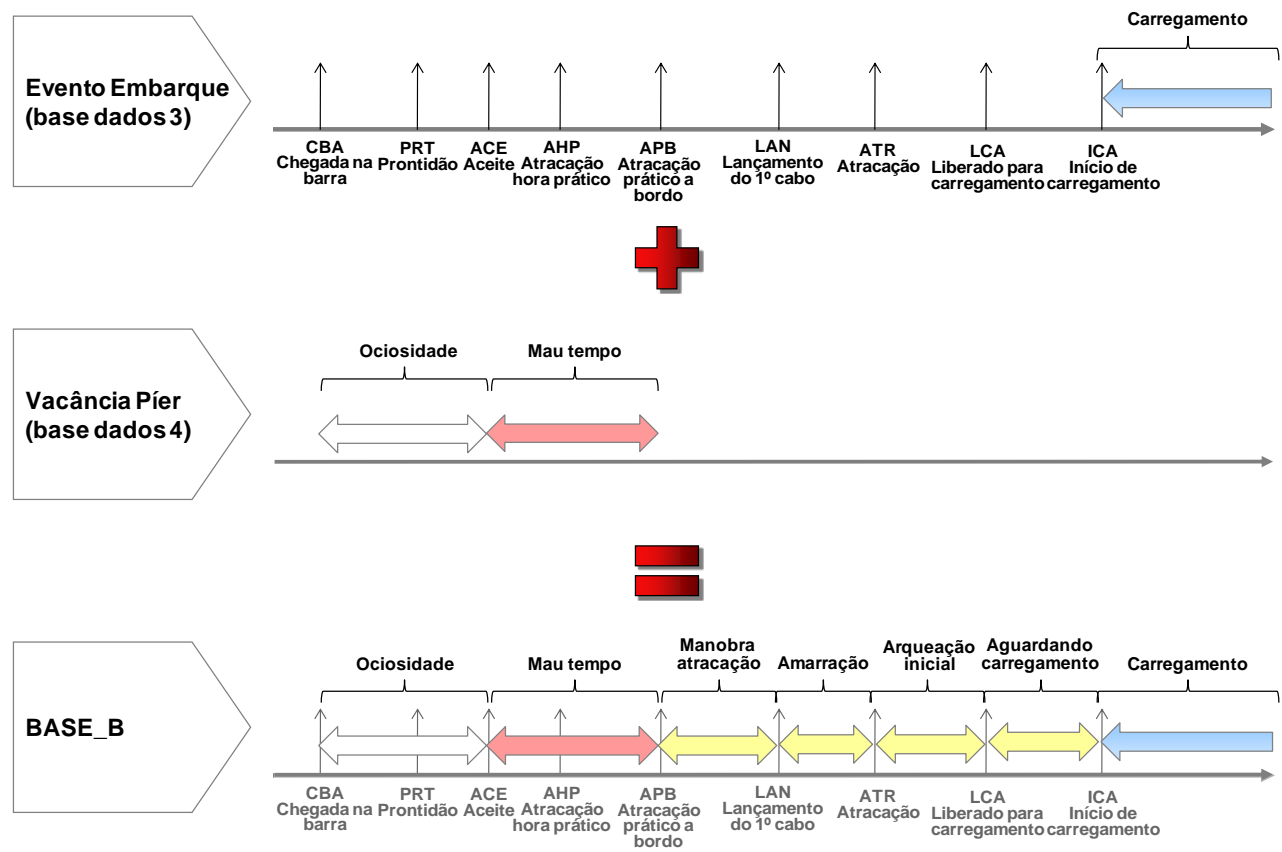

Figura 16: Consolidação das informações na criação da BASE_B. Fonte: Elaborado pelo autor

\begin{tabular}{|c|c|c|c|c|c|c|c|c|c|}
\hline & inicio & fim & $\begin{array}{c}\text { Tempo } \\
\text { [h] }\end{array}$ & evento & descrição & $\begin{array}{c}\text { equipam } \\
\text { ento }\end{array}$ & $\begin{array}{c}\text { rota } \\
\text { produto }\end{array}$ & $\begin{array}{c}\text { taxa efetiva } \\
\text { [tph] }\end{array}$ & $\begin{array}{c}\text { navio } \\
\text { BASE_A }\end{array}$ \\
\hline $1 / 1 / 0713: 00$ & $1 / 1 / 0713: 26$ & 0,43 & OPE & Carregando & & 1487 SSAX & 2.945 & BUCC \\
\hline $1 / 1 / 0713: 26$ & $1 / 1 / 0713: 40$ & 0,23 & O50 & Probl. de contaminacao & ERS1 & 1487 SSAX & 2.945 & BUCC \\
\hline $1 / 1 / 0713: 40$ & $1 / 1 / 0715: 59$ & 2,32 & OPE & Carregando & & 1487 SSAX & 2.945 & BUCC \\
\hline $1 / 1 / 0715: 59$ & $1 / 1 / 0718: 00$ & 2,02 & V03 & Rasgo na correia & TR01 & 1487 SSAX & 2.945 & BUCC \\
\hline
\end{tabular}

\begin{tabular}{|l|l|c|c|c|c|c|c|c|}
\hline inicio & fim & $\begin{array}{c}\text { Tempo } \\
\text { [h] }\end{array}$ & evento & descrição & $\begin{array}{c}\text { equipam } \\
\text { ento }\end{array}$ & $\begin{array}{c}\text { rota } \\
\text { produto }\end{array}$ & $\begin{array}{c}\text { taxa efetiva } \\
\text { [tph] }\end{array}$ & $\begin{array}{c}\text { navio } \\
\text { BASE_B }\end{array}$ \\
\hline $1 / 1 / 070: 00$ & $1 / 1 / 079: 00$ & 9,00 & VACC & Vacância & & \\
\hline $1 / 1 / 079: 00$ & $1 / 1 / 0711: 00$ & 2,00 & MAAT & Manobra de atracação & & & \\
\hline $1 / 1 / 0711: 00$ & $1 / 1 / 0711: 50$ & 0,83 & AMAR & Amarração na atracação & & & \\
\hline $1 / 1 / 0711: 50$ & $1 / 1 / 0712: 00$ & 0,17 & AIN & Arqueacao inicial & & \\
\hline $1 / 1 / 0712: 00$ & $1 / 1 / 0712: 50$ & 0,83 & PMV & Problema mecanico Vale & & \\
\hline $1 / 1 / 0712: 50$ & $1 / 1 / 0713: 00$ & 0,17 & ACM & Aguardando carga minerio & & \\
\hline $1 / 1 / 0713: 00$ & $1 / 1 / 0713: 26$ & 0,43 & CAR & Carregando & & \\
\hline $1 / 1 / 0713: 26$ & $1 / 1 / 0713: 40$ & 0,23 & POV & Problema operacional Vale & & \\
\hline $1 / 1 / 0713: 40$ & $1 / 1 / 0715: 59$ & 2,32 & CAR & Carregando & & \\
\hline $1 / 1 / 0715: 59$ & $1 / 1 / 0718: 00$ & 2,02 & PMV & Problema mecanico Vale & & & \\
\hline
\end{tabular}

\begin{tabular}{|c|c|c|c|c|c|c|c|c|c|c|}
\hline \multirow{11}{*}{ BASE_C } & inicio & fim & $\begin{array}{c}\text { Tempo } \\
{[\mathrm{h}]}\end{array}$ & evento & descrição & $\begin{array}{c}\text { equipam } \\
\text { ento }\end{array}$ & rota & produto & $\begin{array}{c}\text { taxa efetiva } \\
\text { [tph] }\end{array}$ & navio \\
\hline & $1 / 1 / 070: 00$ & 1/1/07 3:30 & 9,00 & VACC & Vacância & & & & & \\
\hline & 1/1/07 9:00 & 1/1/07 11:00 & 2,00 & MAAT & Manobra de atracação & & & & & \\
\hline & 1/1/07 11:00 & $1 / 1 / 0711: 50$ & 0,83 & AMAR & Amarração na atracação & & & & & \\
\hline & $1 / 1 / 07$ 11:50 & 1/1/07 12:00 & 0,17 & AIN & Arqueacao inicial & & & & & \\
\hline & 1/1/07 12:00 & $1 / 1 / 0712: 50$ & 0,83 & PMV & Problema mecanico Vale & & & & & \\
\hline & 1/1/07 12:50 & 1/1/07 13:00 & 0,17 & ACM & Aguardando carga minerio & & & & & \\
\hline & 1/1/07 13:00 & 1/1/07 13:26 & 0,43 & OPE & Carregando & & \multicolumn{2}{|c|}{1487 SSAX } & 2.945 & BUCC \\
\hline & 1/1/07 13:26 & 1/1/07 13:40 & 0,23 & 050 & Probl. de contaminacao & ERS1 & \multicolumn{2}{|c|}{ 1487SSAX } & 2.945 & BUCC \\
\hline & 1/1/07 13:40 & $1 / 1 / 0715: 59$ & 2,32 & OPE & Carregando & & \multicolumn{2}{|c|}{ 1487SSAX } & 2.945 & BUCC \\
\hline & $1 / 1 / 0715: 59$ & 1/1/07 18:00 & 2,02 & V03 & Rasgo na correia & TR01 & \multicolumn{2}{|c|}{ 1487SSAX } & 2.945 & BUCC \\
\hline
\end{tabular}

Figura 17: Consolidação das informações na criação da BASE_C. Fonte: Elaborado pelo autor 
A principal dificuldade encontrada ao longo desse trabalho de consolidação refere-se à dúvida de qual evento escolher no caso de uma discordância entre as bases de dados. Esses impasses tinham como origem a falha no apontamento humano e representavam cerca de $2 \%$ do período total coletado.

Quando questionada sobre tais discordâncias no apontamento, a equipe responsável pela apropriação e consolidação dos dados sugeriu a adoção de uma lista de prioridade entre os eventos. Essa lista, que é utilizada na empresa, permite que a base de dados seja ajustada sem a necessidade de descartar nenhum período. Para tanto, leva-se em consideração qual base de dados está sendo criada, como explicitado a seguir:

- Concomitância na criação da Base A:

- Se a concomitância ocorrer em uma mesma rota se priorizará os eventos de acordo com a seguinte ordem:

- Paradas não gerenciáveis (PNG);

- Paradas devido a quebras e bloqueios $\left(\mathrm{MC}_{\mathrm{C}}, \mathrm{MC}_{\mathrm{R}}, \mathrm{BL}_{\mathrm{C}}\right.$ e $\left.\mathrm{BL} \mathrm{L}_{\mathrm{R}}\right)$;

- Paradas operacionais (PO);

- Atividades pré e pós-operacionais (PR);

- Manutenção preventiva (MP);

- Carregamento (HO).

- Se a concomitância ocorrer entre rotas distintas, somam-se as produtividades das rotas em operação.

- Se a concomitância ocorrer entre rotas distintas e nenhuma delas estiver operando, priorizam-se os eventos de acordo com a prioridade listada anteriormente.

- Concomitância na criação da Base C: se a concomitância ocorrer entre eventos de base de dados diferentes, prioriza-se o evento da Planilha Evento Embarque, que forma a BASE_B. Isso porque os dados da Planilha Evento Embarque são considerados como resultado oficial da empresa. 
Ao término do tratamento das bases de dados realizaram-se os cálculos dos indicadores operacionais, cujos resultados são apresentados a seguir. A empresa não autorizou a publicação dos dados brutos na documentação do trabalho.

\subsection{Resultados dos indicadores de desempenho operacional}

\section{OEE}

A apresentação dos resultados é iniciada pelo OEE, que indica qual porcentagem da capacidade do sistema foi efetivamente utilizada de maneira produtiva. De acordo com a Figura 18, o Berço 6 é o que mais usufrui da capacidade instalada, com aproveitamento cerca de $50 \%$ acima da média da amostra. Também estão acima da média os Berços 4, 7 e 9. O Berço 1 está muito próximo da média, e abaixo dela estão os Berços 2, 3, 5 e 8.

Por se tratar de um índice macro que engloba outros indicadores, não é possível, a partir dos resultados do OEE, identificar e justificar as diferenças entre os terminais. Para isso, deve-se analisar cada indicador micro que o compõem.

Como o OEE é influenciado pelas particularidades dos sistemas, o indicador não possui nenhum grupo de comparação e, portanto, não será considerado na análise de benchmarking.

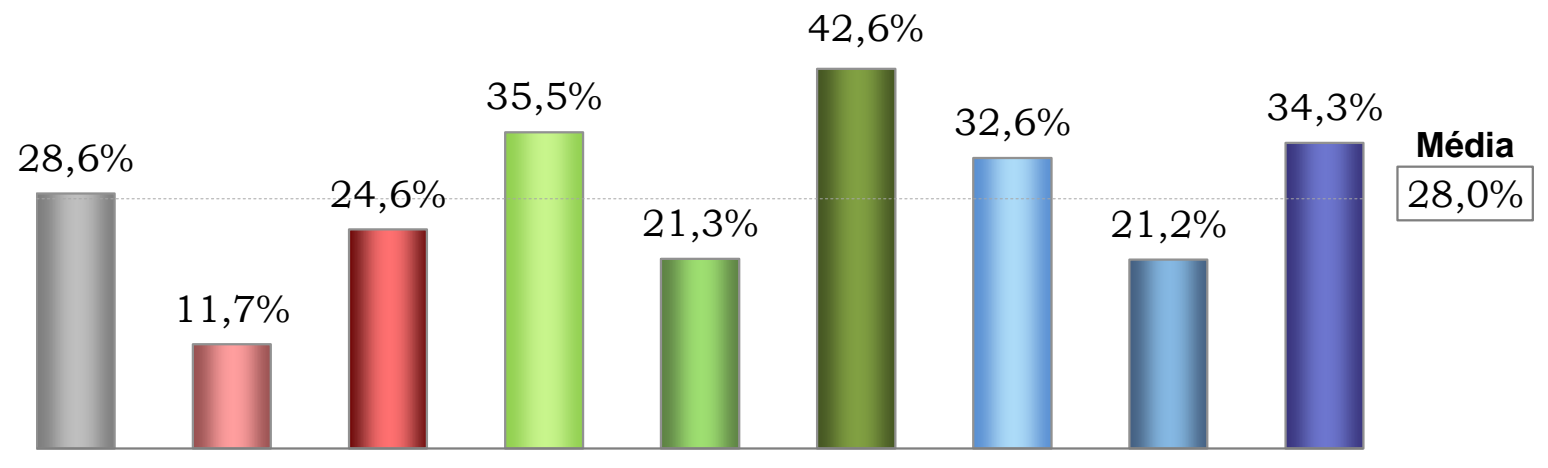

Berço 1 Berço 2 Berço 3 Berço 4 Berço 5 Berço 6 Berço 7 Berço 8 Berço 9

Sem grupos de comparação

Figura 18: OEE dos berços da amostra. Fonte: Elaborado pelo autor 


\section{Índice de Ocupação}

O Índice de Ocupação permite identificar o tempo de comprometimento com a operação dos sistemas. De forma geral, os berços apresentaram ocupação próxima a $90 \%$, exceto o Berço 8 , que apresentou valor abaixo de $80 \%$.

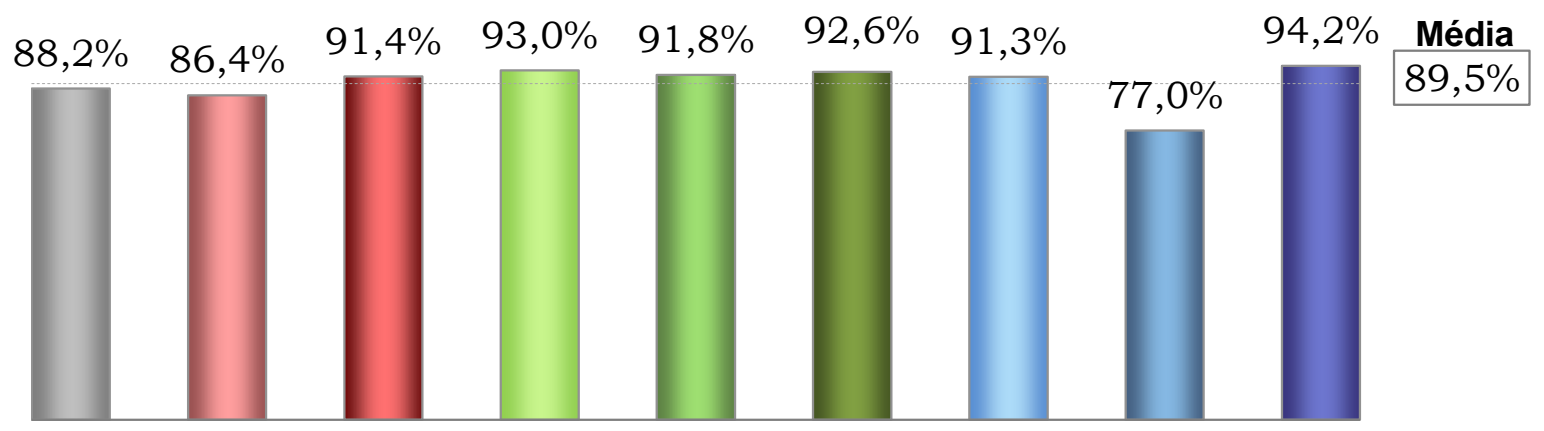

Berço 1 Berço 2 Berço 3 Berço 4 Berço 5 Berço 6 Berço 7 Berço 8 Berço 9

Sem grupos de comparação

Figura 19: Índice de Ocupação. Fonte: Elaborado pelo autor

Assim como o OEE, o Índice de Ocupação também engloba outros indicadores e não consegue justificar as diferenças entre os terminais.

O Índice de Ocupação também é influenciado pelas particularidades dos sistemas, não podendo ser utilizado na análise de benchmarking dos terminais.

\section{ID 1 - Índice de Ociosidade}

A alta ocupação observada no indicador anterior decorre, dentre outros motivos, do baixo período de ociosidade dos sistemas (Figura 20), que compromete os ativos por cerca de $100 \%$ do tempo. Isso significa que no período analisado, quase sempre existia navios em fila. 


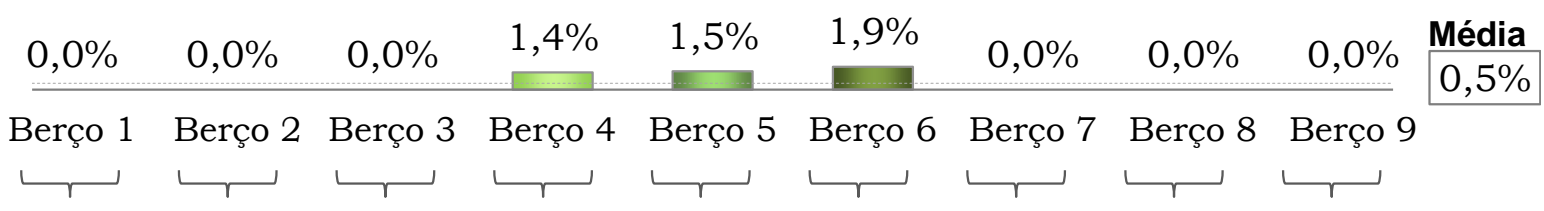

Sem grupos de comparação

Figura 20: Índice de Ociosidade. Fonte: Elaborado pelo autor

A pequena diferença entre os resultados dos elementos da amostra pouco influencia os valores dos indicadores macros, o que faz da ociosidade um fator pouco relevante para justificar as diferenças entre os sistemas.

Por ser de cunho estratégico da corporação e muitas vezes independer da gestão operacional dos terminais, o Índice de Ociosidade também não será utilizado na análise de benchmarking dos terminais.

\section{ID 2 - Índice de Indisponibilidade}

As indisponibilidades impossibilitaram as atracações dos navios em cerca de 5,7\% do tempo (Figura 21). Os Berços 4, 5, 6 e 7 foram pouco afetados por esses eventos. Já os Berços 8 e 9 foram bastante prejudicados em razão de obras em sua infraestrutura compartilhada, que interromperam a operação em $22,1 \%$ e $4,7 \%$ do período analisado, respectivamente.

Os Berços 1, 2 e 3, por sua vez, foram principalmente afetados pelo mau tempo e pelo congestionamento do canal de acesso. O Berço 1 ainda realizou uma pequena obra em seus dólfins de amarração no período, o que contribuiu para o aumento de sua indisponibilidade. Esses valores justificam a maior parte das diferenças entre os resultados do Índice de Ocupação, observados na Figura 19. 


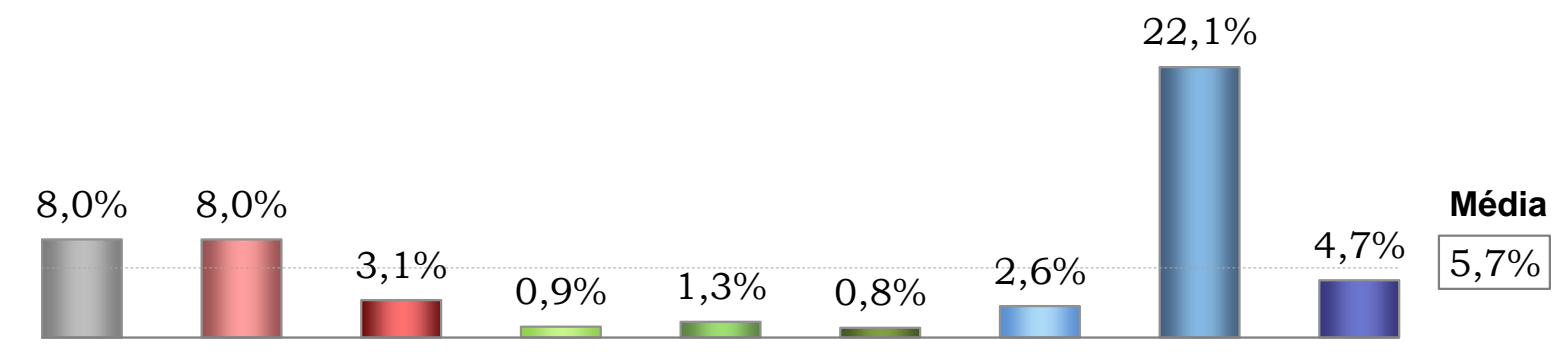

Berço 1 Berço 2 Berço 3 Berço 4 Berço 5 Berço 6 Berço 7 Berço 8 Berço 9

\section{Sem grupos de comparação}

Figura 21: Índice de Indisponibilidade. Fonte: Elaborado pelo autor

Como o Índice de Indisponibilidade é influenciado pelas particularidades dos sistemas, não pode ser utilizado na análise de benchmarking dos terminais.

\section{ID 3 - Índice de Manutenção Preventiva}

Os sistemas realizaram manutenções preventivas em cerca de $4,2 \%$ do período. As exceções foram os Berços 8 e 9, que por possuir um CN adicional, ficaram indisponíveis apenas um quinto do tempo dos demais (Figura 22).

O sistema que apresenta o maior Índice de Manutenção Preventiva é o Berço 7, com $6,1 \%$. Os demais berços apresentaram valores próximos à média.

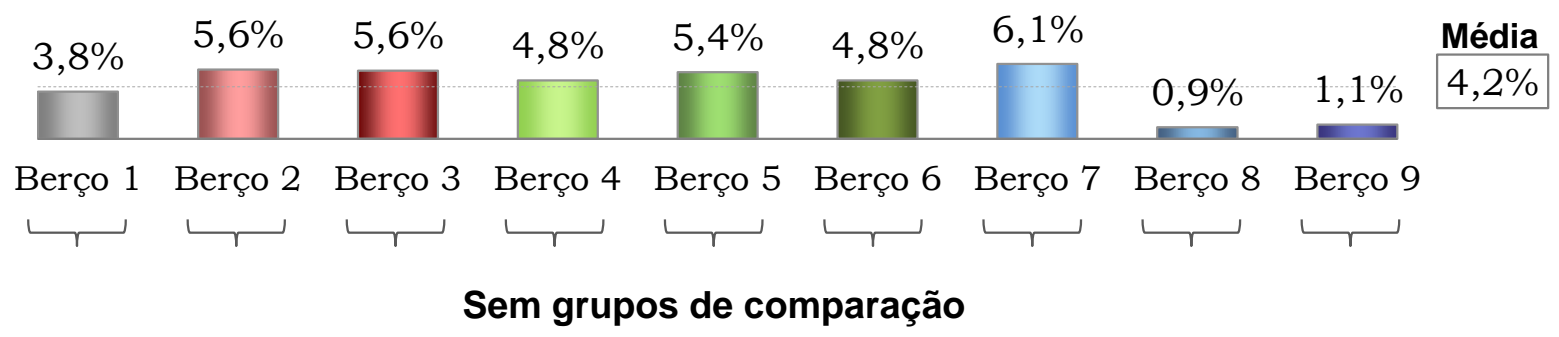

Figura 22: Índice de Manutenção Preventiva. Fonte: Elaborado pelo autor

Por depender do planejamento do terminal, do tipo e do fabricante dos equipamentos, o Índice de Manutenção Preventiva também não será utilizado no na análise de benchmarking dos terminais. 


\section{Índice de Utilização}

O Índice de Utilização indica quanto o terminal consegue efetivamente operar das horas que o sistema estava ocupado.

O Berço 6 é o ativo que apresentou o maior aproveitamento, com uma eficiência de $71,2 \%$.

Com exceção dos Berços 2 e 3, que apresentaram média de apenas 35,5\%, os sistemas que trabalham com mais de uma rota simultaneamente (Berços 1, 6 e 7) tiveram os melhores resultados, com média de $63,0 \%$ ante $42,7 \%$ dos demais.

O Berço 4 apresentou um alto desempenho, de $55,5 \%$, superando inclusive o Berço 7, que opera com mais de uma rota (Figura 23).

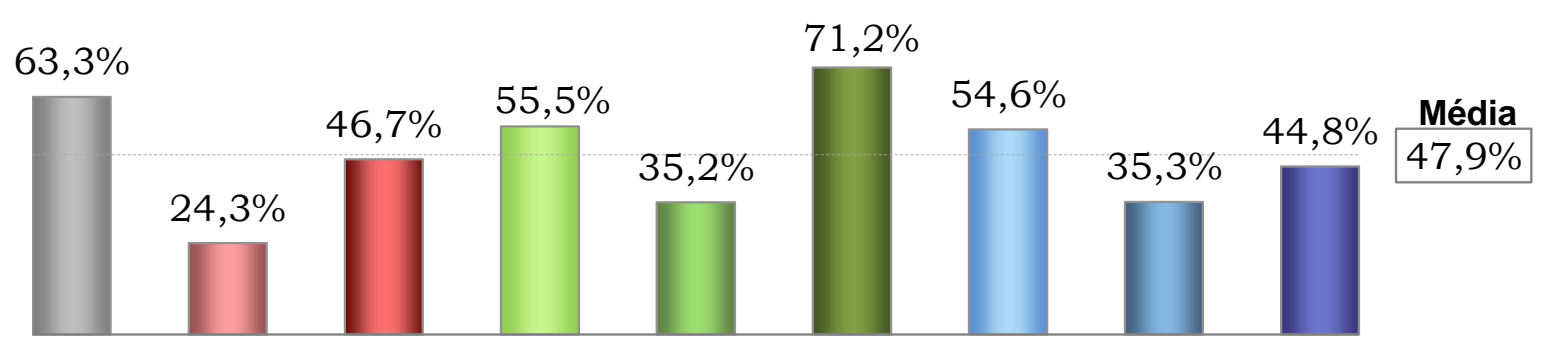

Berço 1 Berço 2 Berço 3 Berço 4 Berço 5 Berço 6 Berço 7 Berço 8 Berço 9

Sem grupos de comparação

Figura 23: Índice de Utilização. Fonte: Elaborado pelo autor

O Índice de Ocupação também é influenciado pelas particularidades dos sistemas, não podendo ser utilizado na análise de benchmarking dos terminais. Por ser um indicador de alto nível, o Índice de Utilização não indicam os motivos da dispersão dos resultados, sendo necessário analisar os demais indicadores propostos.

\section{ID 4 - Índice de Espera por Maré}

Esse indicador mensura o tempo em que as correntes marítimas e a maré impediram a operação dos navios. A média desse indicador é de 0,55 horas (ou 33 minutos) por embarcação. Os índices mais altos são dos Berços 7 (1,71h), 8 (1,35h), 
$9(1,34 h)$ e $4(0,44 h)$. Os outros berços foram pouco prejudicados pela maré, como pode ser observado na Figura 24.

[h/embarcação]

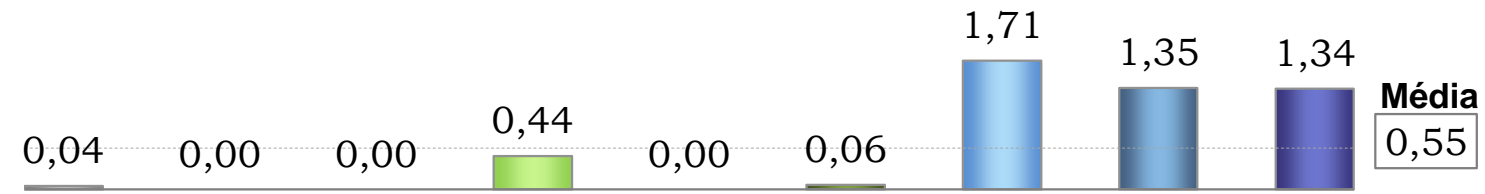

Berço 1 Berço 2 Berço 3 Berço 4 Berço 5 Berço 6 Berço 7 Berço 8 Berço 9

Sem grupos de comparação

Figura 24: Índice de Espera por Maré, em horas. Fonte: Elaborado pelo autor

Naturalmente, o Índice de Espera por Maré é peculiar de cada sistema, não podendo ser utilizado na análise de benchmarking dos terminais.

\section{ID 5 - Índice de Espera por Manobras}

O Índice de Espera por Manobras mensura a interrupção dos berços devido às manobras de atracação e de desatracação. Em média, os terminais param 1,73 horas por embarcação. O berço com maior índice é o Berço 2 (3,21h), cujo valor é consideravelmente superior ao seu vizinho, o Berço $3(1,99 \mathrm{~h})$, em razão da dificuldade natural de se acostar no local - segundo o operador portuário. O valor do indicador para o Berço 1 é de $1,82 \mathrm{~h}$ e todos os outros berços possuem valor ligeiramente inferior à média, como pode ser visto na Figura 25. 
[h/embarcação]

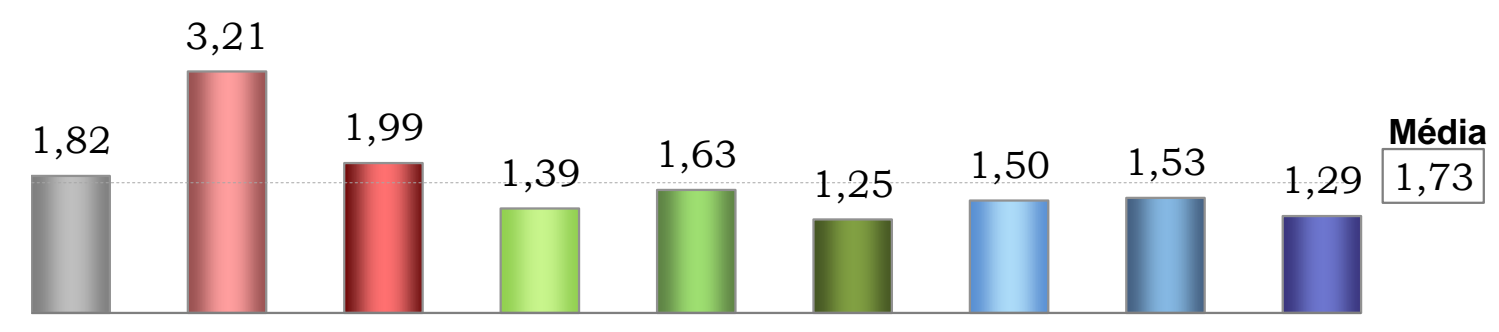

Berço 1 Berço 2 Berço 3 Berço 4 Berço 5 Berço 6 Berço 7 Berço 8 Berço 9

Sem grupos de comparação

Figura 25: Índice de Espera por Manobras, em horas. Fonte: Elaborado pelo autor

O Índice de Espera pro Manobras também é peculiar de cada sistema, não podendo ser utilizado na análise de benchmarking dos terminais.

\section{ID 6 - Índice de Paradas Pré e Pós Operacionais}

Os eventos mais representativos nas atividades pré e pós-operacionais são: aguardando vistoria, amarração e aguardando carga inicial. A média do indicador que mede essas atividades é de 3,62 horas por embarcação (Figura 26). Os melhores desempenhos estão nos Berços 4, 7, 8 e 9, cuja média foi de 2,2 horas. Os Berços 2, 5 e 6 também apresentaram bons resultados, com média de 2,8 horas. Todavia, os Berços 1 e 3 apresentaram índices consideravelmente superiores: 4,53h para o primeiro e 10,64h para o segundo. Ressalta-se que o resultado do Berço 3 foi bastante discrepante do seu vizinho, o Berço 2. O autor não conseguiu identificar qual o motivo dessa discrepância a partir dos dados apresentados pelo terminal e desconfia de erros na base de dados.

Por envolver atividades e eventos aparentemente semelhantes em todos os sistemas, o Índice de Paradas Pré e Pós Operacionais será utilizado na análise de benchmarking dos terminais e terá um único grupo de comparação. 
[h/embarcação]

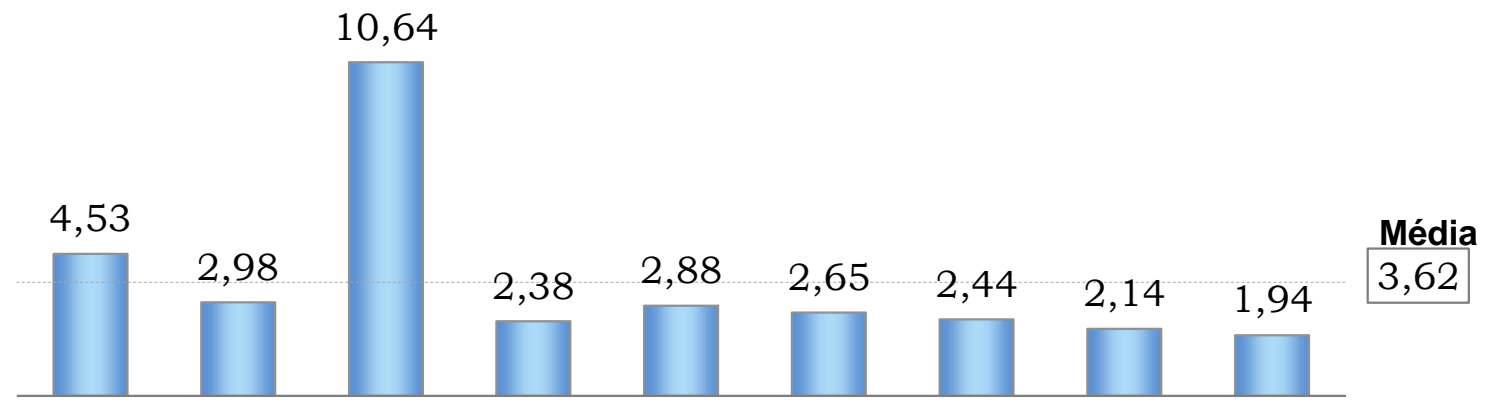

Berço 1 Berço 2 Berço 3 Berço 4 Berço 5 Berço 6 Berço 7 Berço 8 Berço 9

\section{1 único grupo de comparação}

Figura 26: Índice de Paradas Pré e Pós Operacionais, em horas. Fonte: Elaborado pelo autor

\section{ID 7 - Índice de Manutenção Corretiva do Circuito de Embarque}

A média do Índice de Manutenção Corretiva do Circuito de Embarque é de 0,12 horas (ou 7,2 minutos) para cada hora de operação (Figura 27). Os melhores desempenhos estão nos Berços $6(0,04)$ e $7(0,06)$. Por outro lado, os piores são os Berços $5(0,21)$ e $8(0,17)$.

O autor esperava que os Berços 8 e 9 apresentassem os menores valores, dado que os ativos possuem um $\mathrm{CN}$ adicional que possibilitaria a substituição em caso de quebras. No entanto isso não foi verificado na prática.

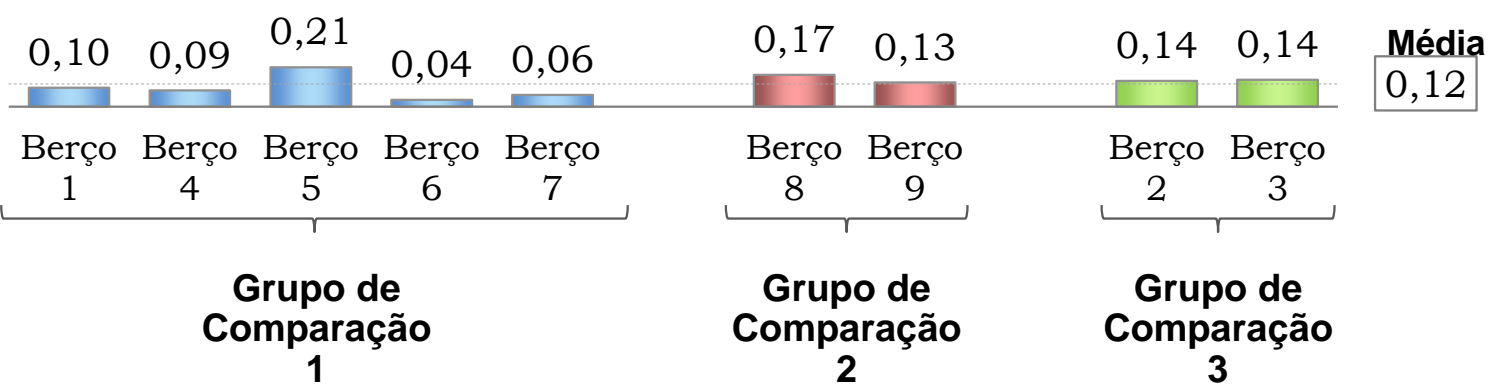

Figura 27: Índice de Manutenção Corretiva do Circuito de Embarque. Fonte: Elaborado pelo autor

Por envolver atividades e eventos semelhantes em todos os sistemas, o Índice de Manutenção Corretiva do Circuito de Embarque será utilizado na análise de 
benchmarking dos terminais. Entretanto, haverá três grupos de comparações em função da mudança de padrão que o número de CNs por berço propicia.

\section{ID 8 - Índice de Manutenção Corretiva das Rotas}

A média do Índice de Manutenção Corretiva das Rotas é de 0,15 horas (ou 9 minutos) para cada hora operada (Figura 28).

O berço com o menor índice é Berço 6, com 0,02. Além de operar com duas rotas é possível que o operador priorize o embarque nesse berço em detrimento dos demais.

Os Berços 5, 7, 8 e 9 apresentaram os valores mais altos, que variam de 0,15 a 0,41 horas para cada hora operada.

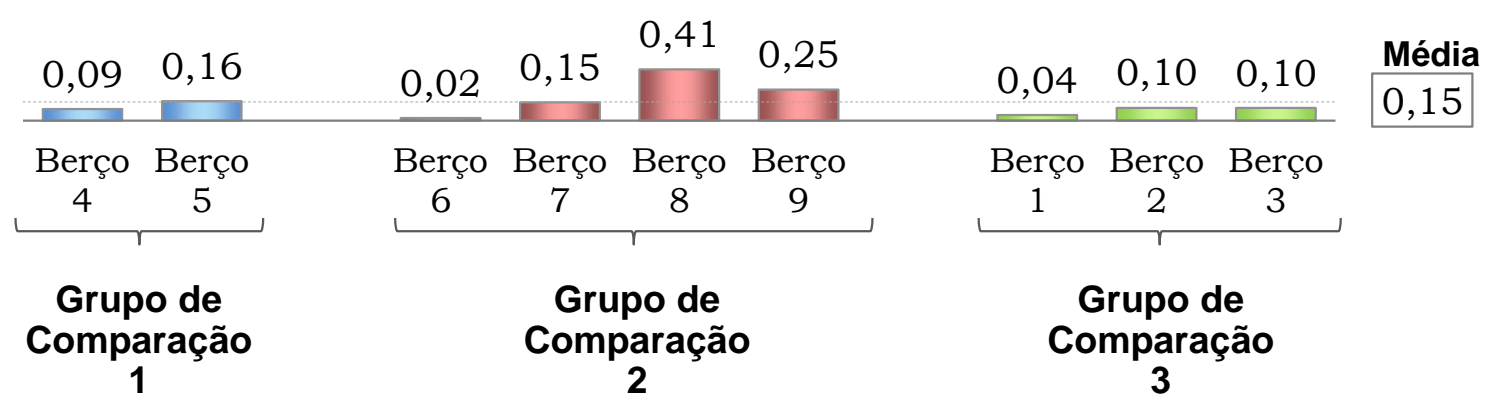

Figura 28: Índice de Manutenção Corretiva das Rotas. Fonte: Elaborado pelo autor

Assim como o índice anterior, o Índice de Manutenção Corretiva das Rotas será utilizado na análise de benchmarking dos terminais. Entretanto, haverá três grupos de comparações em função do número de CNs por berço, o número de rotas por $\mathrm{CN}$ e as diferentes disponibilidades de máquinas de pátio.

\section{ID 9 - Índice de Paradas Operacionais}

O evento mais representativo nesse indicador é a Mudança de Porão, sendo fortemente influenciado pelo tipo do $\mathrm{CN}$. O valor médio do indicador é de 0,10 horas (ou 6 minutos) para cada hora operada, como mostra a Figura 29. 
O Berço 6 apresenta o índice mais baixo, de apenas 0,01, devido ao seu $\mathrm{CN}$ ser do tipo duo-radial e permitir a troca de porão sem interromper a operação. Os Berços 1 , 4 e 5 também apresentaram bom desempenho, parando em torno de 0,08 horas para cada hora operada.

O Berço 2 teve o índice mais alto, de 0,22. Também apresentaram altos índices os Berços 7, 8 e 9 com média de 0,12. Novamente esperava-se que os berços 8 e 9 apresentassem baixos valores, mas a utilização do terceiro CN para evitar a interrupção do carregamento foi pouco utilizada.

\begin{tabular}{|c|c|c|c|c|c|c|c|c|c|}
\hline 0,08 & 0,22 & 0,12 & 0,06 & 0,07 & 0,14 & 0,01 & 0,13 & 0,09 & $\begin{array}{l}\text { Média } \\
0,10 \\
\end{array}$ \\
\hline $\begin{array}{c}\text { Berço } \\
1\end{array}$ & $\begin{array}{c}\text { Berço } \\
2\end{array}$ & $\begin{array}{c}\text { Berço } \\
3\end{array}$ & $\begin{array}{c}\text { Berço } \\
4\end{array}$ & $\begin{array}{c}\text { Berço } \\
5\end{array}$ & $\begin{array}{c}\text { Berço } \\
7\end{array}$ & $\begin{array}{c}\text { Berço } \\
6\end{array}$ & $\begin{array}{c}\text { Berço } \\
8\end{array}$ & $\begin{array}{c}\text { Berço } \\
9\end{array}$ & \\
\hline
\end{tabular}

Figura 29: Índice de Paradas Operacionais. Fonte: Elaborado pelo autor

O Índice de Paradas Operacionais será utilizado na análise de benchmarking, e possuirá três grupos de comparações devido o número de CNs por berço.

\section{ID 10 - Índice de Bloqueio do Circuito de Embarque}

Esse indicador mensura o tempo que o circuito de embarque é interrompido devido os bloqueios e as paradas de responsabilidade do terminal (incluindo a falta de equipamento de cais).

Em média, os sistemas analisados ficam bloqueados por 0,43 horas (ou 26 minutos) para cada hora de operação. O Berços 2 e 3, que compartilham a infraestrutura, foram os mais prejudicados, com média de 1,13 . Ou seja, a falta de um CN nesse sistema faz que seus berços passem mais tempo bloqueados do que operando.

Excluindo os Berços 2 e 3 da comparação, os berços que têm a possibilidade de compartilhar os CNs (Berços 4, 5, 8 e 9) apresentam os maiores índices de bloqueios, com média de 0,37, ante 0,04 dos demais (Figura 30). 


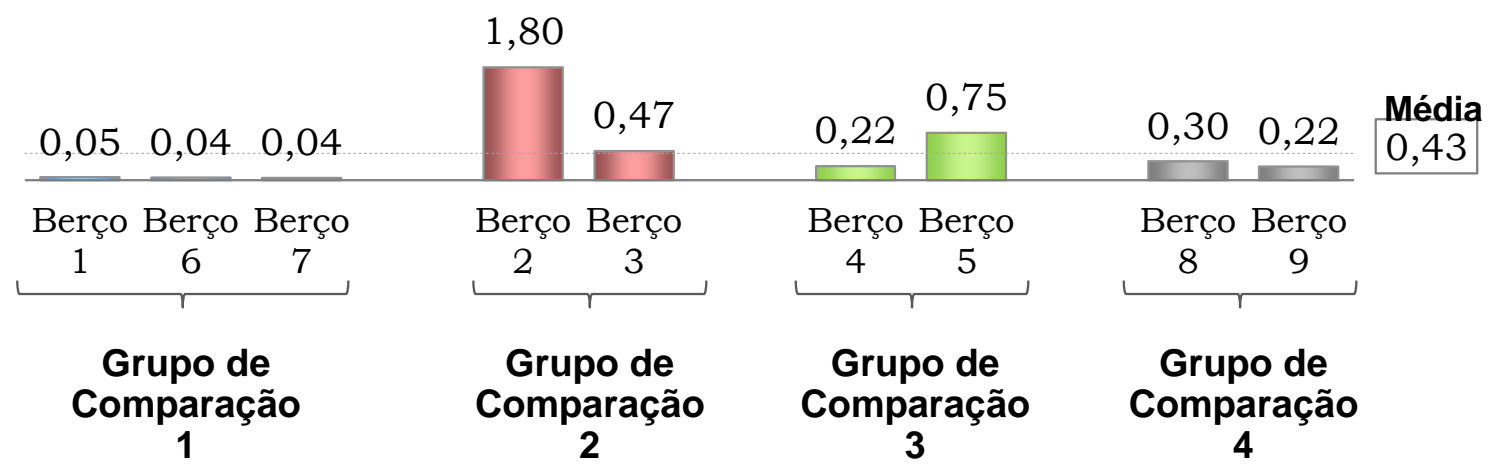

Figura 30: Índice de Bloqueio do Circuito de Embarque. Fonte: Elaborado pelo autor

O Índice de Bloqueio do Circuito de Embarque também será utilizado na análise de benchmarking dos terminais. Entretanto, haverá quatro grupos de comparações para esse indicador em função do número de CNs por berço e do risco de colisão entre os equipamentos.

\section{ID 11 - Índice de Bloqueio das Rotas}

Os eventos mais significativos na mensuração desse indicador são: aguardando empilhamento ou recuperação de outro sistema, manutenção programada dos equipamentos de pátio e manobras de equipamento de pátio.

A média desse indicador é 0,16 horas (ou 9,6 minutos) para cada hora operada. Assim como na manutenção corretiva, os CNs alimentados por duas rotas (Berços 1, 2, 3, 6 e 7) são os menos prejudicados, média de 0,05 ante 0,28 dos alimentados por rota singela.

O berço menos impactado foi Berço $6(0,02)$, seguido do Berço $1(0,04)$ e do Berço 3 $(0,05)$. Por outro lado, os maiores índices foram registrados no Berço $8(0,46)$, Berço $9(0,28)$ e Berço $5(0,28)$. 


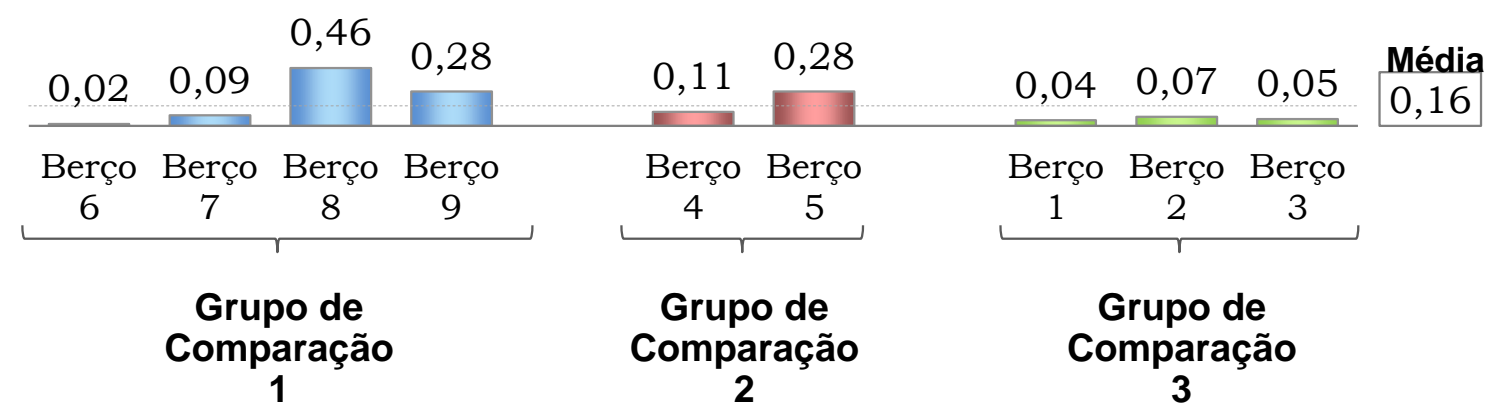

Figura 31: Índice de Bloqueio das Rotas. Fonte: Elaborado pelo autor

O Índice de Manutenção Corretiva das Rotas será utilizado na análise de benchmarking dos terminais considerando a existência de três grupos de comparações, decorrentes do número de $\mathrm{CNs}$ por berço, do número de rotas por $\mathrm{CN}$ e das diferentes disponibilidades de máquinas de pátio.

\section{ID 12 - Índice de Paradas Não Gerenciáveis}

O Índice de Paradas Não Gerenciáveis mensura o tempo de interrupção gerado por eventos que independem do controle do terminal. Essas paradas são pouco significativas quando comparadas com os demais, com média de 0,04 horas (ou 2,4 minutos) para cada hora de operação. Como se observa na Figura 32, nenhum terminal apresentou resultado significativamente discrepante para esse indicador.

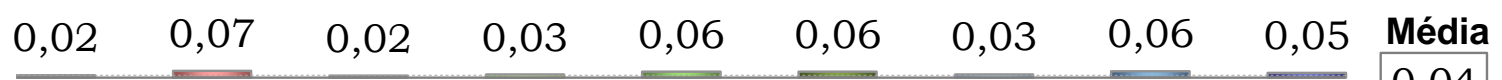

Berço 1 Berço 2 Berço 3 Berço 4 Berço 5 Berço 6 Berço 7 Berço 8 Berço 90,04

\section{Sem grupos de comparação}

Figura 32: Índice de Paradas Não Gerenciáveis. Fonte: Elaborado pelo autor

Por depender de peculiaridades e ser pouco inerente à gestão operacional do terminal, esse indicador não será utilizado na análise de benchmarking. 


\section{Índice de Produtividade}

O Índice de Produtividade estima as perdas de produtividade durante as horas de operação.

Conforme esperado, os sistemas que trabalharam com mais de uma rota simultaneamente (Berços 1, 2, 3, 6 e 7) apresentaram os piores índices de produtividade, com média de $59 \%{ }^{19}$. Os demais tiveram média de $73 \%$.

O berço com a maior eficiência produtiva foi o Berço 9 , com $82,2 \%$, seguido do Berço 8 (78,6\%) e dos Berços 4 e 5 (ambos com 68,7\%).

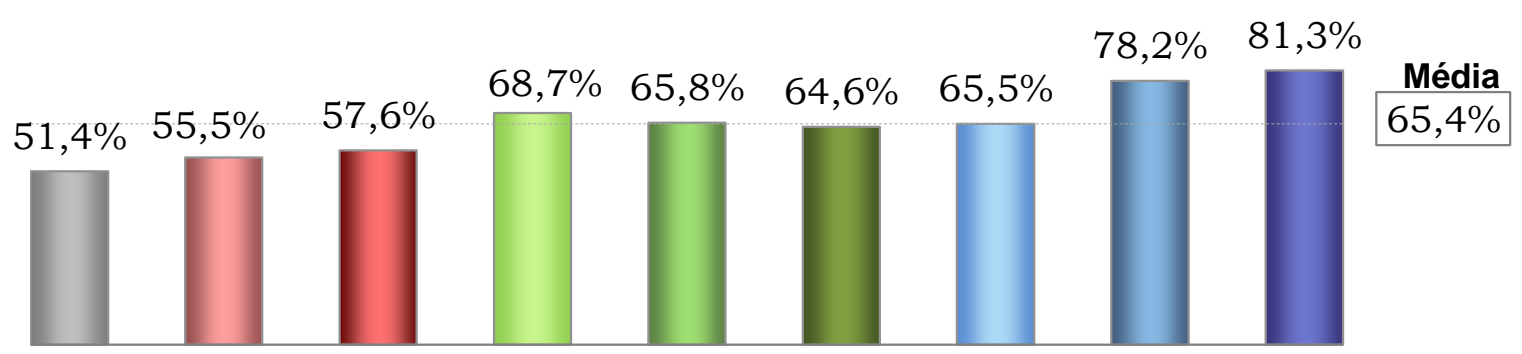

Berço 1 Berço 2 Berço 3 Berço 4 Berço 5 Berço 6 Berço 7 Berço 8 Berço 9
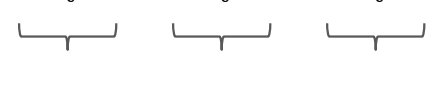

\section{Sem grupos de comparação}

Figura 33: Índice de Produtividade. Fonte: Elaborado pelo autor

É importante observar que esse indicador é influenciado por fatores que independem da gestão operacional do terminal, como o tipo de produto movimentado ou a falta de equipamentos de pátio. Por isso, esse indicador não será utilizado na análise de benchmarking dos terminais.

Os indicadores a seguir explicitam a origem das discrepâncias entres os resultados.

\section{ID 13 - Índice de Variação da Densidade}

Esse indicador mostra quanto o terminal foi prejudicado por movimentar produtos menos densos. O berço mais prejudicado foi o Berço 5 , cuja taxa efetiva média

\footnotetext{
${ }^{19}$ Espera-se que os sistemas que operam com mais de uma rota possuam menos tempos de paradas que os demais, já que frequentemente uma rota é interrompida e a outra permanece operando. Quando isso ocorre, a produtividade do sistema operante diminui.
} 
representou $84,9 \%$ da taxa efetiva teórica se o berço tivesse movimentado somente Sinter Feed.

Outros berços que também foram prejudicados são: Berço 4 (91,6\%), Berço 6 $(94,2 \%)$ e Berço 9 (93,9\%). Por outro lado, os Berços 1, 7, 2 e 3 foram pouco impactados (Figura 34).

Por ser de cunho estratégico da corporação e muitas vezes independer da gestão operacional dos terminais, esse indicador não será utilizado na análise de benchmarking dos terminais.

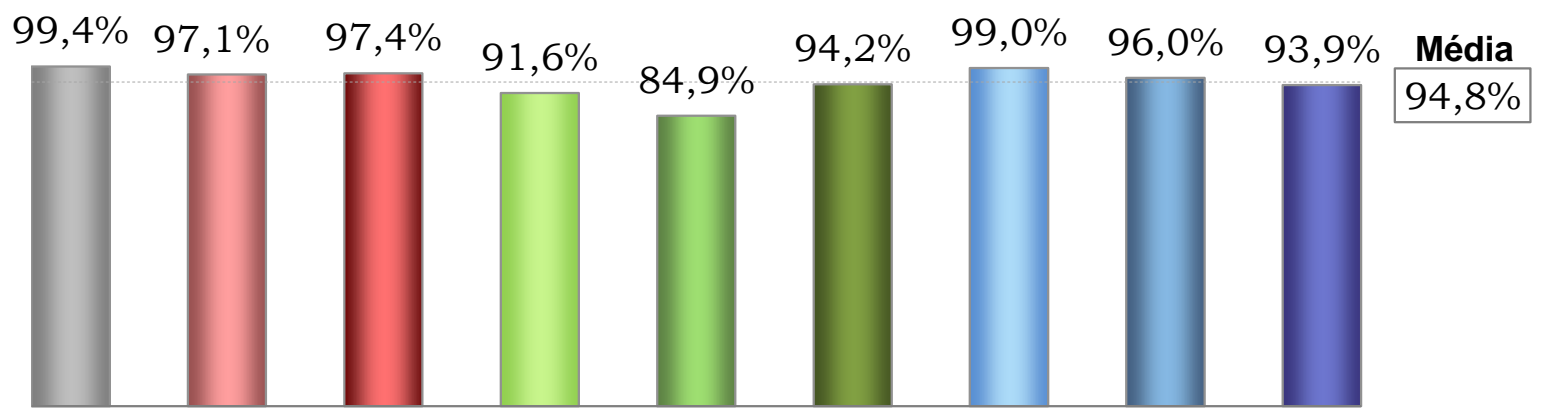

Berço 1 Berço 2 Berço 3 Berço 4 Berço 5 Berço 6 Berço 7 Berço 8 Berço 9

\section{Sem grupos de comparação}

Figura 34: Índice de Variação da Densidade. Fonte: Elaborado pelo autor

\section{ID 14 - Índice de Variação da Taxa de Movimentação}

O Índice de Variação da Taxa de Movimentação mede a eficiência da recuperação e movimentação de carga.

A média desse indicador é $78,6 \%$. Os sistemas com os melhores resultados são: Berço $9(86,6 \%)$, Berço $8(81,5 \%)$ e Berço $6(80,9 \%)$. Já os piores resultados estão associados aos Berços 2 (71,7\%), 3 (72,1\%) e 1 (74,6\%).

O Terminal 4 (Berços 7, 8 e 9) apresentou a maior média entre os portos, 82,9\%, seguido do Terminal 3 (Berços 4, 5 e $6-80,2 \%$ ), Terminal 1 (Berço $1-74,6 \%$ ) e Terminal 2 (Berços 2 e $3-71,9 \%$ ). 


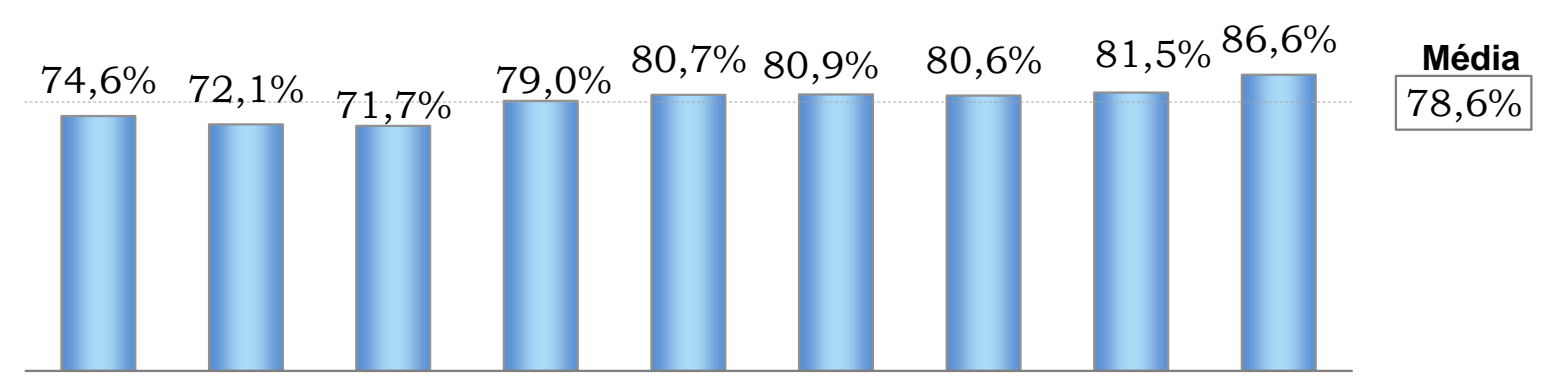

Berço 1 Berço 2 Berço 3 Berço 4 Berço 5 Berço 6 Berço 7 Berço 8 Berço 9

\section{1 único grupo de comparação}

Figura 35: Índice de Variação da Taxa de Movimentação. Fonte: Elaborado pelo autor

Por envolver atividades e eventos semelhantes em todos os sistemas, o Índice de Variação da Taxa de Movimentação será utilizado na análise de benchmarking dos terminais e terá um único grupo de comparação.

\section{ID 15 - Índice de Variação da Taxa Nominal}

O Índice de Variação da Taxa Nominal mensura a perda por não alocar rotas suficientes e, assim, não operar na taxa nominal do sistema de embarque. Essa ineficiência pode decorrer da falta de equipamentos ou por outros motivos como quebras, bloqueios, falta de produtos, dentre outros. Fazendo com que o desempenho de sistemas de múltiplas rotas seja inferior.

De fato, a média desses sistemas (Berços 1, 2, 3, 6 e 7) foi igual a 79,6\%, bastante inferior à média dos sistemas de rota singela, de $97,7 \%$.

O Berço 1 possui o agravante da falta de máquinas no pátio, o que faz sua média ser ainda menor, de 69,3\%. Os Berços 2 e 3 também possuem essa restrição, mas seu indicador não refletiu o déficit de máquinas de pátio, com média de 80,9\%, valor próximo ao do Berço 7.

O Terminal 3 (Berços 4, 5 e 6 ) tende a ser mais prejudicados que os demais porque em seu pátio há equipamentos com taxas nominais diferentes que estreitam a capacidade de escoamento de alguns sistemas, resultando em um índice de 94,9\% no Berço 4, 96,0\% no Berço 3 e 84,8\% no Berço 6, como pode ser observado no Figura 36. 


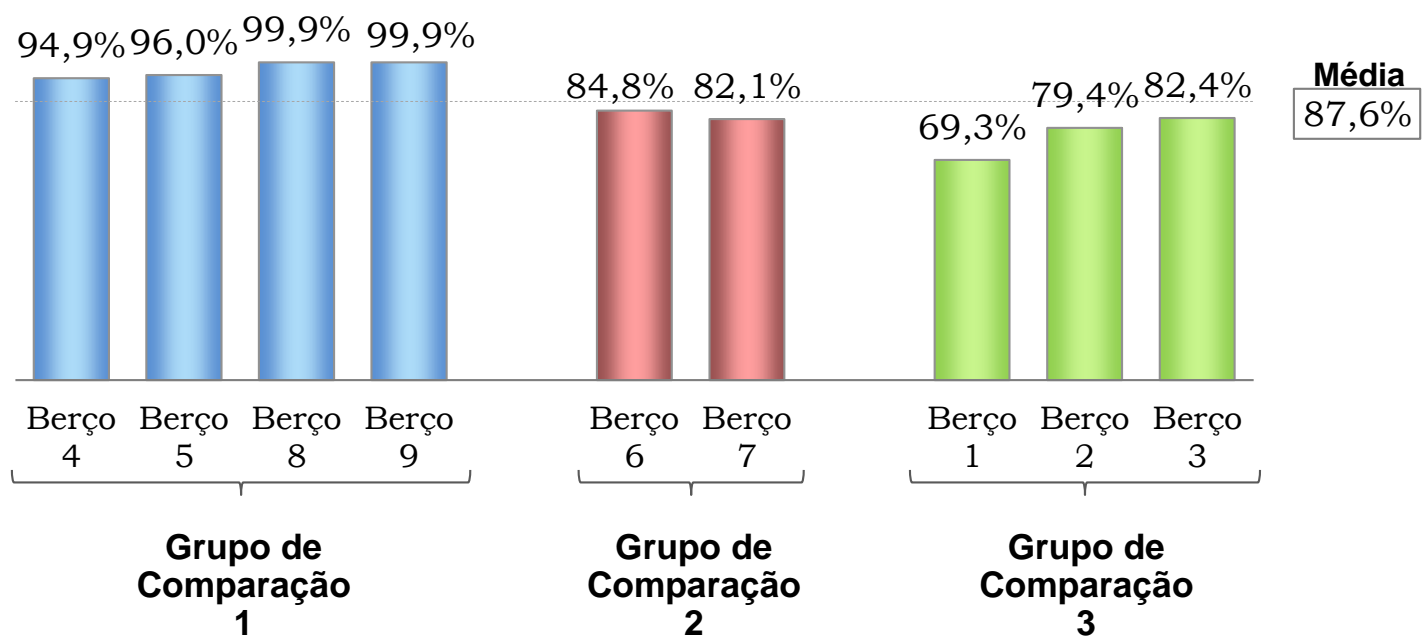

Figura 36: Índice de Variação da Taxa Nominal. Fonte: Elaborado pelo autor

O Índice de Variação da Taxa Nominal será utilizado na análise de benchmarking dos terminais, considerando a existência de três grupos de comparações decorrentes do número de $\mathrm{CNs}$ por berço, do número de rotas por $\mathrm{CN}$ e das diferentes disponibilidades de máquinas de pátio.

A síntese de todos os resultados dos indicadores é apresentada na Tabela 1.

Tabela 1: Síntese dos resultados dos indicadores de desempenho. Fonte: Elaborado pelo autor INDICADOR UNID. Berço 1 Berço 2 Berço 3 Berço 4 Berço 5 Berço 6 Berço 7 Berço 8 Berço 9

\begin{tabular}{|c|c|c|c|c|c|c|c|c|c|c|}
\hline OEE & - & $28,6 \%$ & $11,7 \%$ & $24,6 \%$ & $35,5 \%$ & $21,3 \%$ & $42,6 \%$ & $32,6 \%$ & $21,2 \%$ & $34,3 \%$ \\
\hline OCUP & - & $88,2 \%$ & $86,4 \%$ & $91,4 \%$ & $93,0 \%$ & $91,8 \%$ & $92,6 \%$ & $91,3 \%$ & $77,0 \%$ & $94,2 \%$ \\
\hline UTIL & - & $63,3 \%$ & $24,3 \%$ & $46,7 \%$ & $55,5 \%$ & $35,2 \%$ & $71,2 \%$ & $54,6 \%$ & $35,3 \%$ & $44,8 \%$ \\
\hline PROD & - & $51,4 \%$ & $55,5 \%$ & $57,6 \%$ & $68,7 \%$ & $65,8 \%$ & $64,6 \%$ & $65,5 \%$ & $78,2 \%$ & $81,3 \%$ \\
\hline ID $1 O C / H C$ & - & $0,0 \%$ & $0,0 \%$ & $0,0 \%$ & $1,4 \%$ & $1,5 \%$ & $1,9 \%$ & $0,0 \%$ & $0,0 \%$ & $0,0 \%$ \\
\hline ID 2 IND/HC & - & $8,0 \%$ & $8,0 \%$ & $3,1 \%$ & $0,9 \%$ & $1,3 \%$ & $0,8 \%$ & $2,6 \%$ & $22,1 \%$ & $4,7 \%$ \\
\hline ID $3 \mathrm{MP} / \mathrm{HC}$ & - & $3,8 \%$ & $5,6 \%$ & $5,6 \%$ & $4,8 \%$ & $5,4 \%$ & $4,8 \%$ & $6,1 \%$ & $0,9 \%$ & $1,1 \%$ \\
\hline ID 4 MAR / \#Navio & Horas & 0,04 & 0,00 & 0,00 & 0,44 & 0,00 & 0,06 & 1,71 & 1,35 & 1,34 \\
\hline ID 5 MA/\#Navio & Horas & 1,82 & 3,21 & 1,99 & 1,39 & 1,63 & 1,25 & 1,50 & 1,53 & 1,29 \\
\hline ID 6 PR/\#Navio & Horas & 4,53 & 10,64 & 2,98 & 2,38 & 2,88 & 2,65 & 2,44 & 2,14 & 1,94 \\
\hline ID $7 \mathrm{MC}_{\mathrm{C}} / \mathrm{HO}$ & - & 0,10 & 0,14 & 0,14 & 0,09 & 0,21 & 0,04 & 0,06 & 0,17 & 0,13 \\
\hline ID $8 M C_{R} / H O$ & - & 0,04 & 0,10 & 0,10 & 0,09 & 0,16 & 0,02 & 0,15 & 0,41 & 0,25 \\
\hline ID $9 \mathrm{PO} / \mathrm{HO}$ & - & 0,08 & 0,22 & 0,12 & 0,06 & 0,07 & 0,01 & 0,14 & 0,13 & 0,09 \\
\hline ID $10 B L_{C} / H O$ & - & 0,05 & 1,80 & 0,47 & 0,22 & 0,75 & 0,04 & 0,04 & 0,30 & 0,22 \\
\hline ID $11 B L_{R} / H O$ & - & 0,04 & 0,07 & 0,05 & 0,11 & 0,28 & 0,02 & 0,09 & 0,46 & 0,28 \\
\hline ID 12 PNG/HO & - & 0,02 & 0,07 & 0,02 & 0,03 & 0,06 & 0,06 & 0,03 & 0,06 & 0,05 \\
\hline ID $13 T E / T N_{P P}$ & - & $99,4 \%$ & $97,1 \%$ & $97,4 \%$ & $91,6 \%$ & $84,9 \%$ & $94,2 \%$ & $99,0 \%$ & $96,0 \%$ & $93,9 \%$ \\
\hline ID $14 T N_{P P} / T N_{R}$ & - & $74,6 \%$ & $72,1 \%$ & $71,7 \%$ & $79,0 \%$ & $80,7 \%$ & $80,9 \%$ & $80,6 \%$ & $81,5 \%$ & $86,6 \%$ \\
\hline ID $15 T N_{R} / T N$ & - & $69,3 \%$ & $79,4 \%$ & $82,4 \%$ & $94,9 \%$ & $96,0 \%$ & $84,8 \%$ & $82,1 \%$ & $99,9 \%$ & $99,9 \%$ \\
\hline
\end{tabular}




\section{Evolução dos indicadores operacionais}

Apesar de não ser o foco desse trabalho, destaca-se que a estrutura proposta também pode ser utilizada para avaliar a evolução da produtividade dos terminais, permitindo identificar tendências e acompanhar os resultados de ações propostas pela gerência.

A Figura 37 ilustra um exemplo no qual se observou uma grande variação no indicador ID 8 (Índice de Manutenção Corretiva do Circuito de Embarque) do Berço 6. A partir do sexto mês, o indicador foi reduzido em $49 \%$. Isso se deve, segundo os funcionários da mineradora, a uma mudança de gestão proposta pela diretoria.

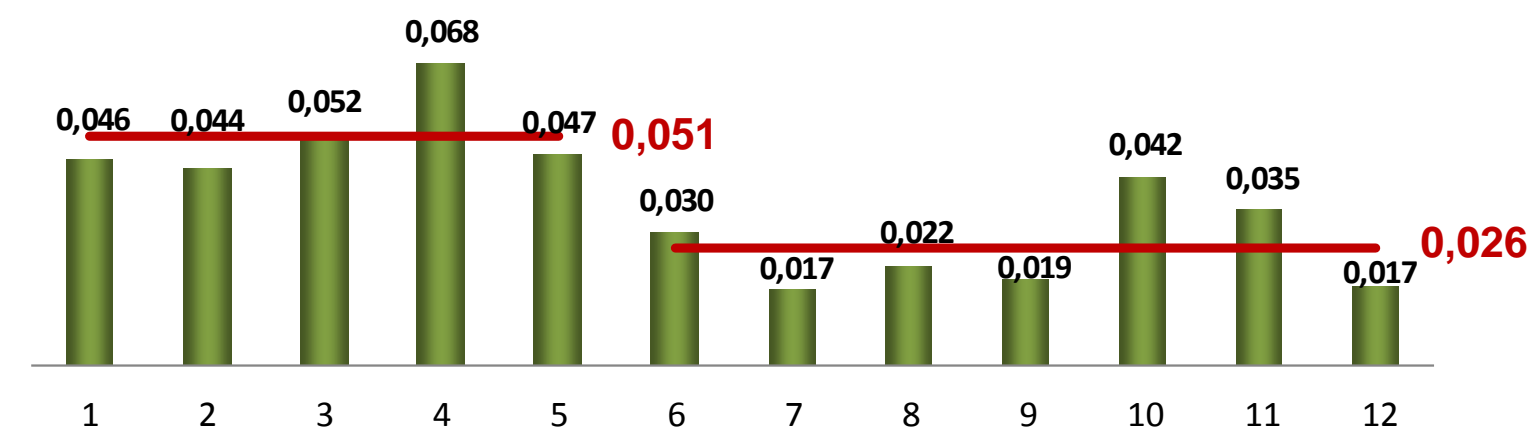

Figura 37: Evolução do Índice de Manutenção Corretiva do Circuito de Embarque. Fonte: Elaborado pelo autor

\subsection{Definição de metas operacionais e estimativa de ganhos de produtividade}

Esta seção apresentará as metas operacionais determinadas a partir do benchmarking dos indicadores de um mesmo grupo de comparação.

Foram identificados e estabelecidos até quatro grupos de comparação para os indicadores, conforme apresentado na Figura 38. 


\begin{tabular}{|c|c|c|c|c|c|}
\hline \multicolumn{2}{|c|}{ INDICADOR } & GRUPO 1 & \multirow[t]{2}{*}{ GRUPO 2} & \multirow[t]{2}{*}{ GRUPO 3} & \multirow[t]{2}{*}{ GRUPO 4} \\
\hline ID 5 & MA / \#Navio & $\begin{array}{l}\text {-Cada berço } \\
\text { isoladamente }\end{array}$ & & & \\
\hline ID 6 & PR / \#Navio & -Todos os berços & & & \\
\hline ID 7 & $\mathrm{MC}_{\mathrm{C}} / \mathrm{HO}$ & $\begin{array}{l}- \text { Berços } 2 \text { e } 3 \\
\text { (0,5 CN por berço) }\end{array}$ & $\begin{array}{l}\text {-Berços } 8 \text { e } 9 \\
\text { (1,5 CN por berço) }\end{array}$ & $\begin{array}{l}\text { - Berços 1, 4, 5, } 6 \text { e } 7 \\
\text { (1 CN por berço) }\end{array}$ & \\
\hline ID 8 & $\mathrm{MC}_{\mathrm{R}} / \mathrm{HO}$ & $\begin{array}{l}\text { - Berços } 4 \text { e } 5 \\
\text { (1 rota por berço) }\end{array}$ & $\begin{array}{l}\text { - Berços } 6,7,8 \text { e } 9 \\
\text { (mais de } 1 \text { rota por berço) }\end{array}$ & $\begin{array}{l}\text { - Berços } 1,2 \text { e } 3 \text { (falta } \\
\text { máq. de pátio) }\end{array}$ & \\
\hline ID 9 & $\mathrm{PO} / \mathrm{HO}$ & $\begin{array}{l}\text {-Berços 1, 2, 3, 4, } 5 \text { e } 7 \\
\text { (1 CN por berço) }\end{array}$ & $\begin{array}{l}\cdot \text { Berços } 8 \text { e } 9 \\
(1,5 \text { CN por berço) }\end{array}$ & $\begin{array}{l}\text { - Berço } 6 \\
\text { (2 braços de CN por berço) }\end{array}$ & \\
\hline ID 10 & $\mathrm{BL}_{\mathrm{C}} / \mathrm{HO}$ & $\begin{array}{l}\text { - Berços } 2 \text { e } 3 \\
(0,5 \mathrm{CN} \text { por berço })\end{array}$ & $\begin{array}{l}- \text { Berços } 8 \text { e } 9 \\
\text { (1,5 CN por berço) }\end{array}$ & $\begin{array}{l}\text {-Berços } 4 \text { e } 5 \\
\text { (1 CN / berço e } 1 \text { rota / CN) }\end{array}$ & $\begin{array}{l}\text { - Berços } 1,6 \text { e } 7 \\
\text { (1 CN / berço e } 2 \text { rotas / CN) }\end{array}$ \\
\hline ID 11 & $\mathrm{BL}_{\mathrm{R}} / \mathrm{HO}$ & $\begin{array}{l}\text { - Berços } 4 \text { e } 5 \\
\text { (1 rota por berço) }\end{array}$ & $\begin{array}{l}\cdot \text { Berços } 6,7,8 \text { e } 9 \\
\text { (mais de } 1 \text { rota por berço) }\end{array}$ & $\begin{array}{l}\text { - Berços } 1,2 \text { e } 3 \text { (falta } \\
\text { máq. de pátio) }\end{array}$ & \\
\hline ID 14 & $\mathrm{TN}_{\mathrm{PP}} / \mathrm{TN}_{\mathrm{R}}$ & -Todos os berços & & & \\
\hline ID 15 & $\mathrm{TN}_{\mathrm{R}} / \mathrm{TN}$ & $\begin{array}{l}\text { - Berços } 4,5,8 \text { e } 9 \\
\text { (1 rota por } C N \text { ) }\end{array}$ & $\begin{array}{l}\text { - Berços } 6 \text { e } 7 \\
\text { (2 rotas por } \mathrm{CN} \text { ) }\end{array}$ & $\begin{array}{l}\text { - Berços } 1,2 \text { e } 3 \\
\text { (falta máq. de pátio) }\end{array}$ & \\
\hline
\end{tabular}

Figura 38: Grupos de terminais com características semelhantes para cada indicador comparável. Fonte: Elaborado pelo autor

Como visto na seção 4.4 , foi considerada como meta operacional a média entre os $25 \%$ dos registros mensais de melhor desempenho.

Julgou-se pertinente não estabelecer metas para as paradas nas rotas (tanto de bloqueio, ID 11, quanto de manutenção corretiva, ID 8) nos Berços 1, 2 e 3 devido à falta de equipamentos de pátio, que não permite a regularidade da operação. Neste caso, presumiu-se que a programação do terminal está fazendo o melhor possível para lidar com a falta de ativos e balancear suas alocações nos sistemas de embarque e descarga, não fazendo sentido atribuir metas a esses sistemas.

Algo semelhante ocorreu na definição de metas para o Índice de Bloqueio do Circuito de Embarque (ID 10), já os Berços 2 e 3, os Berços 4 e 5, e os Berços 8 e 9 possuem riscos de colisão de equipamentos diferenciados e que dificilmente pode ser evitados, não fazendo sentido estabelecer metas.

Desta forma, os valores-alvos resultantes são apresentados na Figura 38. 


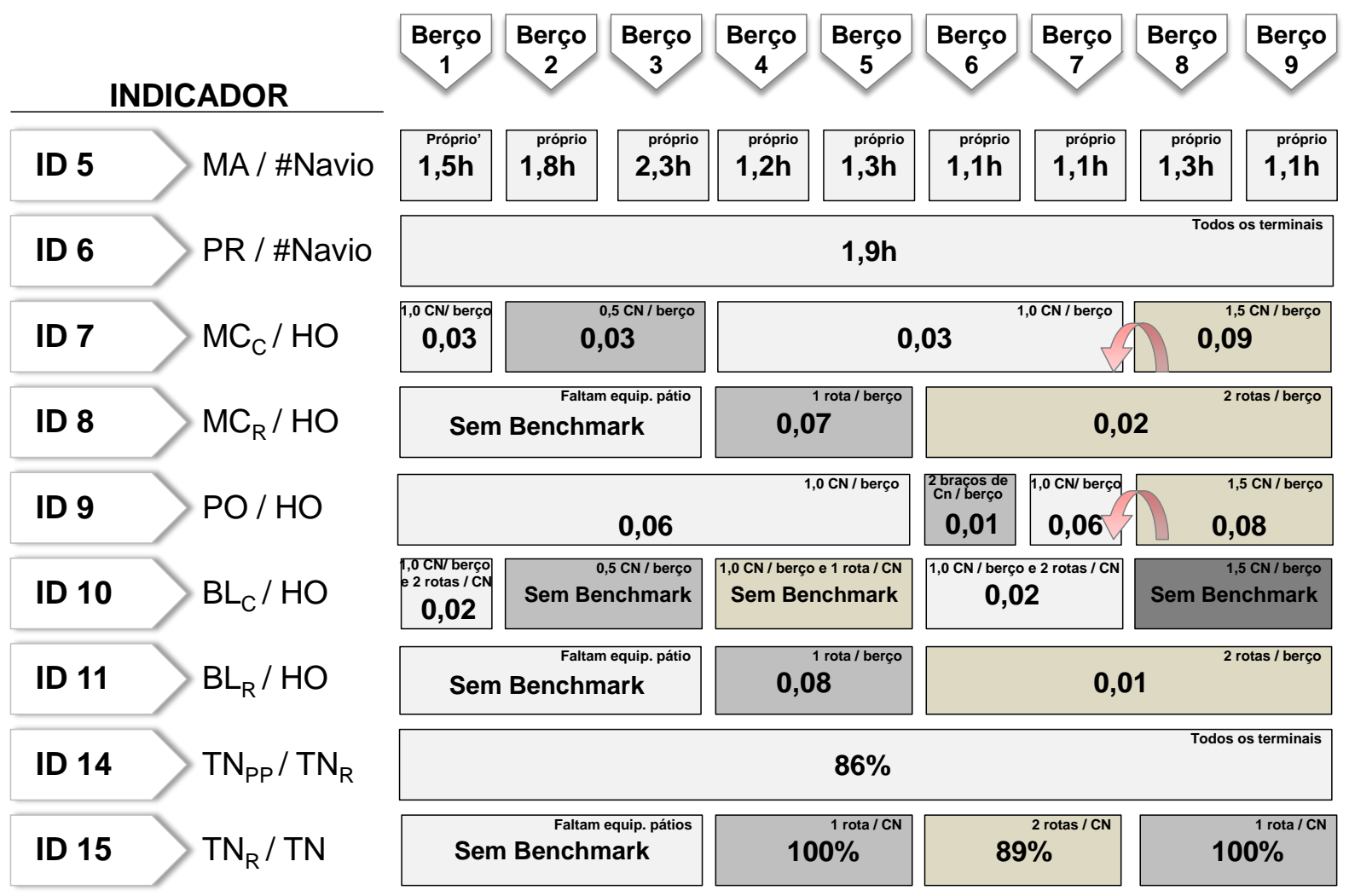

Figura 39: Metas operacionais para cada indicador comparável. Fonte: Elaborado pelo autor

Note-se que a meta para as paradas nas rotas (soma das metas dos indicadores ID 8 e ID 11) são cerca de 5 vezes maiores nos Berços 4 e 5, se comparado com os demais. Neste caso, para cada hora de operação, o sistema deve ficar parado por 0,15 horas (ou 9 minutos) no primeiro grupo e apenas 0,03 horas (ou 1,8 minutos) no segundo.

O valor benchmark para o tempo de parada devido a quebras nos equipamentos do circuito (ID 7) é de 0,03 horas (ou 1,8 minutos) para todos os sistemas. $O$ autor esperava que esse tempo fosse consideravelmente inferior para os Berços 8 e 9 , que compartilham um circuito de embarque adicional - o que possibilita continuar a operação mesmo com a parada de um dos equipamentos. Observou-se, no entanto, que nos meses de melhor desempenho desses berços, as quebras no circuito de embarque são cerca de três vezes maiores que o Berço 7 , de circuito único. Dessa forma, considerou-se que esses berços poderiam, pelo menos, alcançar o nível benchmark dos demais terminais.

Algo semelhante ocorre para o indicador de paradas operacionais (ID 9). Os Berços 8 e 9 apresentaram valores superiores do que os berços que possuem apenas um 
CN. Da mesma forma, considerou-se que esses berços poderiam, pelo menos, alcançar o nível benchmark dos demais. Assim, somente o Berço 6, que possui um $\mathrm{CN}$ do tipo duo-radial, terá uma meta diferenciada de paradas operacionais, de apenas 0,01 horas (ou 36 segundos) por hora operada.

Por fim, destaca-se que a meta do indicador ID 15 para os Berços 6 e 7 é inferior a dos demais porque seus $\mathrm{CNs}$ utilizam duas rotas simultâneas e qualquer interrupção e uma das rotas faz com que o sistema não utilize toda a capacidade potencial. Dessa forma, o índice que mede a utilização da capacidade desses sistemas terá meta de apenas $89 \%$, ante os $100 \%$ dos demais.

A seguir, serão descritos os ganhos teóricos de volume movimentado se os terminais conseguirem atingir suas metas para todos os indicadores simultaneamente.

\subsubsection{Ganhos potenciais teóricos}

A Figura 40 indica que, se alcançados os valores benchmark, as melhorias no Berço 1 adicionariam 8,0Mt por ano na movimentação do terminal sem aumentar o comprometimento dos sistemas.

A variação da taxa de movimentação (ID 14) aparece como o item com maior perspectiva de ganho potencial: $3,8 \mathrm{Mt}$ adicionais.

Outras 4,2 Mt poderiam ser movimentadas diminuindo-se os tempos de quebras e bloqueios no circuito de embarque (ID 7 e ID 10 -1,9Mt), de pré e pós-operacionais (ID 6 - 1,7Mt) e de paradas operacionais (ID 9 - 0,5Mt). As 0,2 Mt restantes dependem de o CPBS atingir seus melhores níveis históricos de manobras (ID 5). 


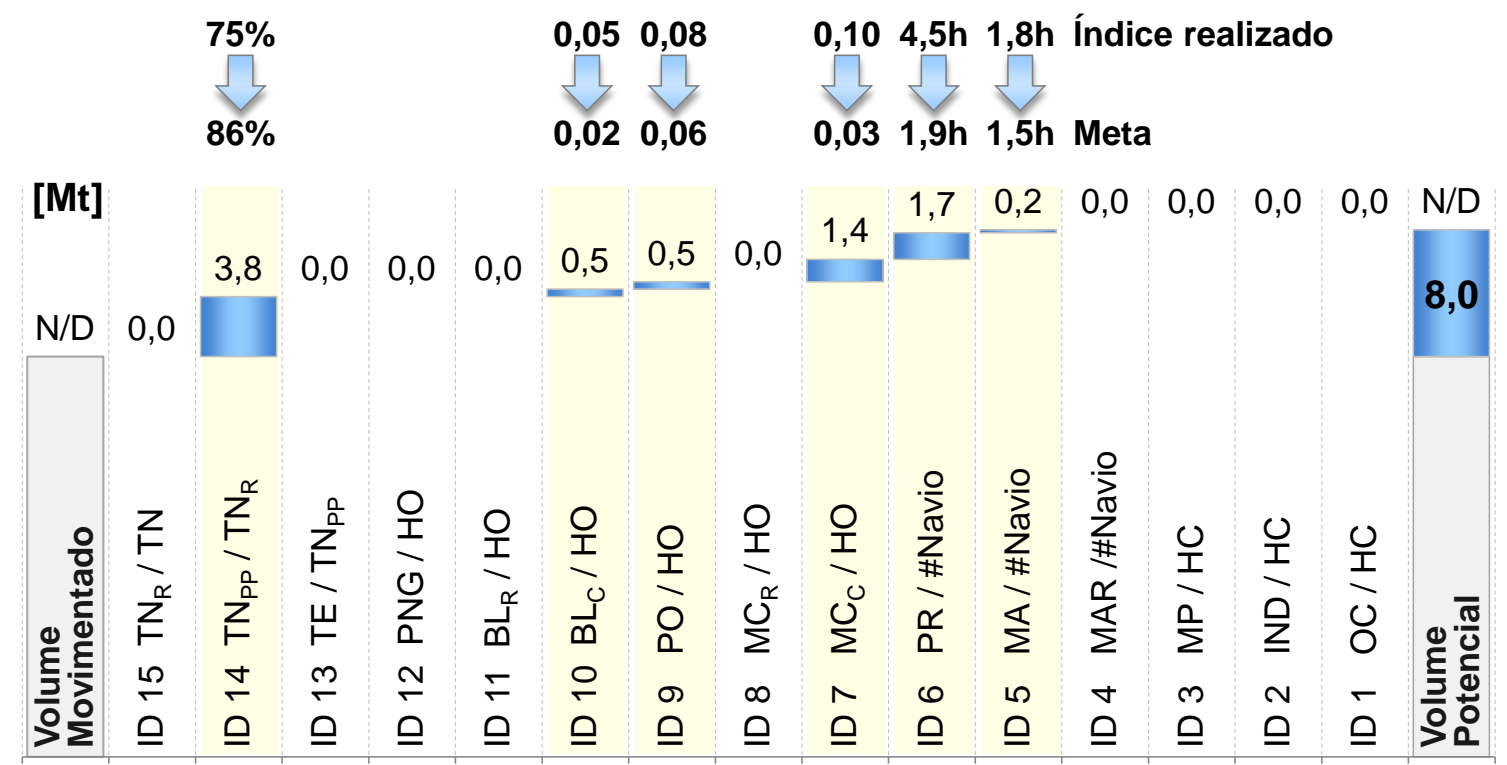

Figura 40: Ganhos Potenciais para o Berço 1. Fonte: Elaborado pelo autor

De forma semelhante, o Terminal 2 (Berços 2 e 3 ) poderia aumentar sua movimentação em até $16 \mathrm{Mt}$ por ano se as metas operacionais forem atingidas.

O Berço 2 também possui o maior potencial de ganhos relacionado à sua variação da taxa de movimentação (ID 14), 3,1 Mt, como se observa na Figura 41.

Aumentos adicionais podem ser conseguidos através de elevações nos indicadores de pré e pós-operacionais (ID 6 - 1,8Mt), paradas operacionais (ID 9 - 0,8Mt), quebras no circuito de embarque (ID 7 - 0,5Mt) e manobras (0,2Mt).

Dessa forma, o incremento teórico de volume para o Berço 2 é 6,3 Mt.

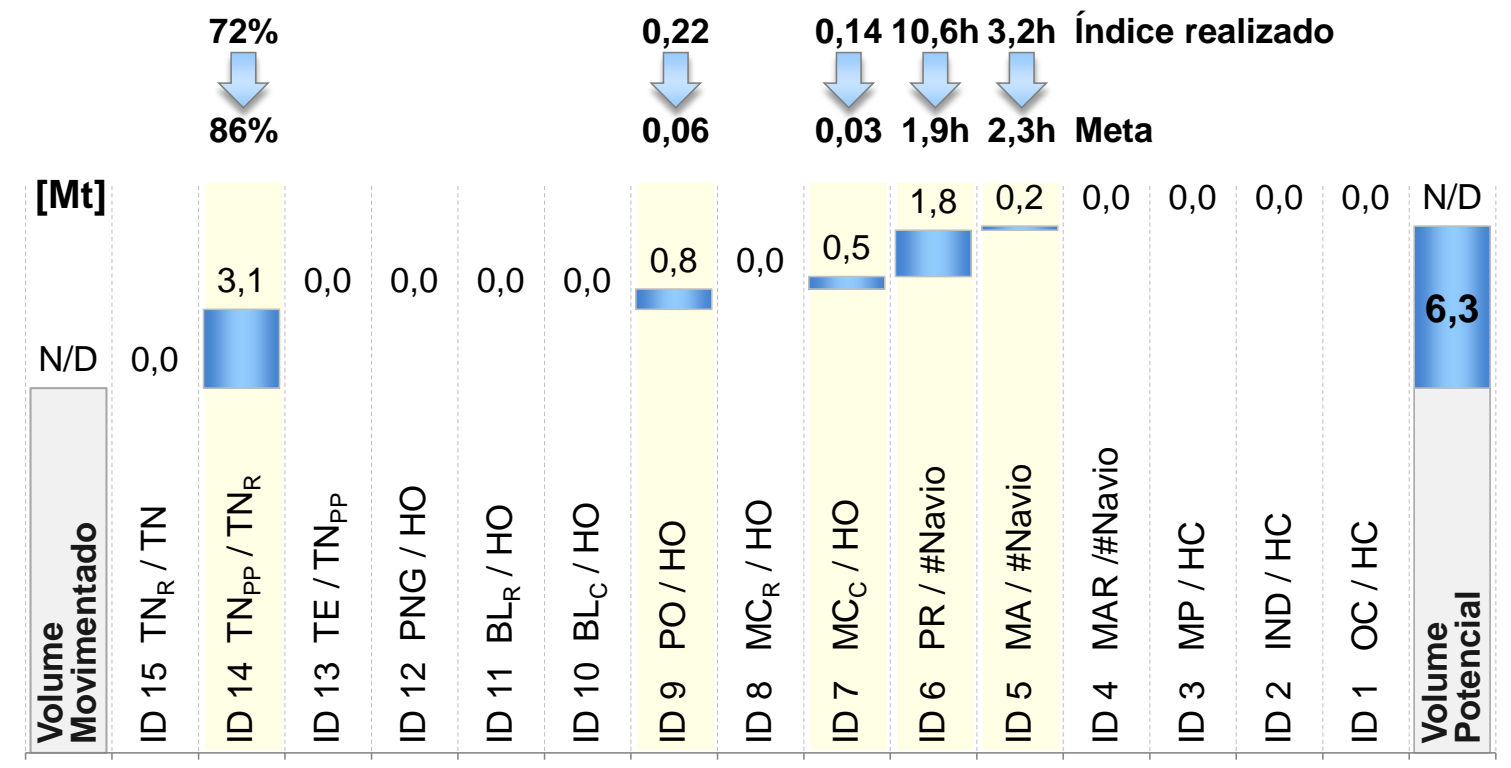

Figura 41: Ganhos Potenciais para o Berço 2. Fonte: Elaborado pelo autor 
A Figura 42 aponta a possibilidade de ganhos de até 5,9 Mt no Berço 3 somente com $20 \%$ de melhoria em sua recuperação (ID 14). Ganhos adicionais de 3,6 Mt podem ser alcançados com a elevação do indicador de quebras no circuito de embarque (ID 7 - 1,8Mt), paradas operacionais (ID 9 - 1,0Mt), pré e pós-operacionais (ID 6 - 0,7Mt) e manobras (ID 5 - 0,1Mt).

Assim, o incremento de volume teórico para o Berço 3 pode chegar a 9,5 Mt em um ano.

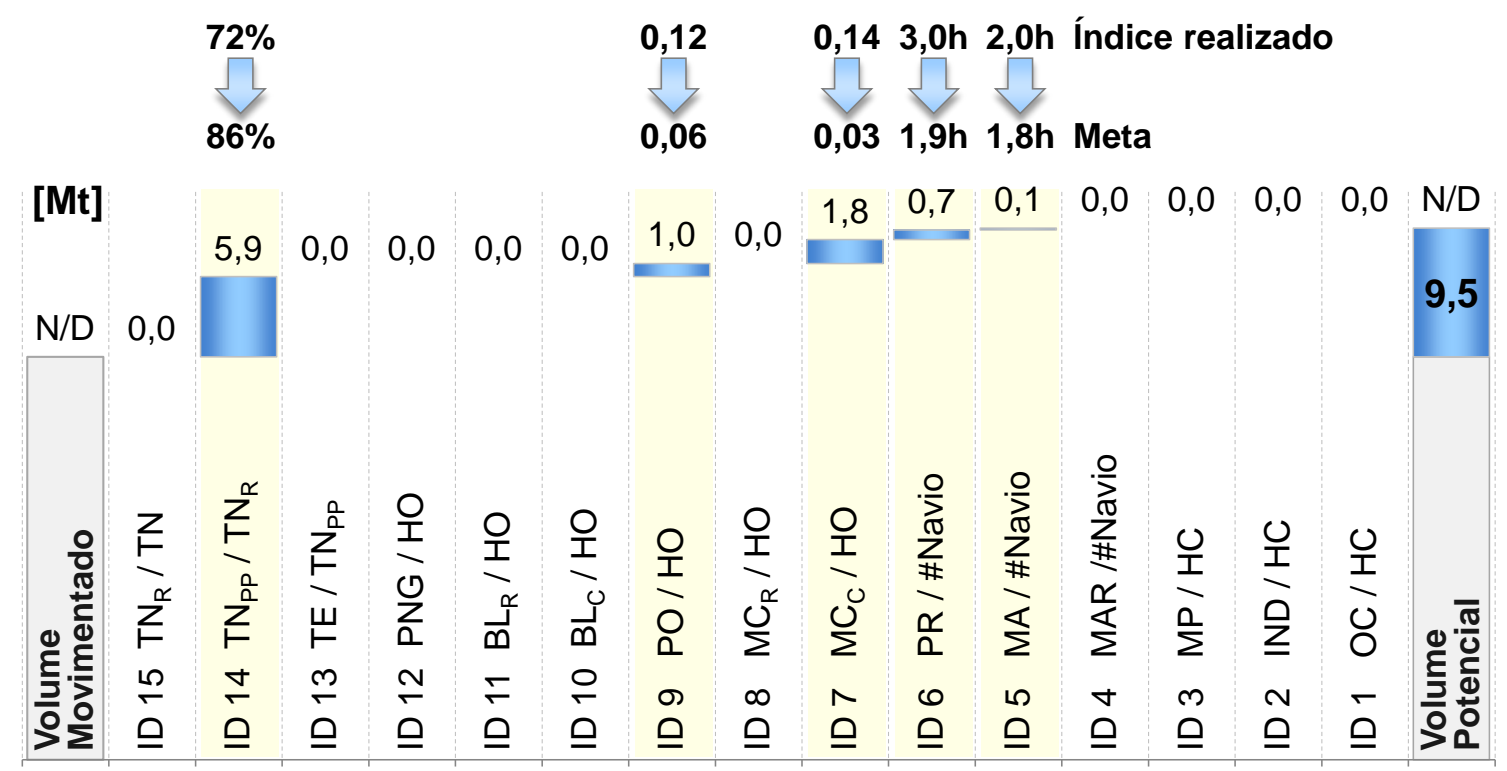

Figura 42: Ganhos Potenciais para o Berço 3. Fonte: Elaborado pelo autor

Se fosse possível alcançar os valores benchmark em todos os índices, o Terminal 3 (Berços 4, 5 e 6) poderiam movimentar mais $20 \mathrm{Mt}$ por ano sem alterar seu comprometimento.

Os maiores ganhos teóricos para o Berço 4 estão relacionados à variação da taxa de movimentação (ID 14 - 2,2 Mt) e a subutilização da capacidade de seus equipamentos (ID 15 - 1,4 Mt), que podem ser atingidos através de um aumento na regularidade da recuperação (grande oscilação de desempenho entre os meses analisados) e através de uma melhora na programação das máquinas, visando minimizar a operação com equipamentos gargalos (Figura 43).

Volumes adicionais de até 2,2Mt podem ser conseguidos através da diminuição das quebras no circuito de embarque (ID 7 - 0,9 Mt), quebras e bloqueios nas rotas (ID 8 
e ID 11 - 0,8 Mt), nos tempos pré e pós-operacionais (ID 6 - 0,3 Mt) e de manobras (ID 5 - 0,1 Mt).

Convém notar que o ganho potencial com a redução das paradas operacionais é diminuto frente aos demais, dado que o berço atingiu uma regularidade próxima ao valor benchmark no período.

Com isso o ganho potencial possível de ser embarcado pode chegar a 5,8 Mt.

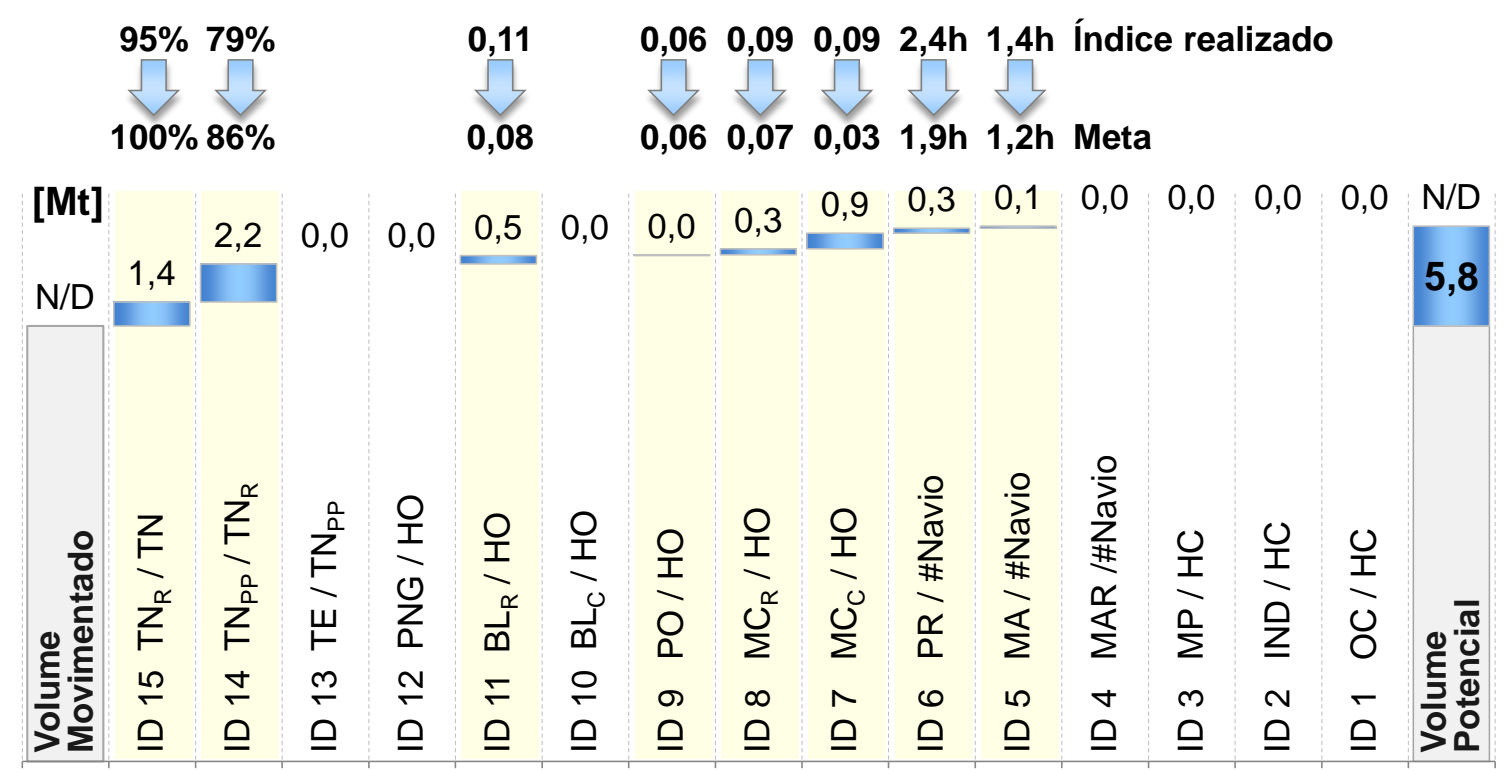

Figura 43: Ganhos Potenciais para o Berço 4. Fonte: Elaborado pelo autor

Já os maiores ganhos potenciais do Berço 5 podem ser alcançados com a diminuição de quebras e bloqueios nas rotas (ID 8 e ID 11) e no circuito (ID 7), 1,4Mt e 1,1Mt, respectivamente (Figura 44).

Outros acréscimos na movimentação podem ser conquistados com melhores desempenhos na recuperação (ID 14 - 0,5Mt) e com uma utilização mais eficiente de seus equipamentos, de forma a mitigar a subutilização do CN (ID 15 -0,5Mt). Além disso, pode-se buscar uma redução nos tempos gastos com pré e pós-operacionais (ID 6 - 0,3Mt) e manobras (ID 5 - 0,1Mt). Novamente o ganho potencial com a redução das paradas operacionais é pouco representativo.

Com isso, o acréscimo teórico de movimentação no embarque do Berço 5 é de 4,0 Mt. 


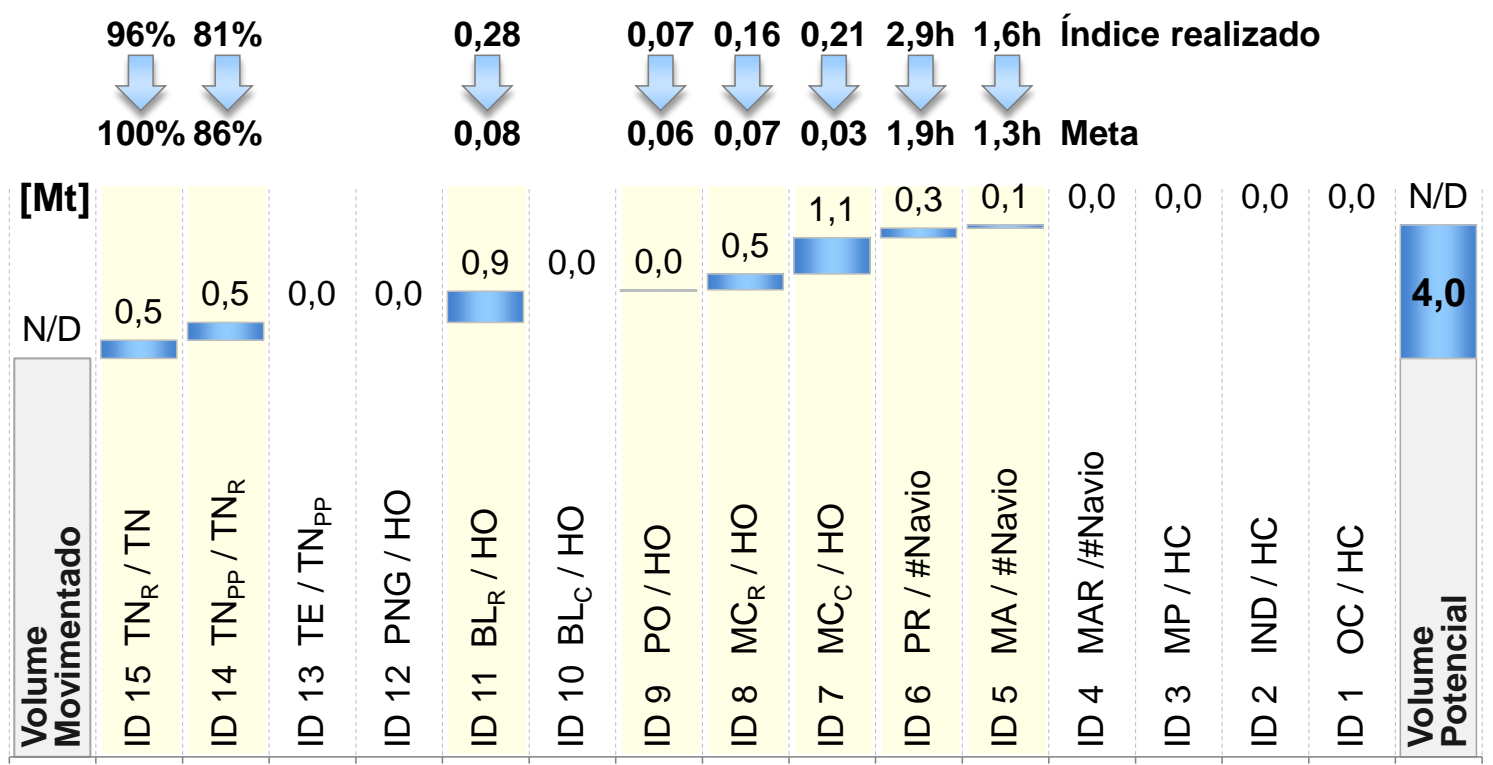

Figura 44: Ganhos Potenciais para o Berço 5. Fonte: Elaborado pelo autor

Os ganhos teóricos mais promissores para o Berço 6 estão relacionados às melhorias na recuperação (ID 14 - 3,8 Mt) e a utilização mais eficiente da capacidade instalada dos equipamentos (ID 15 - 2,8Mt), como mostra a Figura 45. Destaca-se que esses ganhos são fruto, principalmente, das oscilações de desempenho apresentadas no período, já que se observou na análise de dados que o berço alcançou os valores benchmark em ambos indicadores.

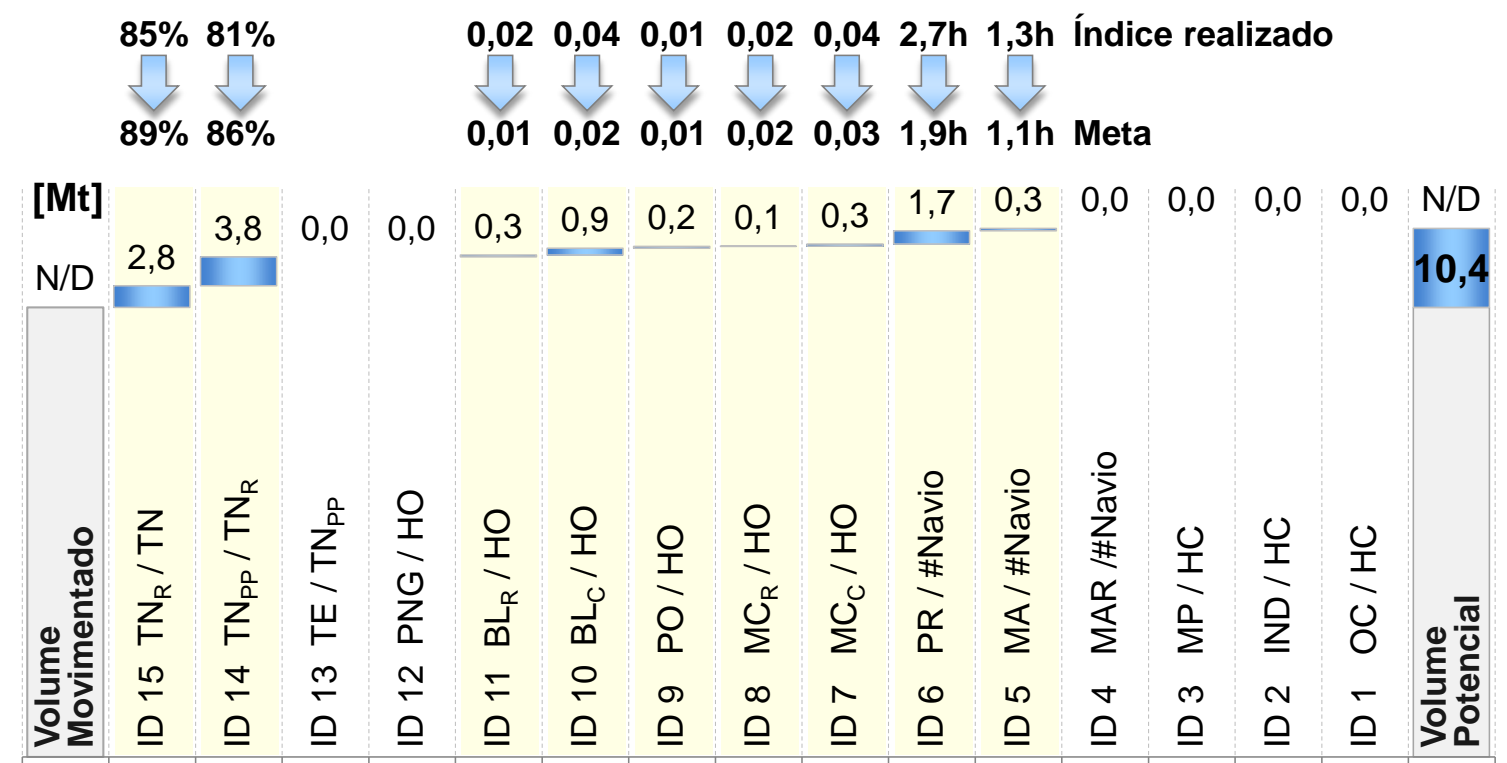

Figura 45: Ganhos Potenciais para o Berço 6. Fonte: Elaborado pelo autor 
Aumentos adicionais no embarque do Berço 6 podem ser conseguidos através de reduções no tempo de pré e pós-operacionais (ID 6 - 1,7 Mt), bloqueios e quebras no circuito (ID 10 e ID 7 - 1,2 Mt) e nas rotas (ID 11 e ID 8 - 0,4 Mt), além de reduções nas oscilações dos tempos de manobras (ID 5 - 0,3 Mt) e de Paradas Operacionais (ID 9 - 0,2 Mt), somando assim 10,4 Mt.

O Terminal 4 (Berços 7, 8 e 9) poderia ter um aumento teórico de até 40 Mt se alcançasse os índices alvo em todos os indicadores de desempenho.

A maior perspectiva de ganho para o Berço 7 deriva-se das quebras e bloqueios nas rotas (ID 8 e ID 11), 6,2 Mt, como mostra a Figura 46. O segundo maior ganho refere-se à utilização da capacidade de seu CN (ID 15), que apresenta grande oscilação mensal. A melhora nesse indicador geraria uma movimentação adicional de outras 4,0 Mt.

As demais possibilidades de incrementos na movimentação referem-se às paradas operacionais (ID 9 - 3,2Mt), a taxa de recuperação (ID 14 - 2,9Mt), aos períodos de quebras e bloqueios no circuito (ID 7 e ID 10 - 1,6Mt), aos tempos pré e pósoperacionais (ID 6 - 0,7Mt) e as manobras (ID 5 - 0,6Mt).

Com isso, o ganho potencial teórico do berço soma-se 19,2 Mt, o maior da amostra.

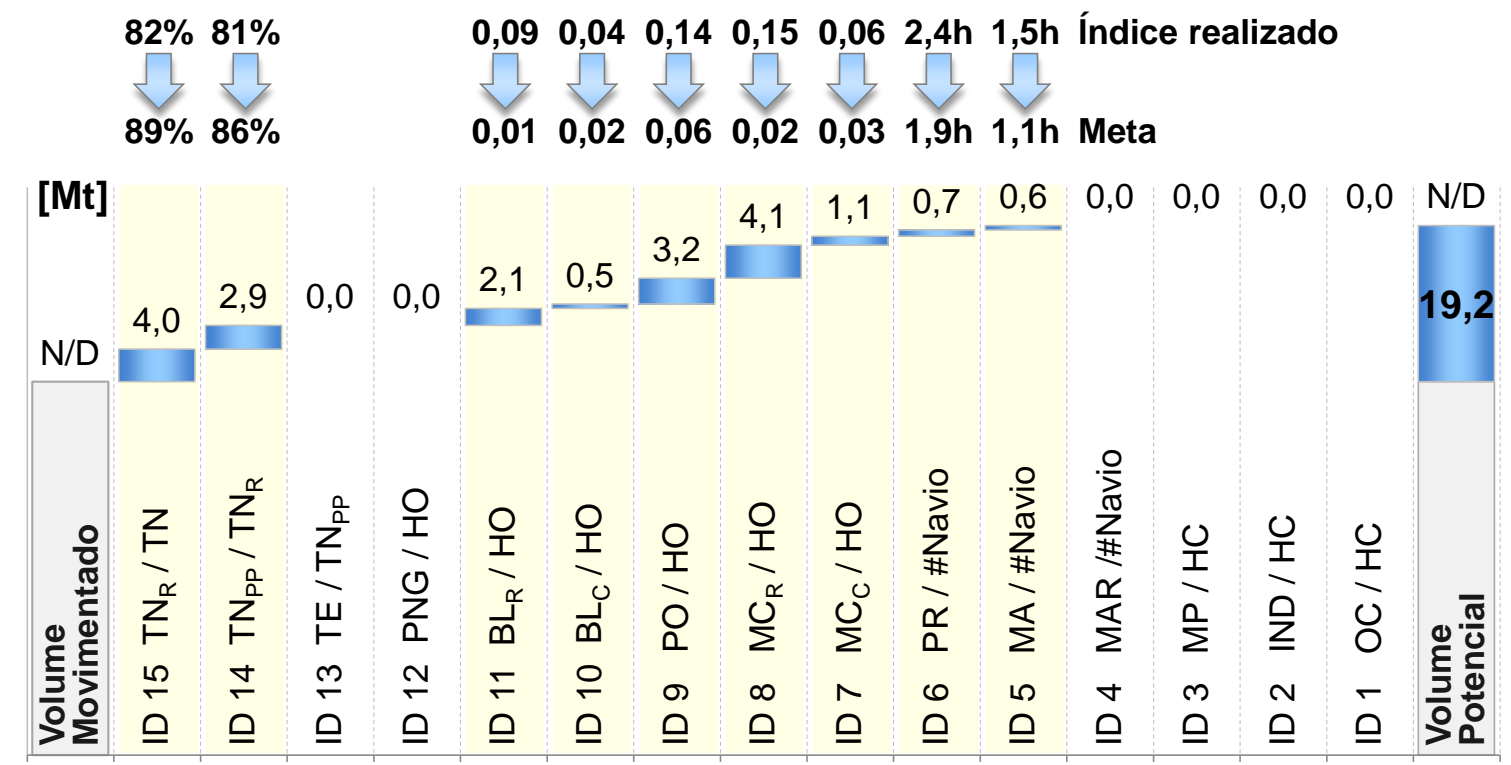

Figura 46: Ganhos Potenciais para o berço 7. Fonte: Elaborado pelo autor

O Berço 8 também concentra suas maiores possibilidades de ganhos na diminuição das quebras e bloqueios nas rotas (ID 8 e ID 11 - 6,8 Mt). 
Outras melhorias podem gerar ainda 4,8 Mt caso sejam alcançadas e são elas: reduções nos tempos de quebras no circuito (ID 7 - 1,7 Mt), variação na taxa de movimentação (ID 14 - 1,2 Mt), paradas operacionais (ID 9 - 0,9 Mt), pré e pósoperacionais (ID 6 - 0,1 Mt) e manobras (ID 5 - 0,1 Mt).

Dessa forma, o incremento potencial teórico do berço é de 10,8 Mt, como indica a Figura 47.

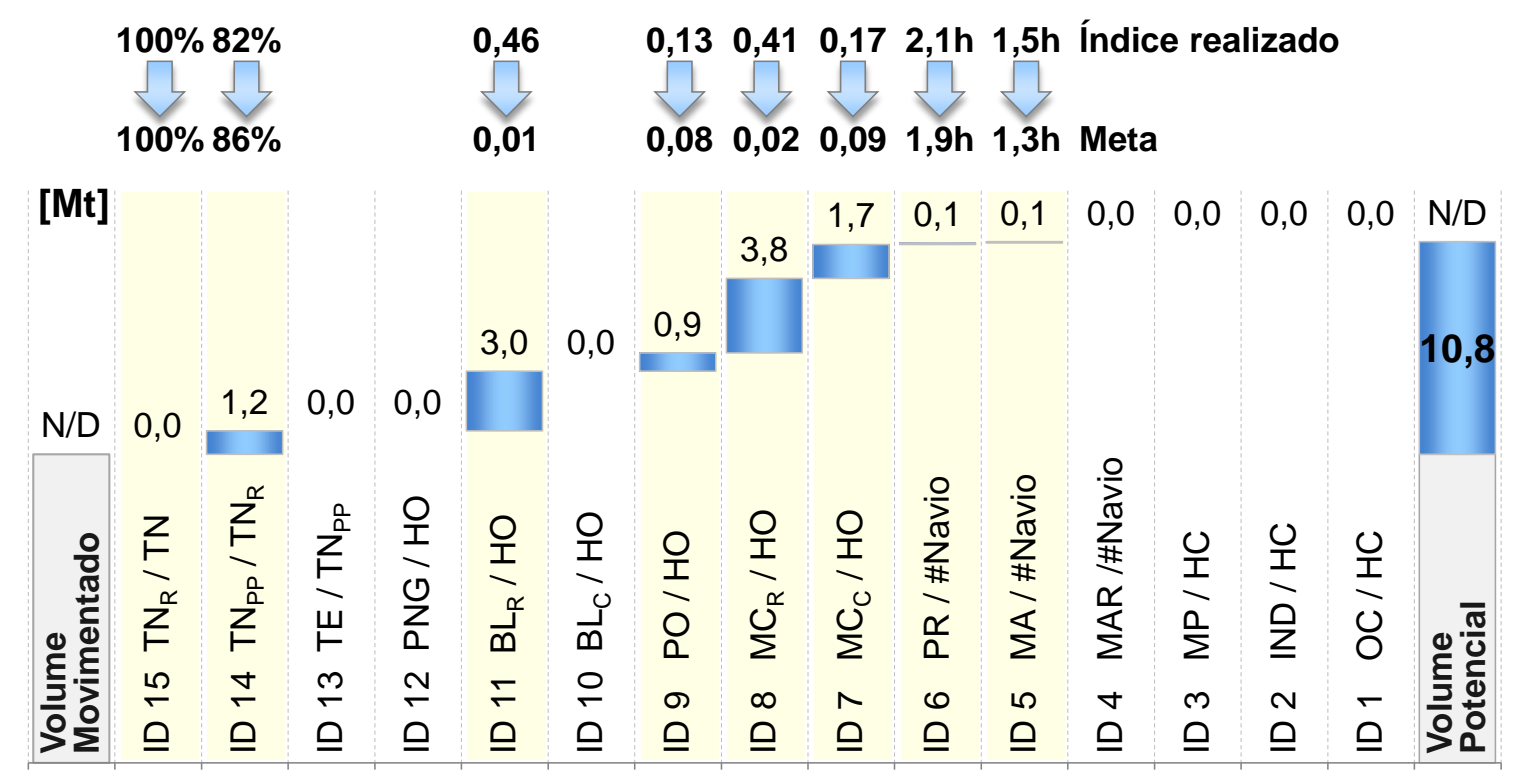

Figura 47: Ganhos Potenciais para o berço 8. Fonte: Elaborado pelo autor

Para o Berço 9, o aumento potencial de volume mais acentuado também está relacionado com as quebras e os bloqueios nas rotas (ID 8 e ID 11), que ampliariam a quantidade de minério embarcada em cerca de 7,0Mt por ano (Figura 48).

Os demais ganhos somam 2,6 Mt, sendo 1,9 Mt devido a reduções nas quebras do circuito (ID 7), 0,6 Mt gerados pela redução nas paradas operacionais (ID 9) e apenas 0,1 Mt pela diminuição do tempo de manobra (ID 5).

Os indicadores de medem as atividades pré e pós-operacionais (ID 6) e a variação da taxa de movimentação (ID 14) possuem ganhos pouco expressivos devido ao bom desempenho desse berço nesses processos.

Dessa forma, as elevações para valores benchmark de todos os indicadores considerados perfazem um aumento teórico de 9,6 Mt no Berço 9. 


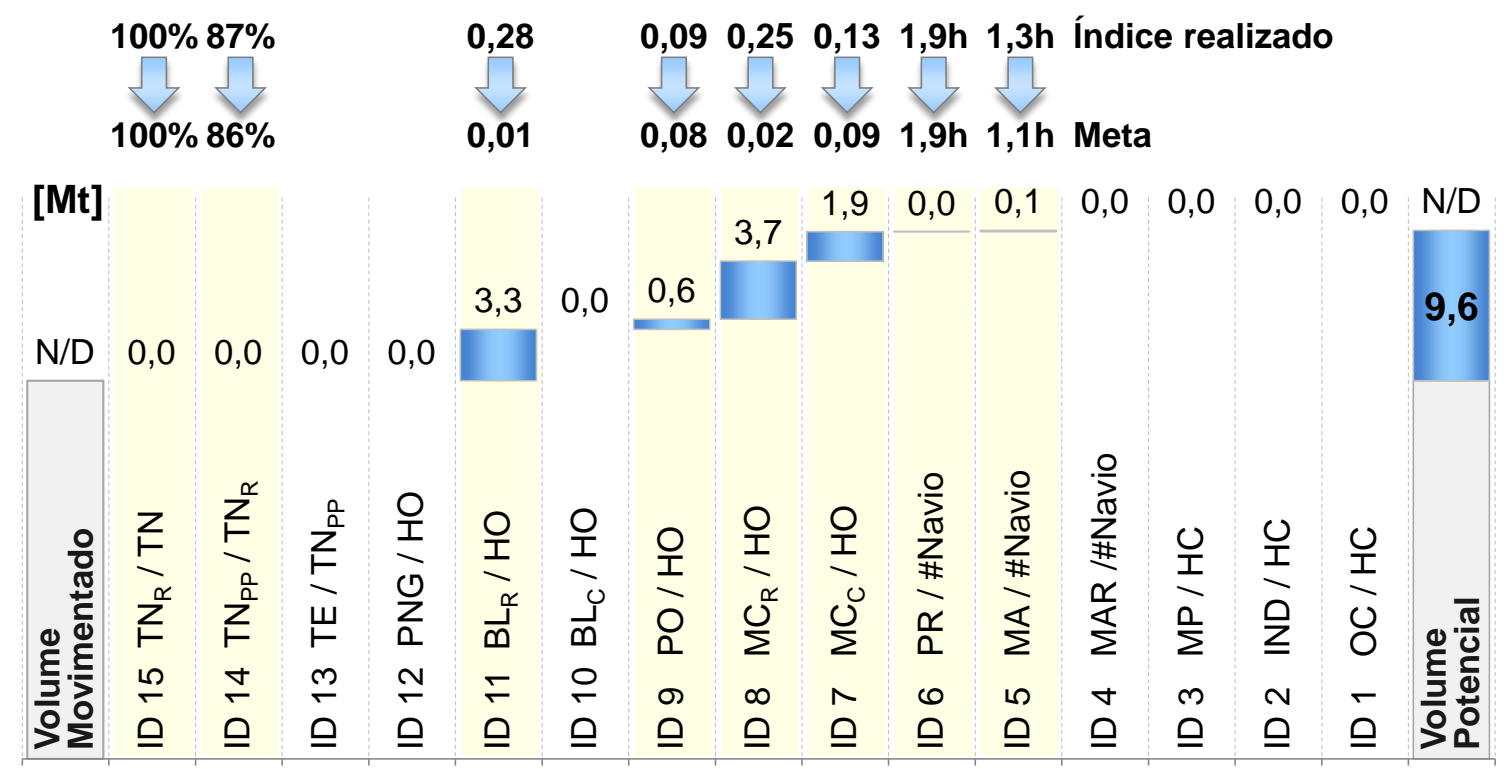

Figura 48: Ganhos Potenciais para o Berço 9. Fonte: Elaborado pelo autor

\subsection{Conclusão do estudo de caso}

Os resultados do estudo são úteis para aumentar a compreensão dos sistemas. Sua conclusão aponta uma grande oscilação no desempenho dos terminais durante o ano. Os Terminais 4 e 3 apresentaram os melhores e alguns dos piores índices mensais, concentrando as maiores possibilidades de ganhos potenciais no período, o que sugere a dispersão das competências (Figura 49 e Figura 50).

As perdas com as maiores perspectivas de melhora e que devem ser investigadas pela empresa são:

- Variação da taxa de movimentação (ID 14) - o que indica uma baixa eficiência das recuperadoras, se comparado aos benchmarks;

- Quebras e bloqueios nas rotas de embarque (ID 8 e ID 11); e

- Quebras e bloqueios no circuito de embarque (ID 7 e ID 10) - principalmente no carregador de navios. 


\section{SOMA TEÓRICA DE MELHORIA POTENCIAL}

INDICADOR

\begin{tabular}{|l|l|}
\hline \multicolumn{1}{|c|}{ INDICADOR } \\
\hline ID 5 & $\mathrm{MA} /$ \#Navio \\
\hline ID 6 & $\mathrm{PR} /$ \#Navio \\
\hline ID 7 E 10 & $\mathrm{MC}_{\mathrm{C}} / \mathrm{HO}+\mathrm{BL}_{\mathrm{C}} / \mathrm{HO}$ \\
\hline ID 8 E 11 & $\mathrm{MC}_{\mathrm{R}} / \mathrm{HO}+\mathrm{BL}_{\mathrm{R}} / \mathrm{HO}$ \\
\hline ID 9 & $\mathrm{PO} / \mathrm{HO}$ \\
\hline ID 14 & $\mathrm{TN}_{\mathrm{PP}} / \mathrm{TN}$ \\
\hline ID 15 & $\mathrm{TN}_{\mathrm{R}} / \mathrm{TN}$ \\
\hline Total \\
\hline
\end{tabular}

[Mt]

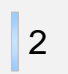

7

13

23

7

23

9

84

\section{MAIORES}

GANHOS

COM QUEM APRENDER

Figura 49: Perdas operacionais com maiores perspectivas de melhora e os terminais benchmark. Fonte: Elaborado pelo autor

Se fosse possível operar com todos indicadores nos níveis benchmark, o operador portuário teria um grande potencial de melhoria, permitindo um aumento teórico de até 84Mt por ano no volume embarcado.

\section{Volume potencial com valores benchmark [Mt]}

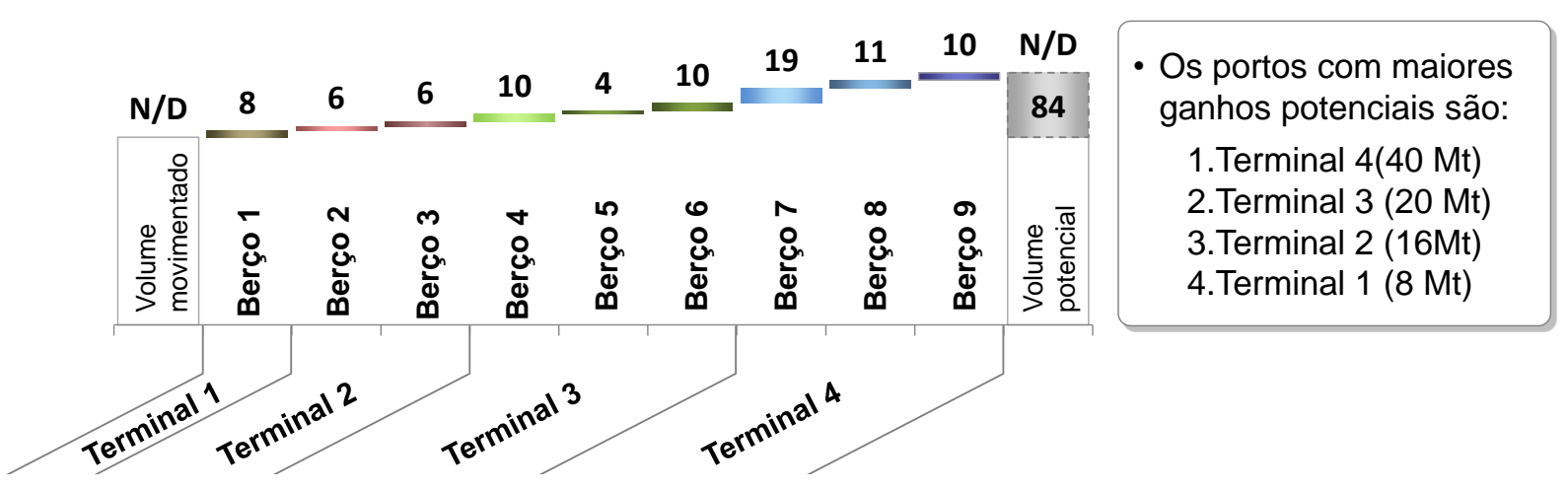

Figura 50: Ganho teórico potencial com todos os indicadores nos níveis benchmark. Fonte: Elaborado pelo autor 


\section{CONCLUSÕES}

O Brasil é uma das economias mais promissoras do mundo, com grande parte do sucesso atrelada a capacidade de produzir e exportar commodities e insumos extrativos básicos, como minério de ferro, que representam cerca de $50 \%$ das exportações.

As exportações dependem de uma infraestrutura altamente custosa. É determinante para a competitividade das empresas e do país a utilização eficiente dos ativos portuários.

A gestão de indicadores de desempenho é um assunto relativamente recente e importante na gestão portuária. Contudo, muitos operadores possuem um sistema de monitoramento simplificado, ou não exploram todo o potencial de análises dos dados coletados, resignando parte dos benefícios possíveis.

O trabalho buscou contribuir avaliando, em um nível maior de detalhe, a eficiência operacional de terminais especializados na exportação de granéis sólidos minerais. O objetivo foi desenvolver uma estrutura de indicadores de desempenho que possuísse índices operacionais comparáveis entre terminais, capazes de subsidiar a identificação de melhores práticas e o estabelecimento de metas operacionais efetivamente pertinentes para cada sistema, através de uma análise de benchmarking.

A aplicação do método exposto por meio de um estudo de caso possibilitou testar sua exequibilidade e coerência, mostrando-se eficaz, uma vez que cumpriu o objetivo proposto. Os indicadores identificaram as principais origens das ineficiências operacionais, indicaram quanto os processos podem ser aperfeiçoados e em quem se espelhar.

A abordagem, baseada em ferramentas e conceitos consagrados de gestão organizacional, gestão por processos e gestão da qualidade, não teve a pretensão de ser inovadora e sofisticada, pelo contrário, buscou-se ser de fácil aplicação e objetiva, para aumentar sua aceitação.

Em sua formulação, relacionam-se os indicadores de desempenho dos processos com o OEE, o que possibilita aferir a relação de cada índice com o desempenho 
global do sistema e com a quantidade de carga movimentada. Isso fornece uma previsão de ganho de produtividade, se forem alcançadas as metas operacionais, além de indicar quais ações devem ser priorizadas para que se obtenham os maiores ganhos.

Este trabalho difere-se dos demais encontrados na literatura em duas situações:

- Quando apresenta e discute os resultados de indicadores para os principais processos críticos que ocorrem durante $o$ atendimento das embarcações, com um alto nível de detalhamento; e

- Quando apresenta uma lista com os principais atributos físicos e operacionais dos terminais que deverão ser levados em consideração na comparação de cada indicador, já que não são todos os indicadores que podem ser comparados entre todos os terminais, devido às características peculiares de cada sistema.

O trabalho indicou os benefícios de se aprimorar os indicadores de desempenho operacional quando se deseja elevar o padrão dos serviços. Entretanto, os indicadores propostos são destinados exclusivamente à operação de exportação de granéis sólidos. $O$ autor julga que metodologia proposta pode ser ajustada para outras especializações de terminais.

Também poderiam ser elaborados, em complementação a este trabalho, estudos que visam ampliar o desempenho portuário em outras frentes de atuação, como o atendimento aos modais terrestres, a gestão dos estoques, a gestão e a competitividade econômica, a gestão da qualidade dos serviços, a satisfação dos clientes, dentre outros. 


\section{REFERÊNCIAS BIBLIOGRÁFICAS}

ANTAQ. Indicadores de Desempenho Portuário - Sistema Permanente de Acompanhamento de Preços e Desempenho Operacional dos Serviços Portuários. Agencia Nacional de Transportes Aquaviários. Brasília, 2003.

APO. Benchmarking Training Manual - a publication of the APO Best Practice Network. Asian Productivity Organization. Tokio, 2005.

ARRUDA, C.M.; JÚNIOR E.F.N. e MAGALHÃES P.S.B. Método dos Indicadores de Desempenho Proposto pela ANTAQ: Uma Aplicação Ao Terminal Portuário Do Pecém. XXVIII Encontro Nacional De Engenharia De Produção. Rio de Janeiro, 2008.

BANDEIRA, A.A. Rede de Indicadores de Desempenho para Gestão de uma Hidrelétrica. Dissertação (Mestrado) - Escola Politécnica da Universidade de São Paulo. São Paulo, 1997.

BARRETO, M.I.F. e PONGELUPPE, C.P. Teoria Geral da Administração. Universidade de Brasília (UnB), Centro de Educação a Distância (CEAD), 2006.

BARROS, C.P. A Benchmark Analysis of Italian Seaports Using Data Envelopment Analysis. Maritime Economics \& Logistics, Agosto de 2006: 347-365.

BARROS, C.P. Decomposing growth in Portuguese seaports: a frontier cost approach. Maritime Economics \& Logistic 7, 2005: 297-315.

BICHOU, K. Review of Port Performance Approaches and a Supply Chain Framework to Port Performance Benchmarking. Devolution, Port Governance and Port Performance. Research in Transport Economics, 17, por M. R. Brools e K. Cullinane. London: Elsevier, 2007.

BOURNE, M.; NEELY, A.; MILLS, J. e PLATTS, K. Implementing performance measurement systems: a literature review. Int. J. Business Performance Management, Vol. 5, No. 1, 2003: 1-24. 
CARDOZA, E. e CARPINETTI, L.C.R. Indicadores de desempenho para o sistema de produção enxuto. Revista Produção. Universidade Federal de Santa Catarina. Florianópolis, 2005.

CARETA, C. B. Indicadores de desempenho logístico: estudo de múltiplos casos no setor de bens de capital agrícolas. Dissertação (mestrado), Escola de Engenharia de São Carlos (EESC), Universidade de São Paulo, São Carlos, 2009.

CESPEDES, Juliana G. Modelos de Fronteira Estocástica: Uma Abordagem Bayesiana. Tese (doutorado) - Escola Superior de Agricultura "Luiz de Queiroz", Universidade de São Paulo, Piracicaba, 2008.

CHIAVENATO, Idalberto. Introdução à Teoria Geral da Administração. 7a edição. Rio de Janeiro: Editora Campus, 2004.

COLIN, E.C. Pesquisa operacional: 170 aplicações em estratégia, finanças, logística, produção, marketing e vendas. Rio de Janeiro: LTC, 2007.

CULLINANE, K.P.B.; SONG, D.W.; JI, P. e WANG, T.F. An application of DEA windows analysis to container port production efficiency. Review of Networks Economics, v. 3, 2004: $184-206$.

CULLINANE, K.P.B.; SONG, D.W. e WANG, T.F. The application of mathematical programming approaches to estimating container port production efficiency. Journal of Productivity Analysis 24, 2005: 73-92.

CULLINANE, K.P.B.; WANG, T.F.; SONG, D.W. e JI, P. The technical efficiency of container ports: comparing data envelopment analysis and stochastic frontier analysis. Transportation Research Part A 40, 2006: 354-374.

CULLINANE, K.P.B.; SONG, D.W. A stochastic frontier model of the productive efficiency of Korean container terminals. Applied Economics 35, 2003: 251-267.

CULLINANE, K.P.B.; SONG, D.W. e GRAY, R. A stochastic frontier model of the efficiency of major container terminals in Asia: assessing the influence of administrative and ownership structures. Transportation Research Part A 36, 2002: 734-762. 
DE MONIE, G. Measuring and Evaluating Port Performance and Productivity. United Nations Conference on Trade and Development. Geneva: UNCTAD Monographs on Port Management No. 6 on Port Management, 1987.

DEPLA. Departamento de Planejamento e Desenvolvimento do Comércio Exterior. Balança Comercial Brasileira - Dados Consolidados. Ministério do Desenvolvimento, Indústria e Comércio Exterior. Brasília, Setembro de 2010.

ESTACHE, A.; GONZÁLEZ, M.M. e TRUJILLO L. Efficiency Gains from Port Reform and the Potential for Yardstick Competition: Lessons from México. World Development, Vol. 30, No. 4, 2002: 545-560.

FOURGEAUD, Patrick. Measuring Port Performance. World Bank. Washington, 2000.

FRANCO, Francisco e Fortuna, Mário. O Método de Fronteira Estocástica na Medição da Eficiência dos Serviços Hospitalares: Uma Revisão Bibliográfica. APES, Associação Portuguesa de Economia da Saúde. Lisboa, 2003.

GOMES, P. A evolução do conceito de qualidade: dos bens manufaturados aos serviços de informação. Cadernos BAD 2, 2004.

GONZÁLEZ, M.M. e TRUJILLO L. Efficiency measurement in the port industry: a survey of the empirical. J Transp Econ Policy 43 (2), 2009: 157-192.

HARRINGTON, H.J. Aperfeiçoando Processos Empresariais. São Paulo: Makron Books, 1993.

HERRERA, S. e PANG G. Efficiency of infrastructure: the case of container ports. World Bank. Washington, DC, 2005.

IMF. World Economic Outlook Update. An update of the key WEO projections. International Monetary Fund. Washington - DC: FMI, July, 2010.

JEONG, K. e PHILIPS, D.T. Operational Efficiency and Effectiveness measurement. International Journal of Operations \& Production Management. Vol. 21 No. 11, 2001: 1404 - 1416. 
JOHNSON, T.H. e KAPLAN, R. Relevance Lost - The Rise and Fall of Management Acconuting. Boston, MA: Harvard Business School Press, 1987.

KAPLAN, R. e NORTON, D. The Balanced Scorecard - Measures That Drive Performance. Harvard Business Review, January, 1992: 71-79.

KARDEC, A.; NASCIF, J. e BARONI, T. Gestão Estratégica e Técnicas Preditivas. Qualitymark: ABRAMAN, 2002.

KRUUP FÖRDERTECHNIK. Port Handling Technology. s.d.

LJUNBERG, Örjan. Measurement of overall equipment effectiveness as a basis for TPM activities. International Journal of Operations \& Production Management, 1998.

MAXIMIANO, A.C.A. Teoria Geral da Administração. São Paulo: Editora Atlas, 2000.

MENDONÇA, E.C.; OLIVEIRA, A.L.R.; PROITE, A.; MENDONÇA, R.P.A. Os Contratos de Licenciamento e a Eficiência Técnica dos Setores Industriais Brasileiros: Uma Análise à Luz do Método de Fronteira Estocástica e da Análise Envoltória de Dados (DEA). Revista Economia, v.7, n.3. Brasília (DF), set/dez 2006: p.531-560.

MIGLIOLI, Afrânio M. Tomada de Decisão na Pequena Empresa: Estudo Multi Caso sobre a Utilização de Ferramentas Informatizadas de Apoio à Decisão. Dissertação (mestrado) - Escola de Engenharia de São Carlos, Universidade de São Paulo, São Carlos, 2006.

MORAES, P.H.A. Manutenção Produtiva Total: estudo de caso em uma empresa automobilística. Dissertação (mestrado) - Departamento de Economia, Contabilidade e Administração, Universidade de Taubaté, Taubaté, 2004.

NEELY, A. Measuring Business Performance. London: The Economist Books, 1998. 
OLIVEIRA, C.M.O. Responsabilidade civil e penal do perito e o profissional de contabilidade na nova legislação civil e falimentar. In: Âmbito Jurídico, Rio Grande, 21, 31/05/2005 [Internet], Disponível em: <http://www.ambitojuridico.com.br/site/index.php?n_link=revista_artigos_leitura\&artigo_id=643>. Acesso em 11/08/2010.

ONU. Organização das Nações Unidas. World Economic Situation and Prospects 2011. High unemployment, fiscal tightening and risk of currency wars threaten global recovery. UN Report. New York, Dezembro de 2010.

PRODUCTIVITY COMMISSION. International Benchmarking of the Australian Waterfront. Research Report, AusInfo, Canberra, April, 1998.

RAMALINGAM, B. e MITCHELL, J. Counting what counts: performance and effectiveness in what counts: performance and effectiveness in of Humanitarian Action. Overseas Development Institute. London, 2009.

RAMOS, A. W. e MIYAKE, D. I. Desenvolvendo Indicadores de Produtividade e Qualidade em Hospitais: Uma Proposta de Método. Produto \& Produção, vol. 11, n. 2, Junho de 2010: p. 67 - 84.

SOUZA, D.P.H. Avaliação de métodos paramétricos e não paramétricos na análise da eficiência da produção de leite. Tese (doutorado) - Escola Superior de Agricultura "Luiz de Queiroz", Universidade de São Paulo, Piracicaba, 2003.

SUYKENS, F. Ports Should be Efficient (even when this Means that some of them are Subsidized). Maritime Policy and Management, 13(2), 1986: 105-26.

SUYKENS, F. A few Observations on Productivity in Seaports. Maritime Policy and Management, 10(1), 1983: 17-40.

THYSSENKRUPP. Rail-Mointed Bucket Wheel Reclaimers for Continuous Bulk Handling. s.d.

TONGZON, J.L. Efficiency Measurement of Selected Australian and Other International Ports Using Data Envelopment Analysis. Transportation Research Part A, 2001: 113-28. 
TONGZON, J.L. Determinants of Port Performance and Efficiency. Transport Research A,Vol. 29, No. 3, 1995: 245-352.

TUPY, O. Fronteiras estocásticas, dualidade neoclássica e eficiência na produção de frangos de corte. Tese (doutorado) - Escola Superior de Agricultura "Luiz de Queiroz", Universidade de São Paulo, Piracicaba, 1996.

UNCTAD. Port Performance Indicators. United Nations Conference on Trade and Development. New York, 1976.

UNCTAD. Port Development: A Handbook for Planners in Developing Countries. United Nations Conference on Trade and Development. Nova York, 1985.

WANKE, P.F.; HIJJAR, M.F. e BARROS, M. Avaliando a eficiência dos terminais brasileiros com Análise Envoltória de Dados. Revista Tecnologística, n. 4, 2008: 72-76.

WANKE, P.F.; FLEURY, P.F. e HIJJAR, M.F. Exportadores brasileiros: estudo exploratório das percepções sobre a qualidade da infraestrutura logística. Brasília: XXIX Enanpad, 2005.

WANKE, P.F.; SILVEIRA, R.V. e BARROS, F.G. Introdução ao planejamento da infraestrutura e operações portuárias. Aplicações de pesquisa operacional. São Paulo: Editora Atlas, 2009.

WORLD BANK. World Bank Port Reform Tool Kit. Second Edition. Module 6: Port Regulation: Overseeing The Economic Public Interest In Ports. World Bank. Washington, DC, 2007.

ZANINI, A. Regulação Econômica No Setor Elétrico Brasileiro: Uma Metodologia Para Definição De Fronteiras De Eficiência E Cálculo Do Fator $\mathbf{X}$ Para Empresas Distribuidoras De Energia Elétrica. Tese (doutorado) Engenharia Elétrica do Departamento de Engenharia Elétrica, Pontifícia Universidade Católica do Rio de Janeiro, Rio de Janeiro, 2004. 